\title{
Copper-Catalyzed Synthesis of Thiadiazine-1-oxides in Reusable Aqueous Medium Under External [Ag]/Ligand/Base-Free Conditions
}

\author{
Cui Wu, Riting Huang, Ming Zhang, and Zhiyuan Chen* \\ Key Laboratory of Functional Small Organic Molecules, Ministry of Education \\ College of Chemistry \& Chemical Engineering, Jiangxi Normal University, 99 Ziyang \\ Road, Nanchang, Jiangxi 330022 (P. R. China). \\ E-mail: zchen@jxnu.edu.cn
}

\section{Contents}

1. ${ }^{1} \mathrm{H}$ and ${ }^{13} \mathrm{C}$ NMR spectrum for the preparation of starting material $\mathbf{1 f}$ (S2-S4).

2. ${ }^{1} \mathrm{H}$ and ${ }^{13} \mathrm{C}$ NMR spectrum for the preparation of compounds 3aa-3az (S2-S32).

3. ${ }^{1} \mathrm{H}$ and ${ }^{13} \mathrm{C}$ NMR spectrum for the preparation of compounds $\mathbf{4 b a - 4 f a}$ (S33-S43).

4. ${ }^{1} \mathrm{H}$ and ${ }^{13} \mathrm{C}$ NMR spectrum for the preparation of compounds $\mathbf{5 a}$ and $\mathbf{5 b}$ (S44-S45).

5. ${ }^{1} \mathrm{H}$ and ${ }^{13} \mathrm{C}$ NMR spectrum for the preparation of compounds $\mathbf{5 a}$ and $\mathbf{5 b}$ (S44-S45).

6. ${ }^{1} \mathrm{H}$ and ${ }^{13} \mathrm{C}$ NMR spectrum for the preparation of compound 6 (S46).

7. ${ }^{1} \mathrm{H}$ and ${ }^{13} \mathrm{C}$ NMR spectrum for the preparation of compound $\mathbf{1 0}$ (S47). 
1. ${ }^{1} \mathrm{H}$ and ${ }^{13} \mathrm{C}$ NMR spectrum for the preparation of starting material $\mathbf{1 f}$. 1f_2
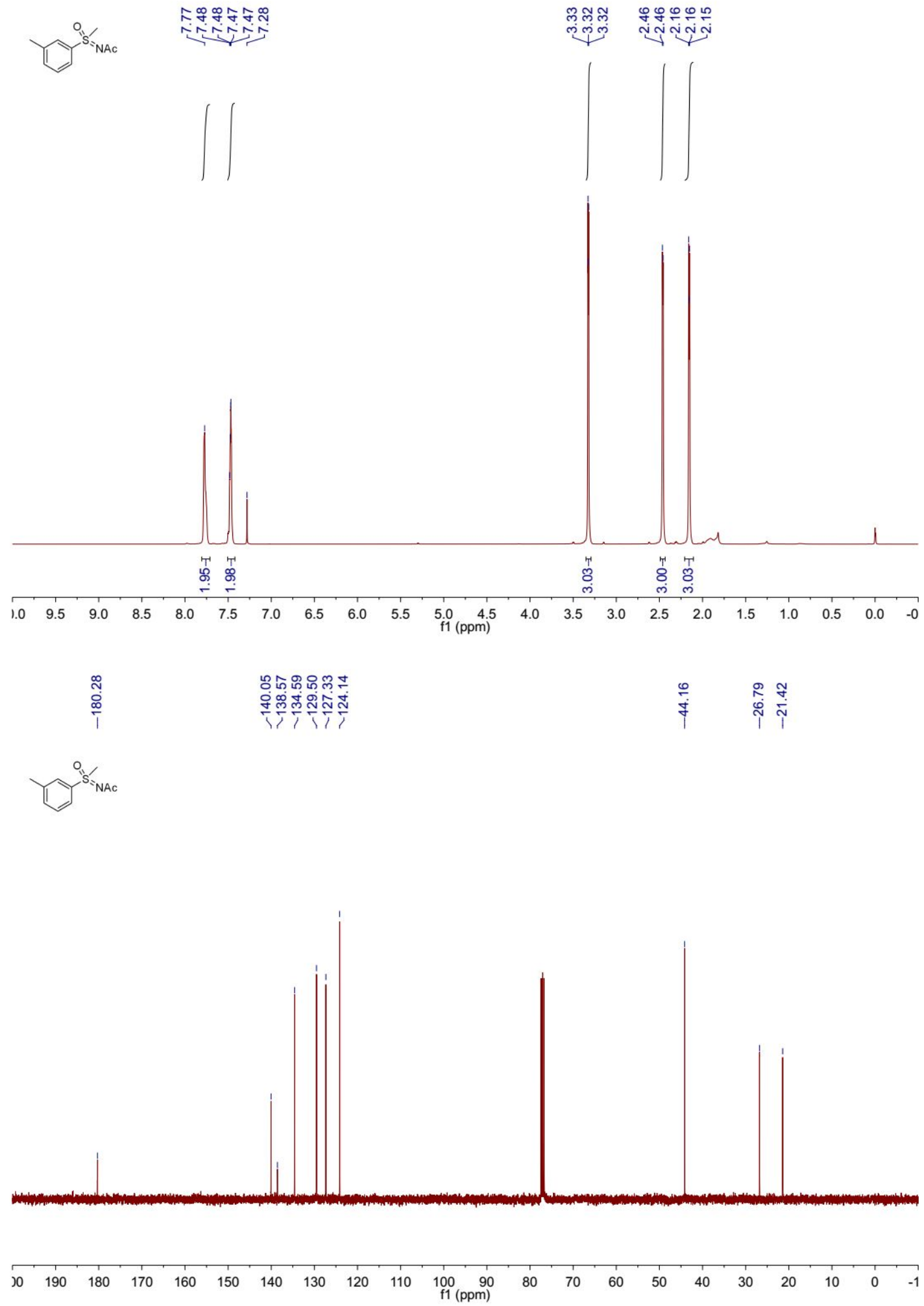
1f 3

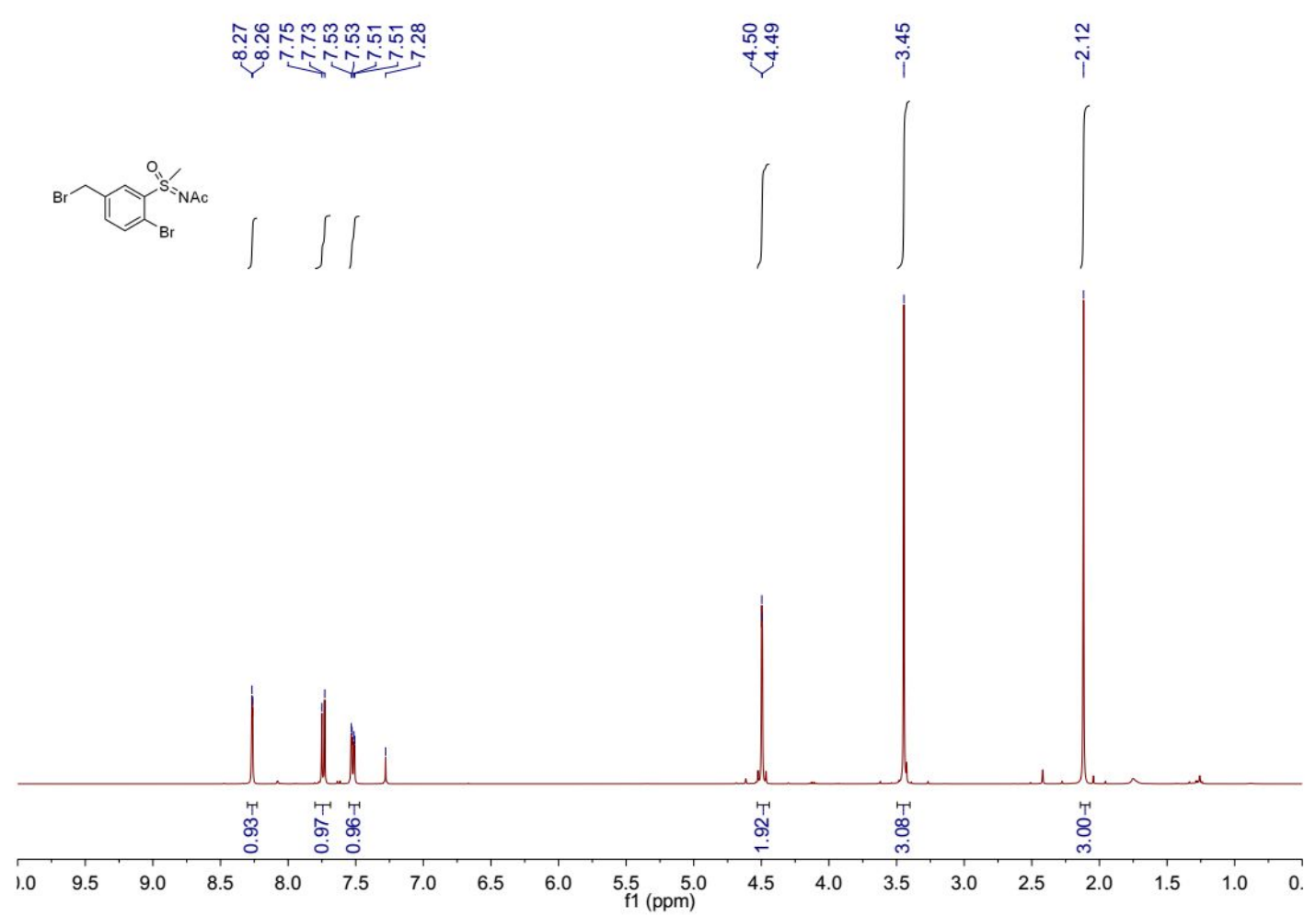

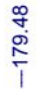

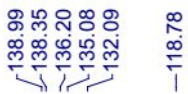

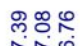
순
每

Br

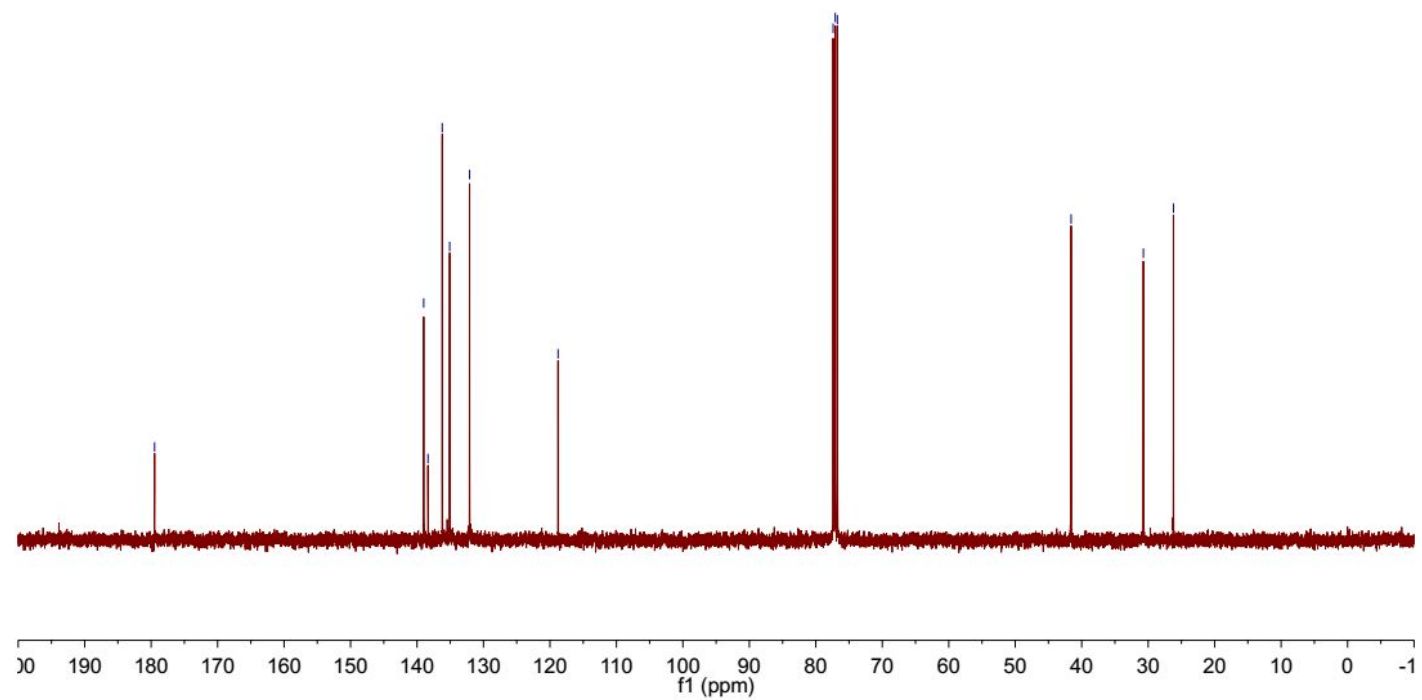




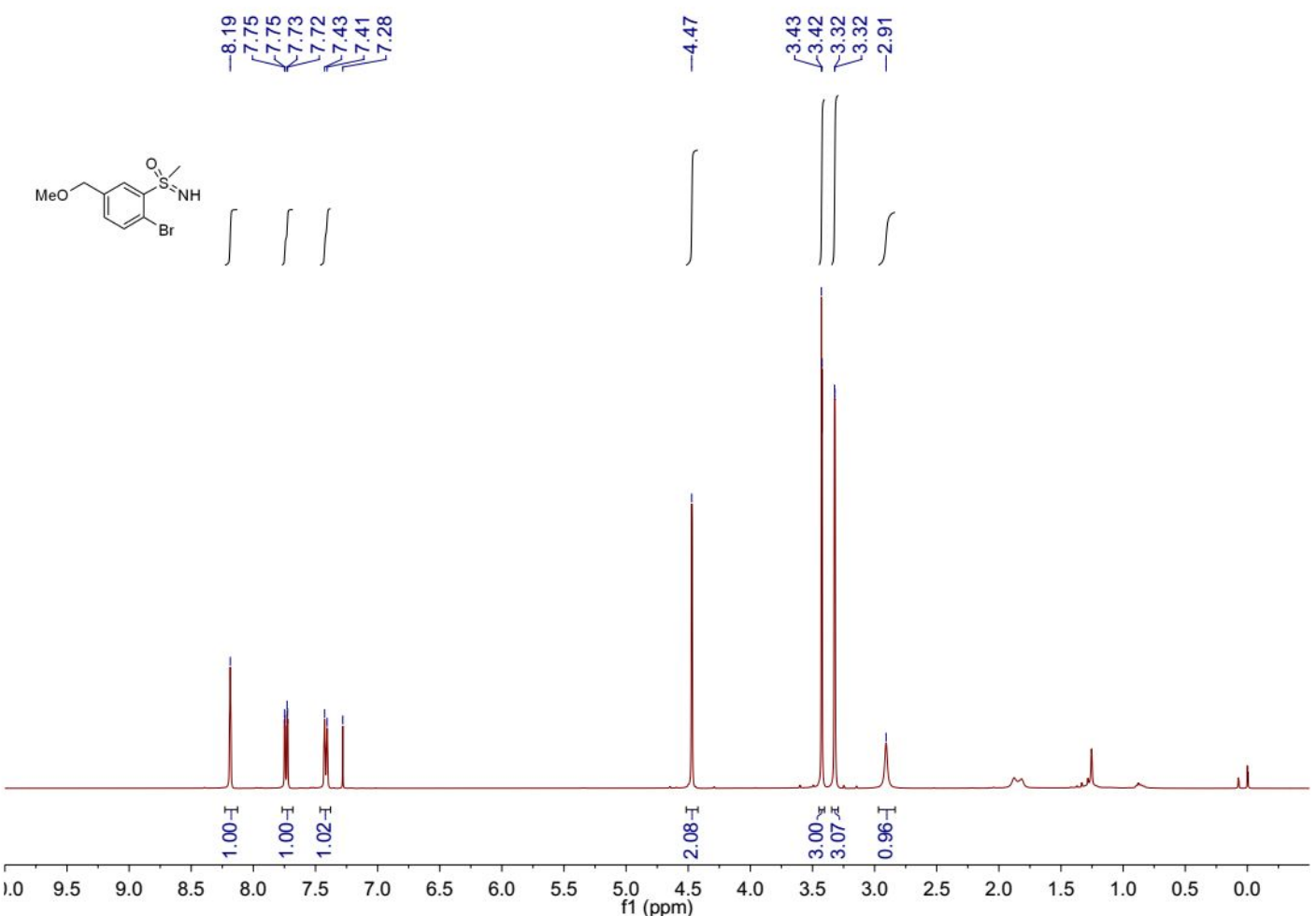

ํㅠ유요

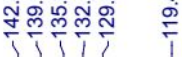

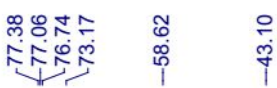

MeO

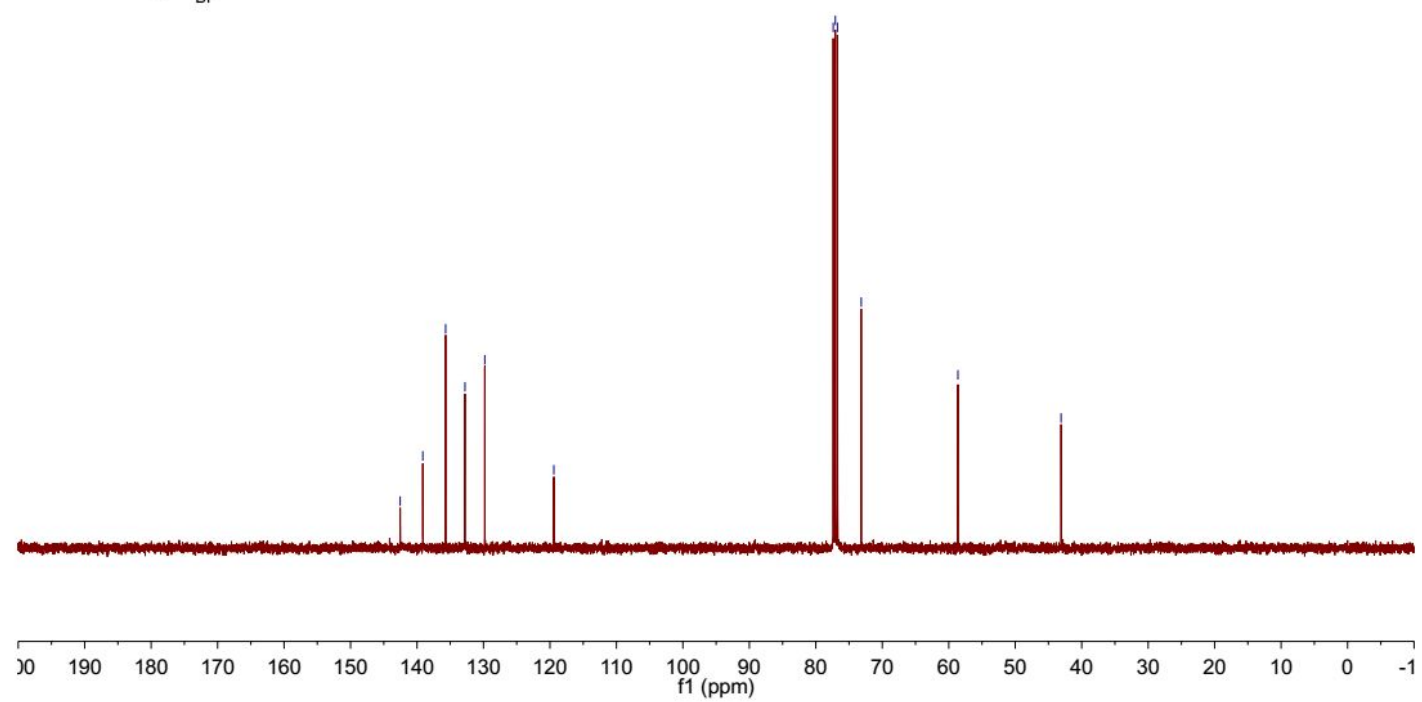


2. ${ }^{1} \mathrm{H}$ and ${ }^{13} \mathrm{C}$ NMR spectrum for the preparation of compounds 3aa-3. 3aa
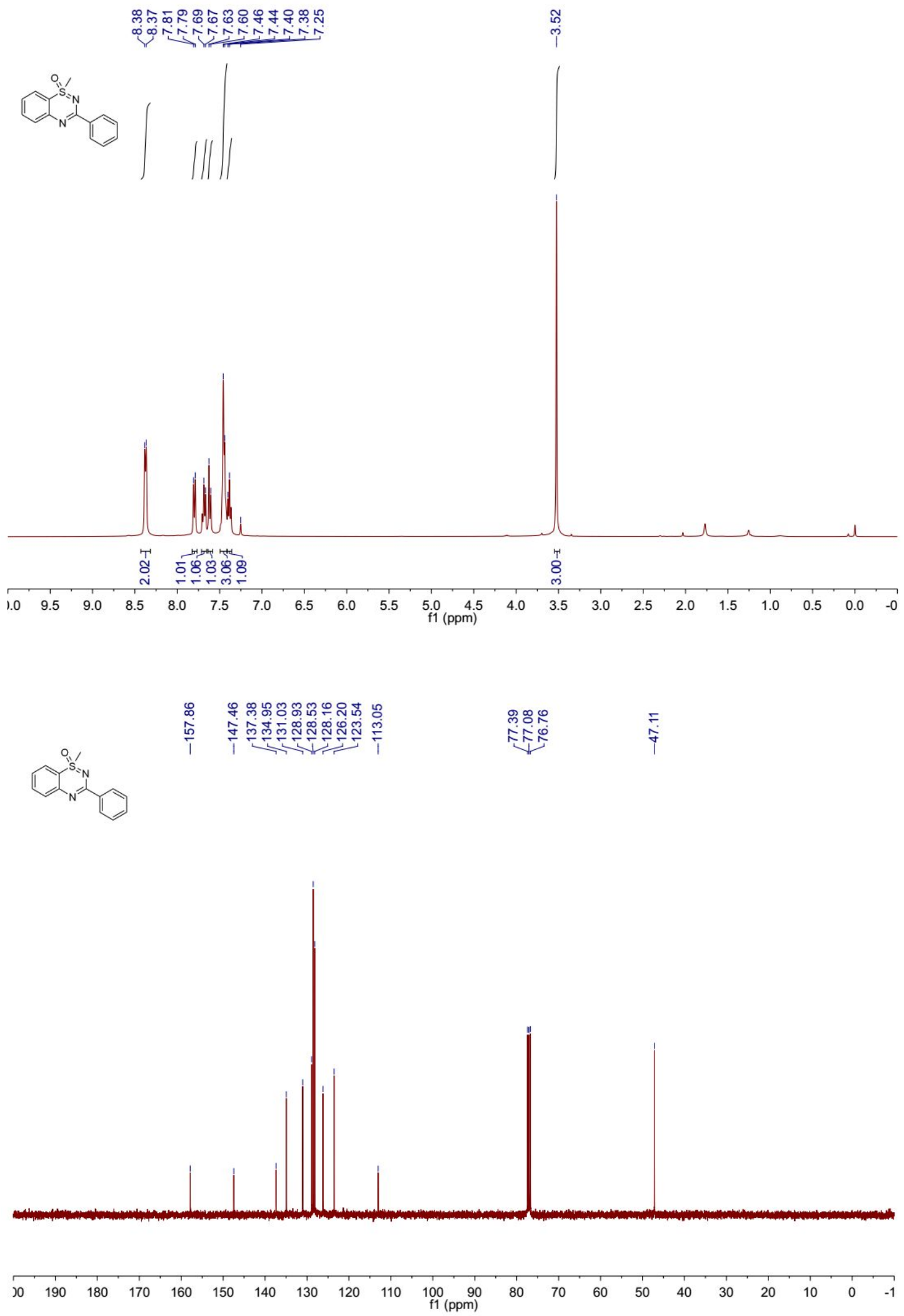
3ab
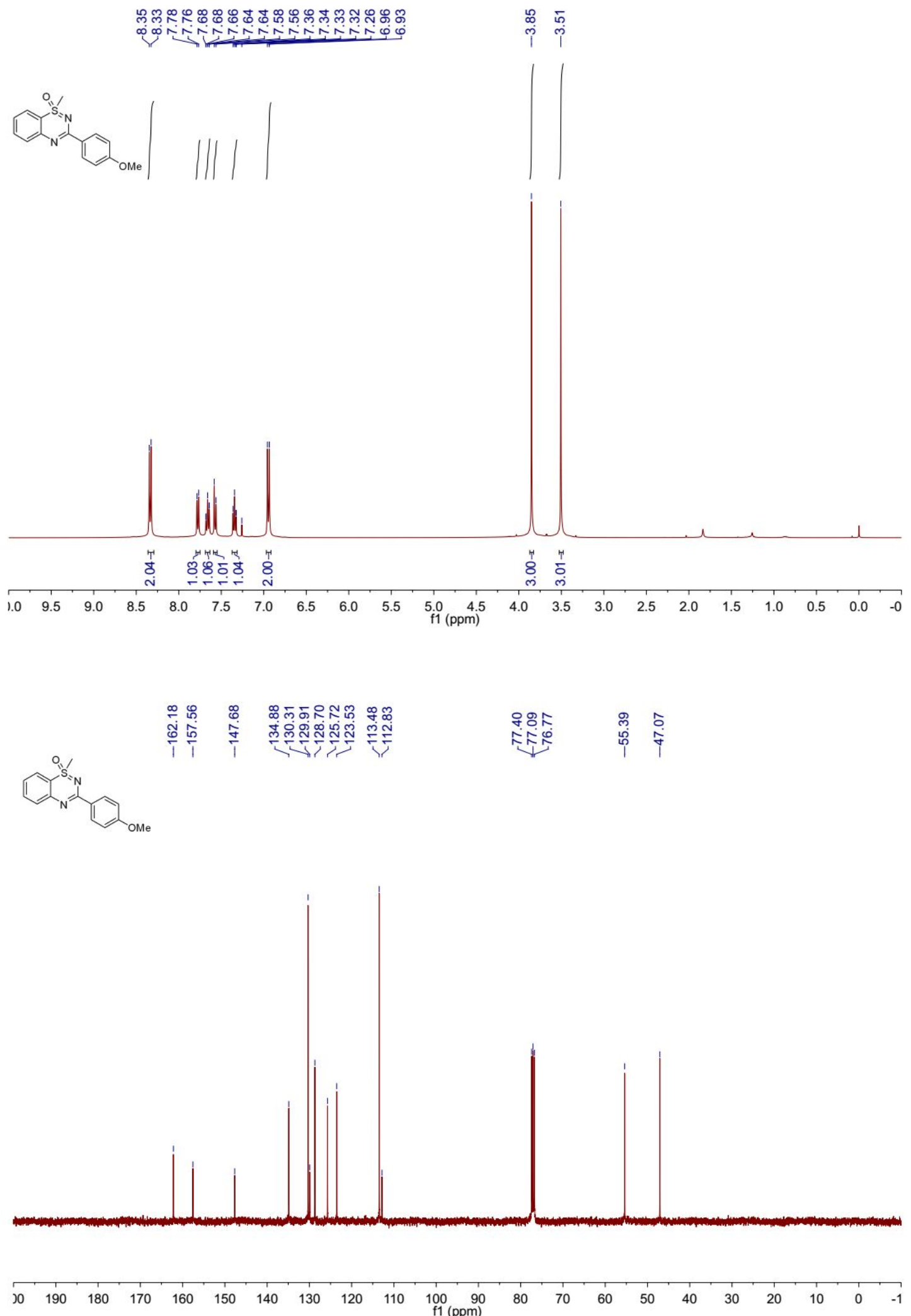
$3 a c$
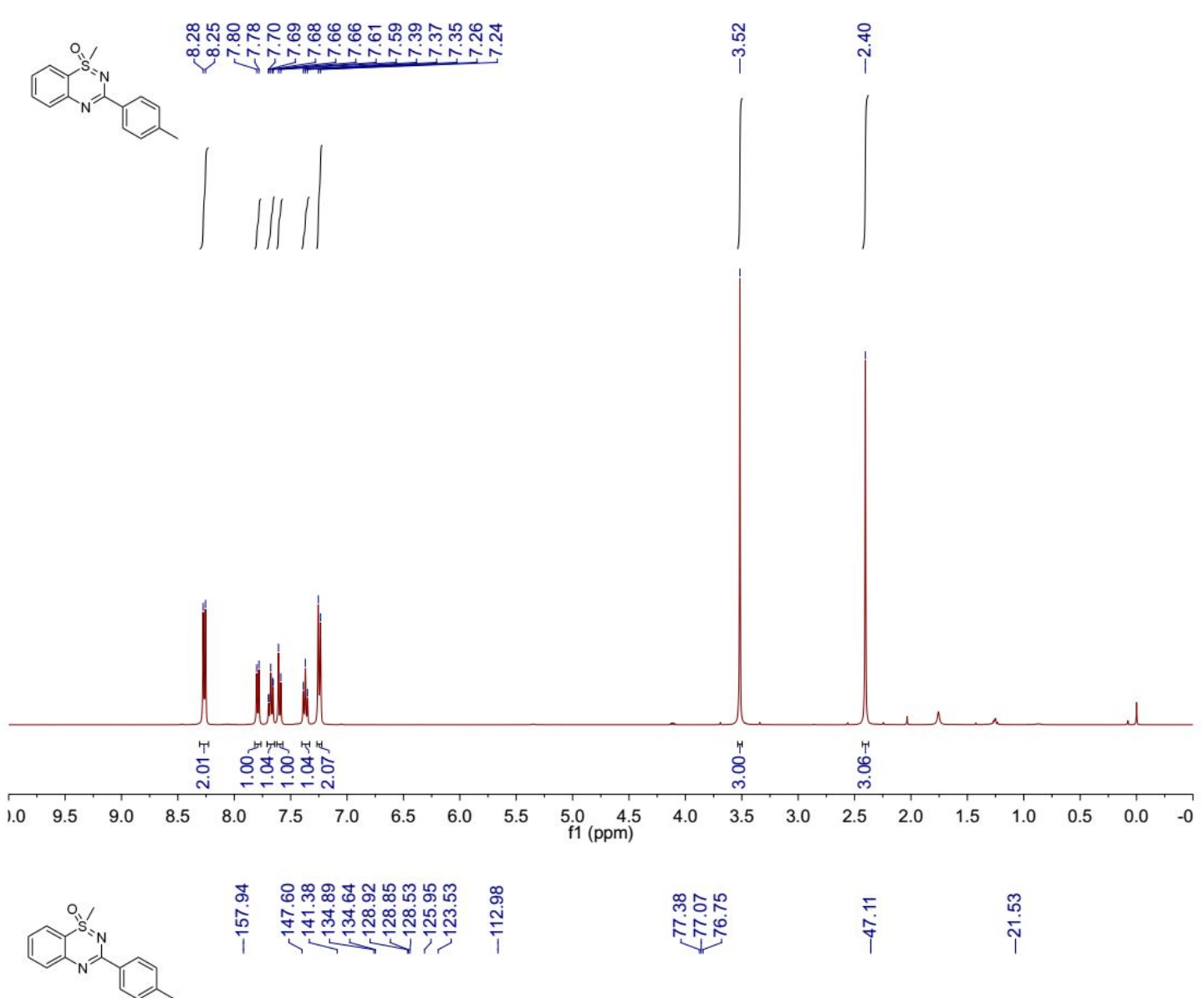

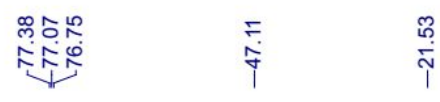

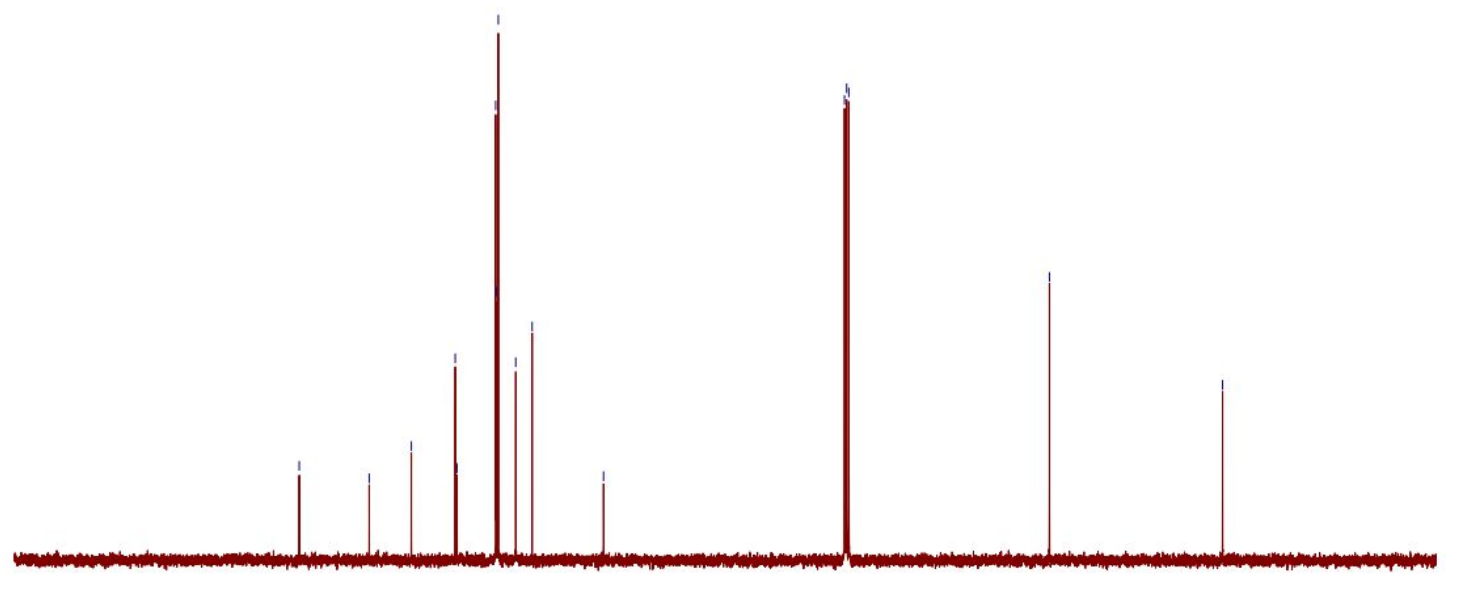

$\begin{array}{lllllllllllllllllllllllll}30 & 190 & 180 & 170 & 160 & 150 & 140 & 130 & 120 & 110 & \begin{array}{c}1 \\ \mathrm{f} 1(\mathrm{ppm})\end{array} & 80 & 70 & 60 & 50 & 40 & 30 & 20 & 10 & 0 & -1\end{array}$

S7 
3ad
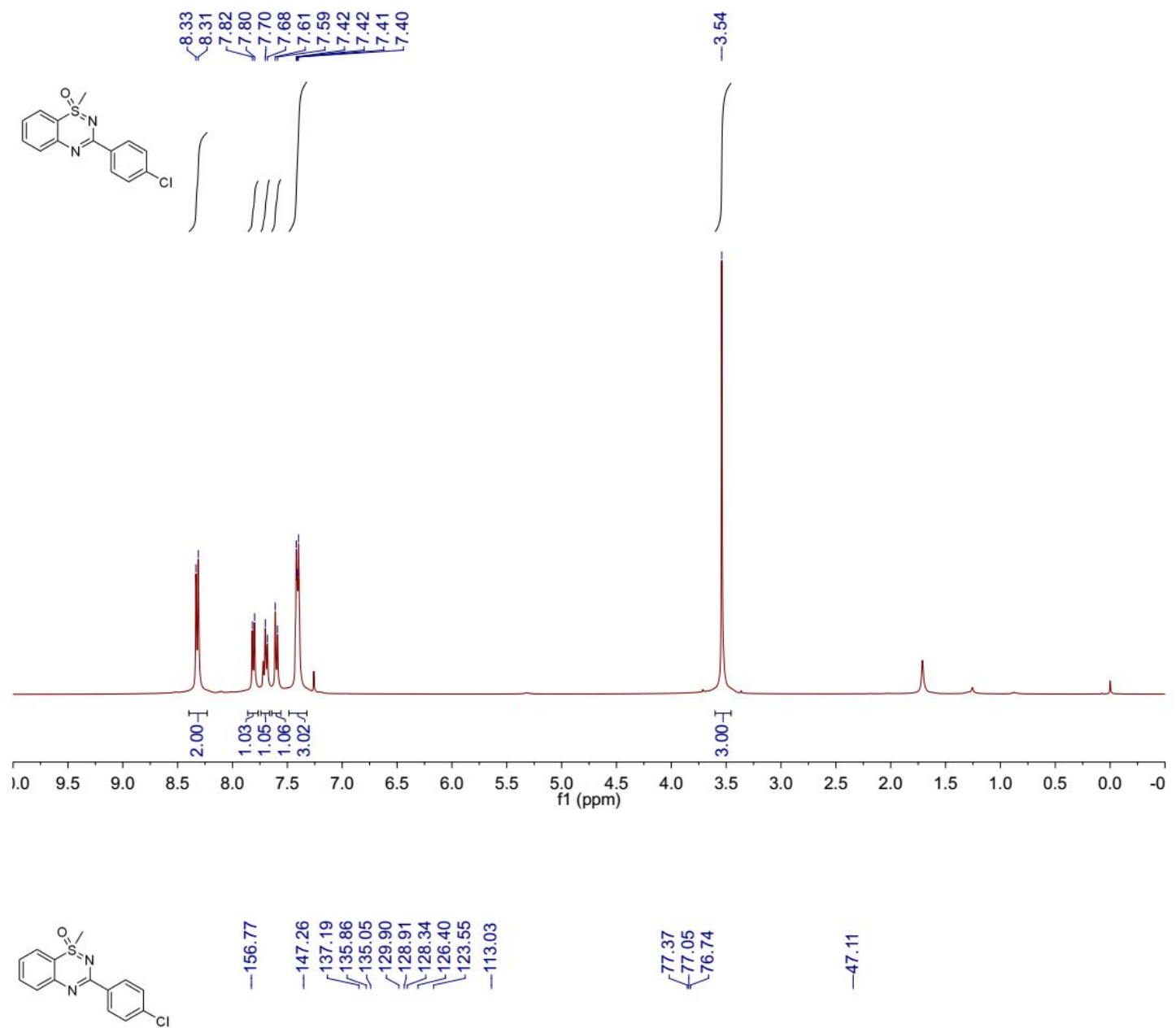

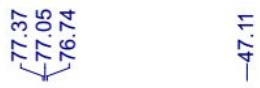

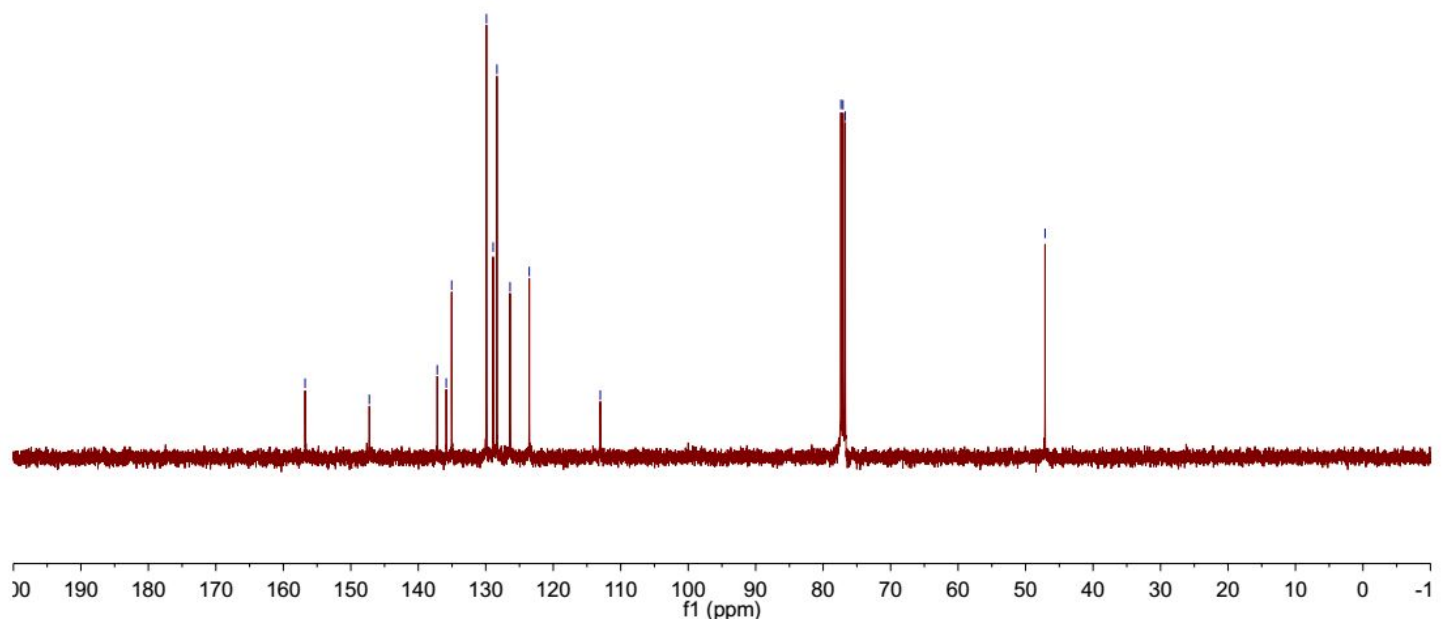


3ae
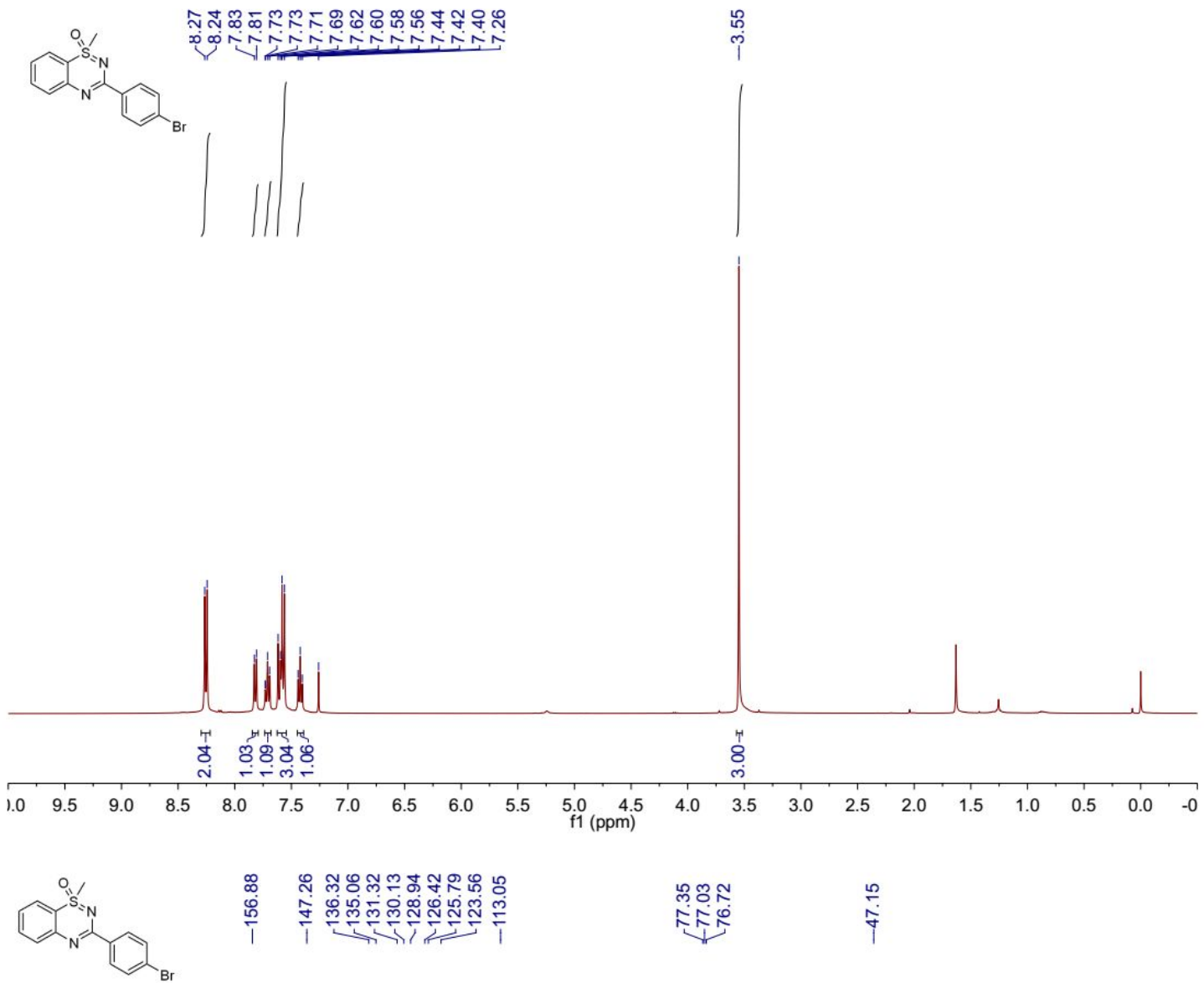

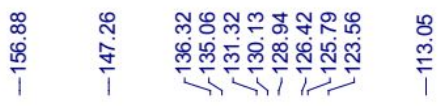
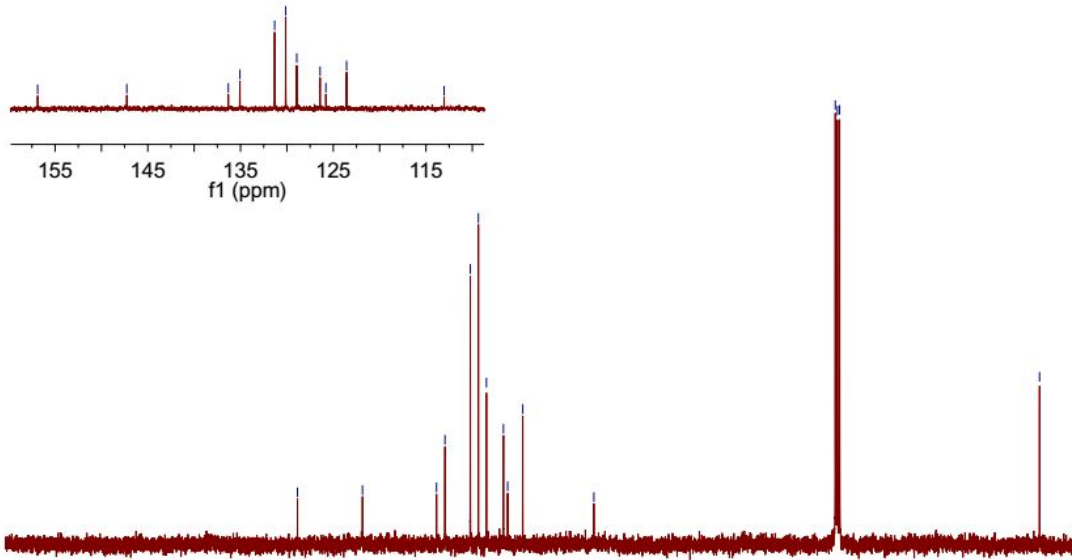

$\begin{array}{llllllllllllllllllllll}\text { J0 } & 190 & 180 & 170 & 160 & 150 & 140 & 130 & 120 & 110 & \underset{f 1}{100} \mathbf{9 0} & 80 & 70 & 60 & 50 & 40 & 30 & 20 & 10 & 0 & -1\end{array}$ 
3af
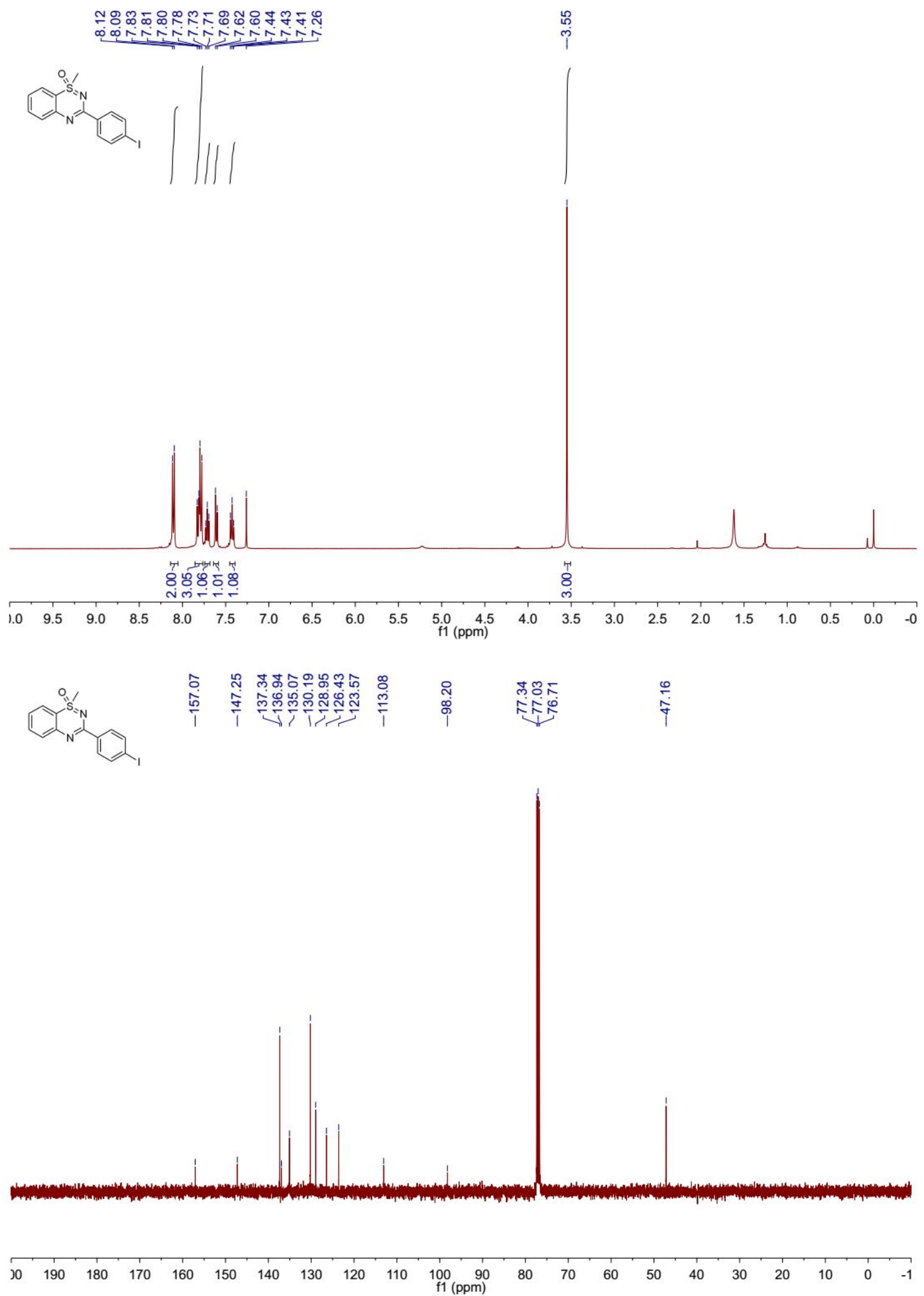
$3 a g$
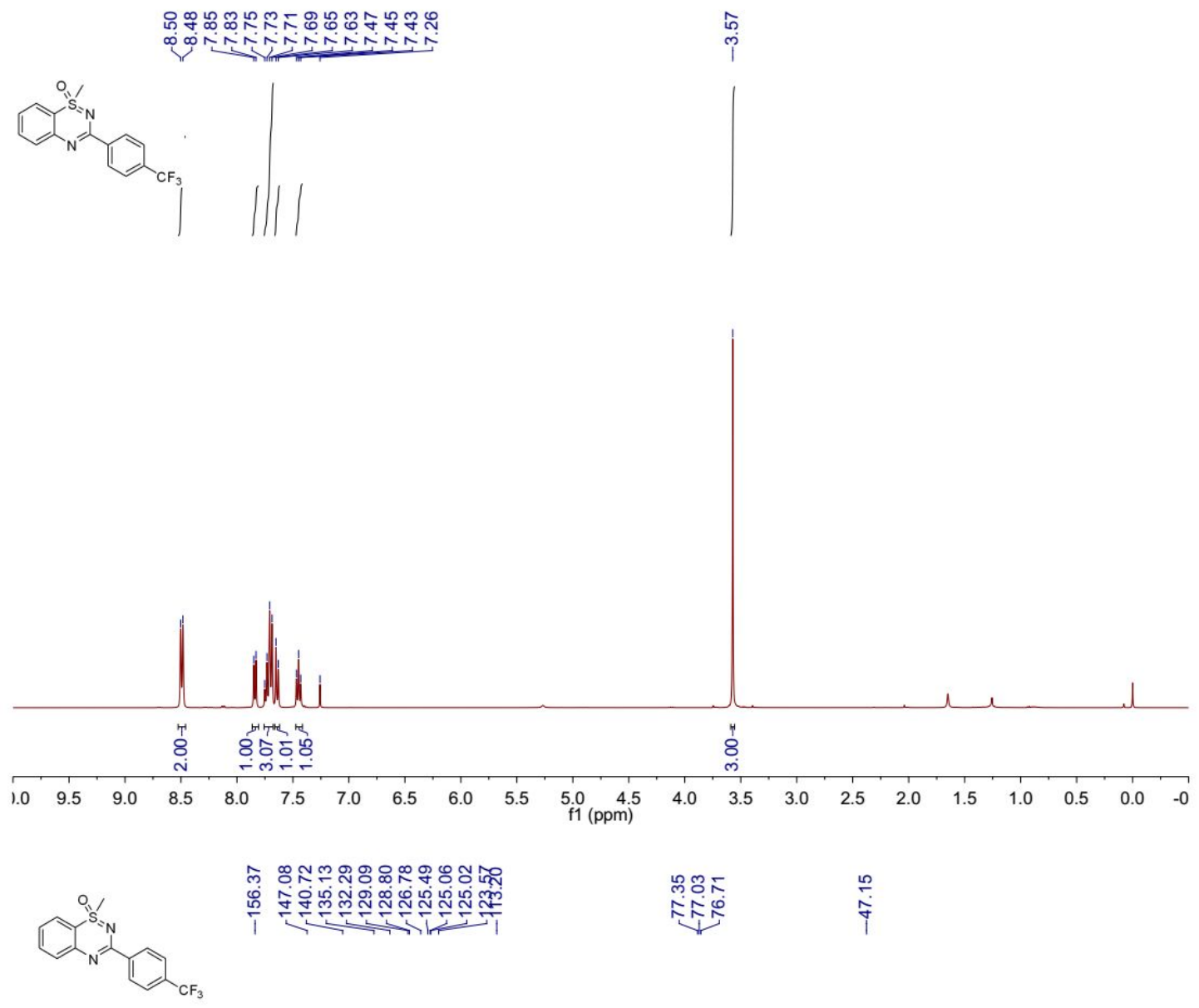

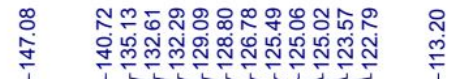

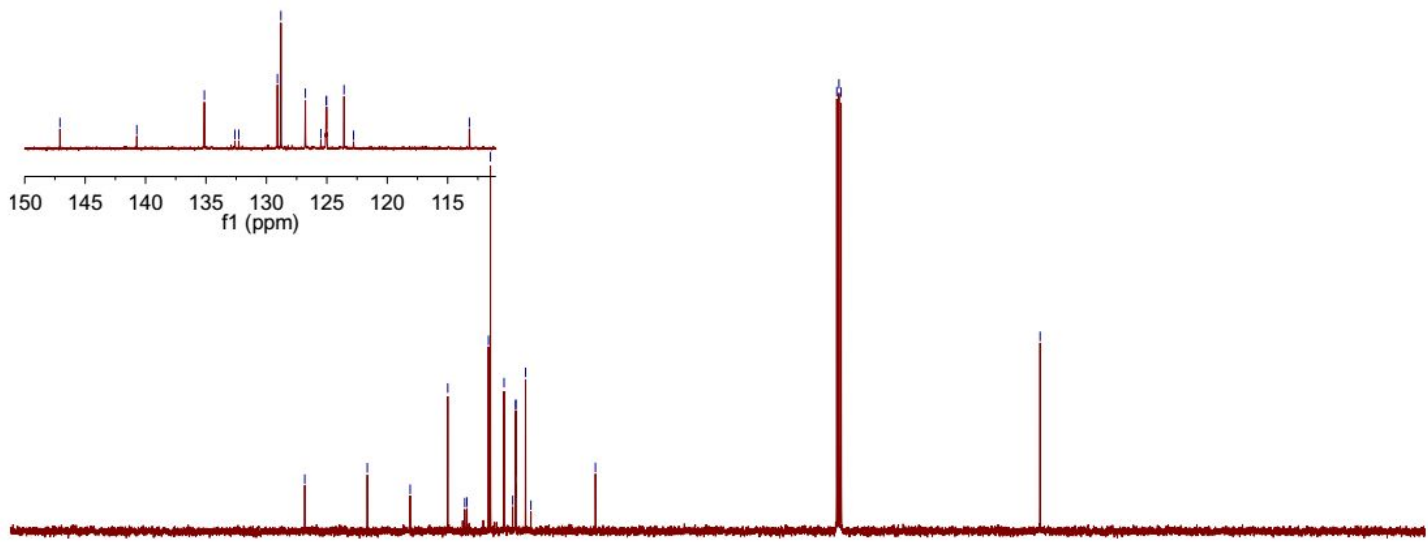

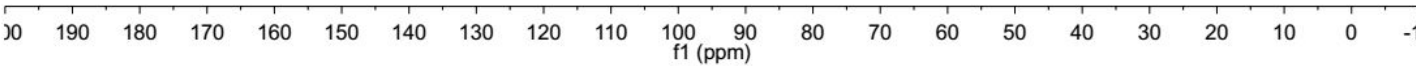




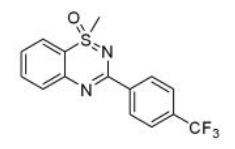

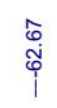
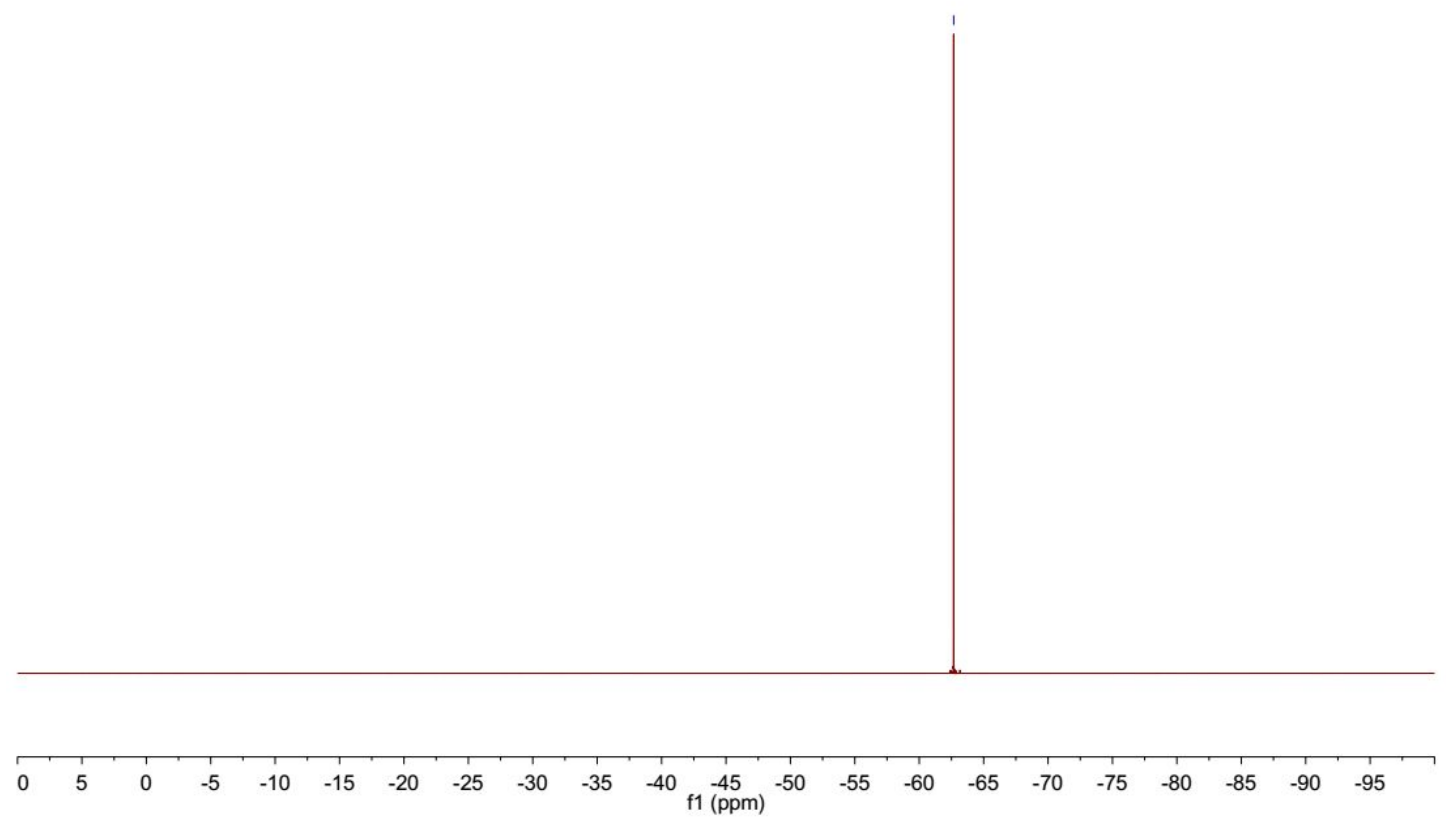

S12 
3ah
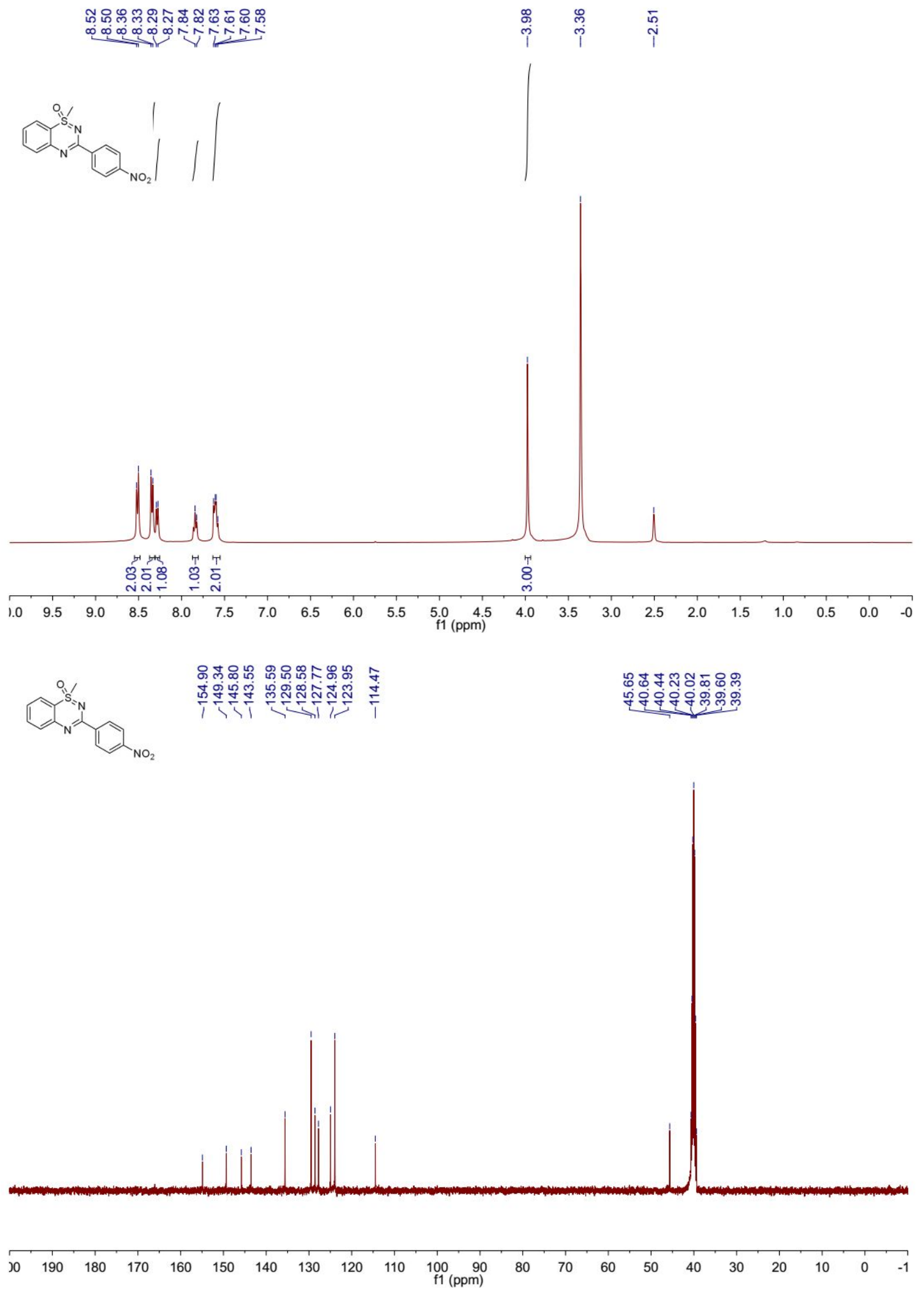
3ai
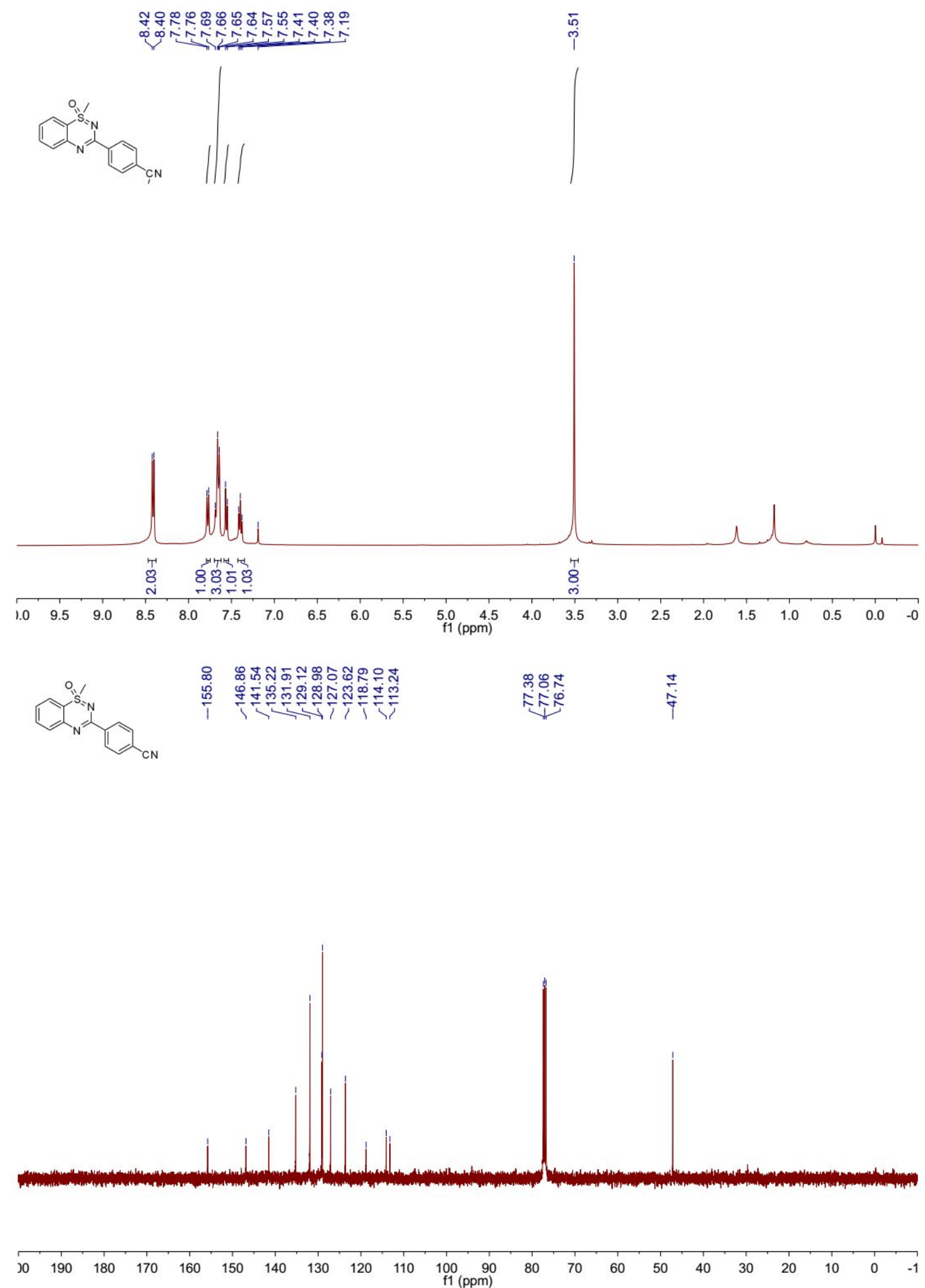
3aj

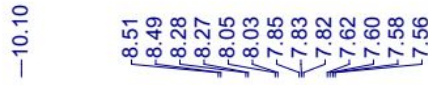

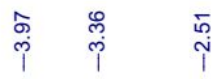

(1)

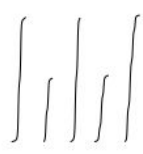

$\lfloor\mid$

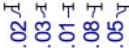

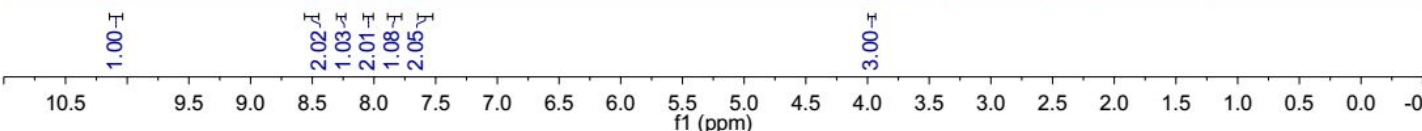

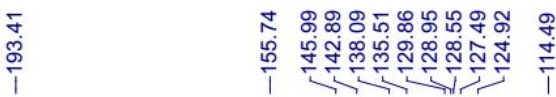

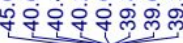
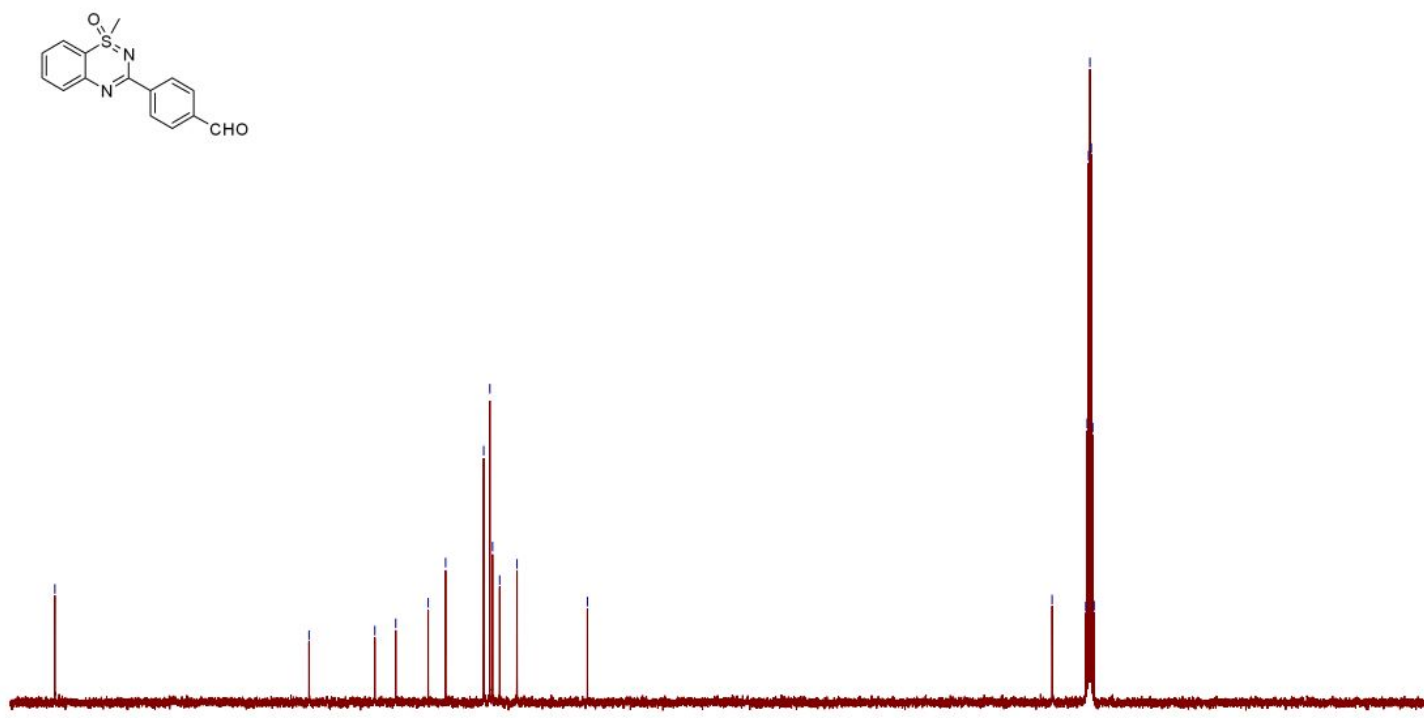

\begin{tabular}{lllllllllll}
\hline 0 & 190 & 180 & 170 & 160 & 150 & 140 & 130 & 120 & 110 & $\underset{\mathrm{f} 1(\mathrm{ppm})}{100}$
\end{tabular}

$\begin{array}{llllllllll}80 & 70 & 60 & 50 & 40 & 30 & 20 & 10 & 0 & -1\end{array}$ 
3ak

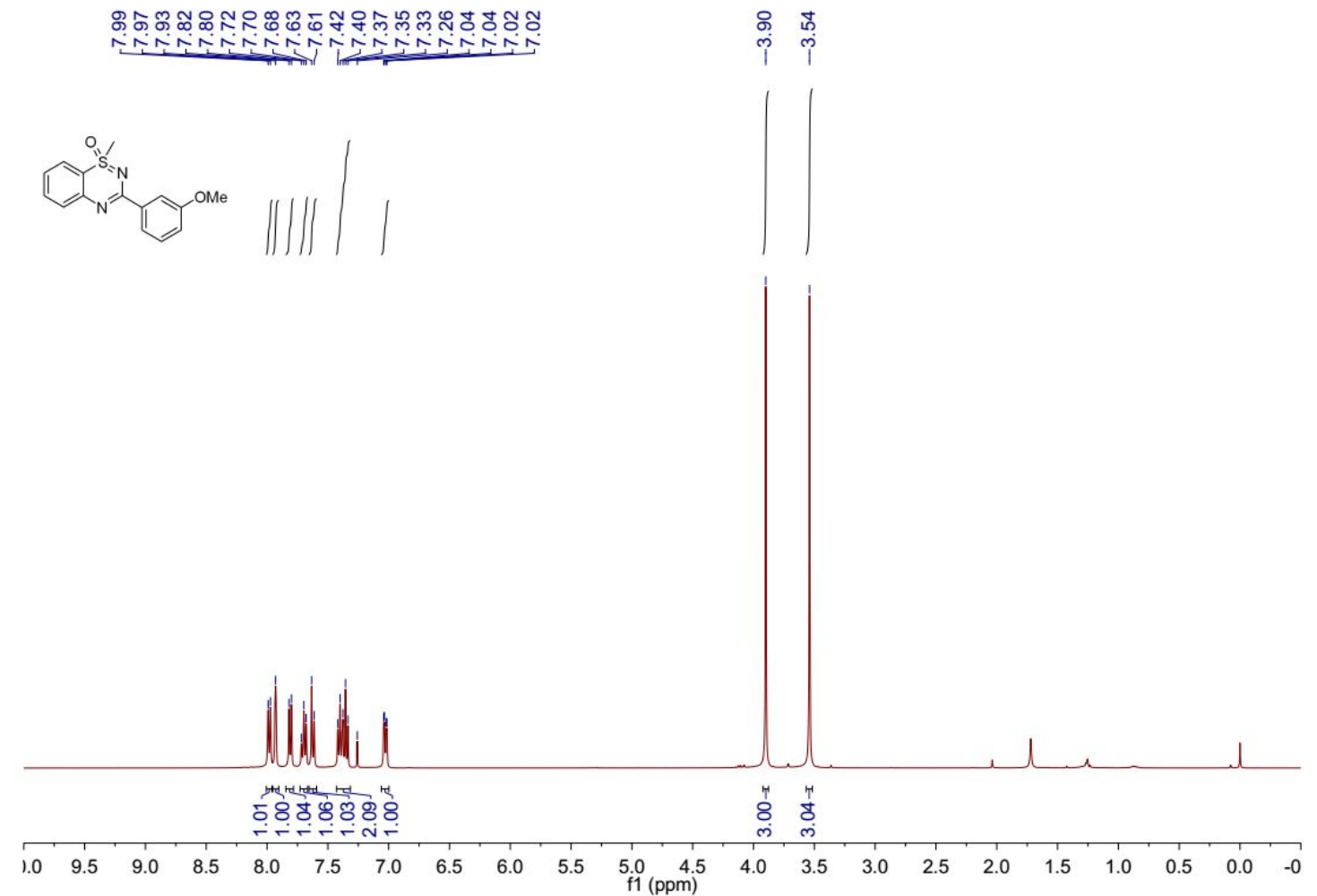

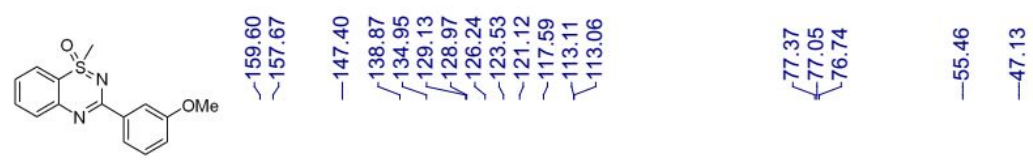

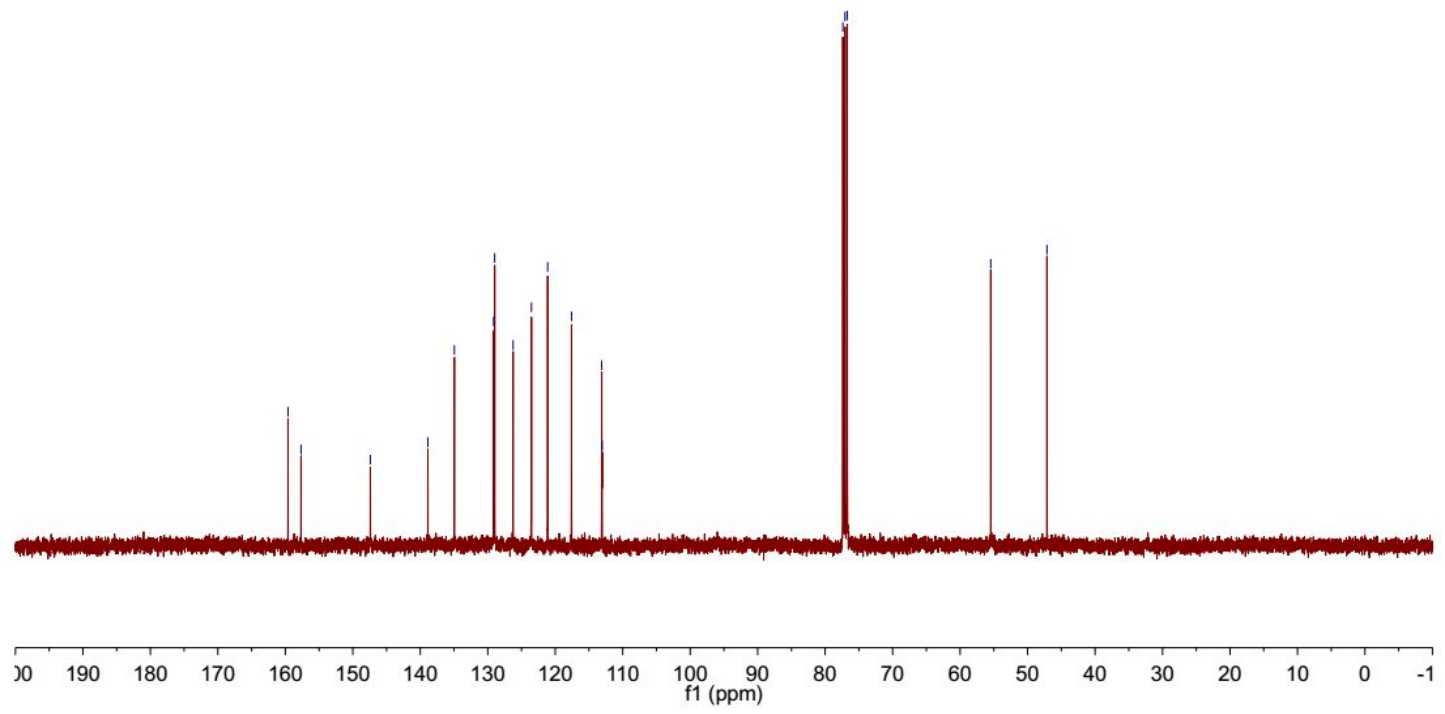


3al
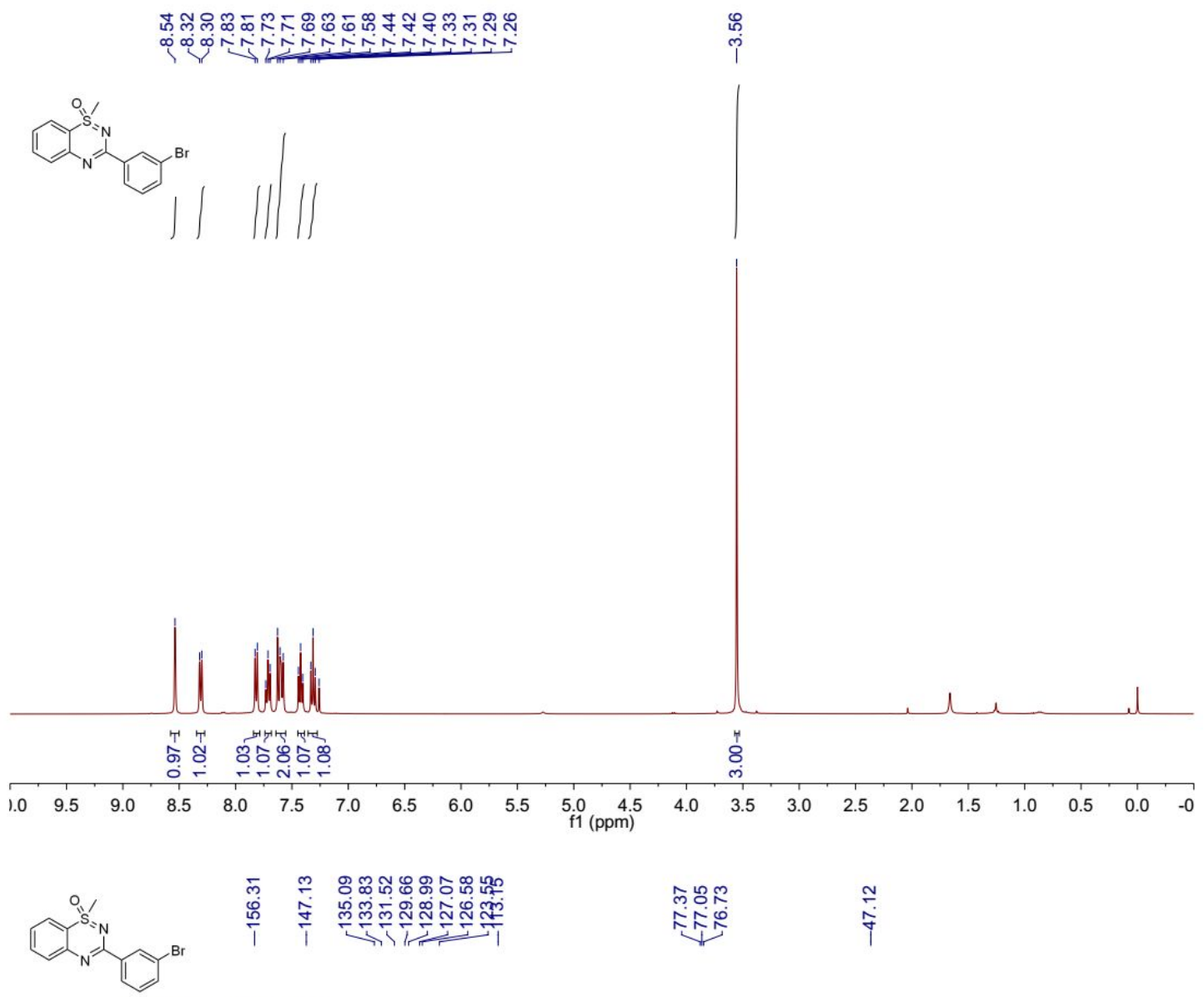

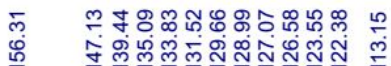

I I
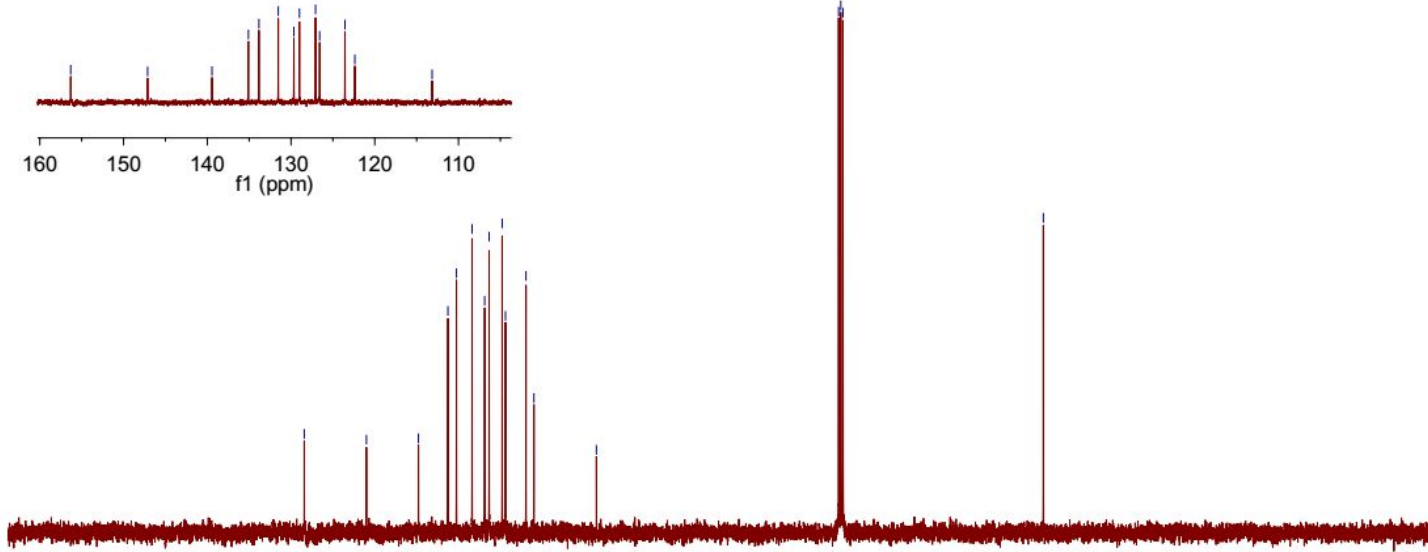

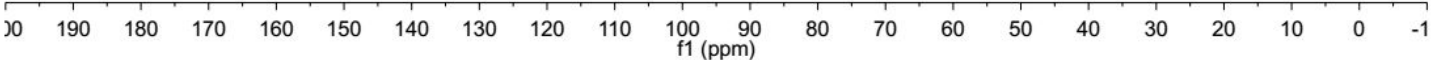




\section{3am}

๙

$\infty \infty$ NरN

\&

IIII
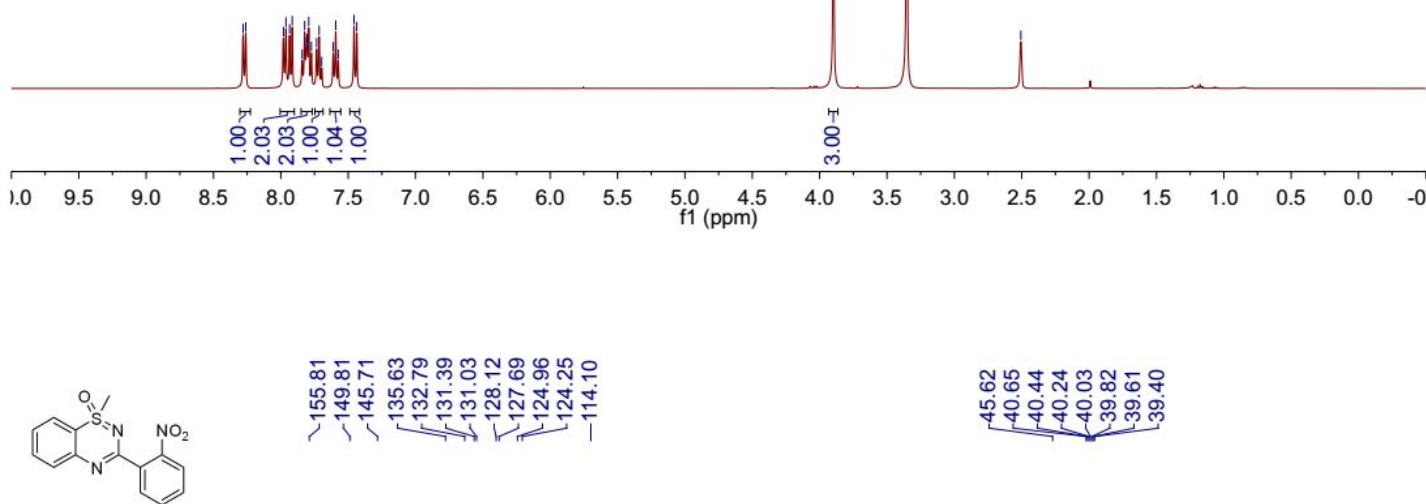

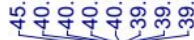

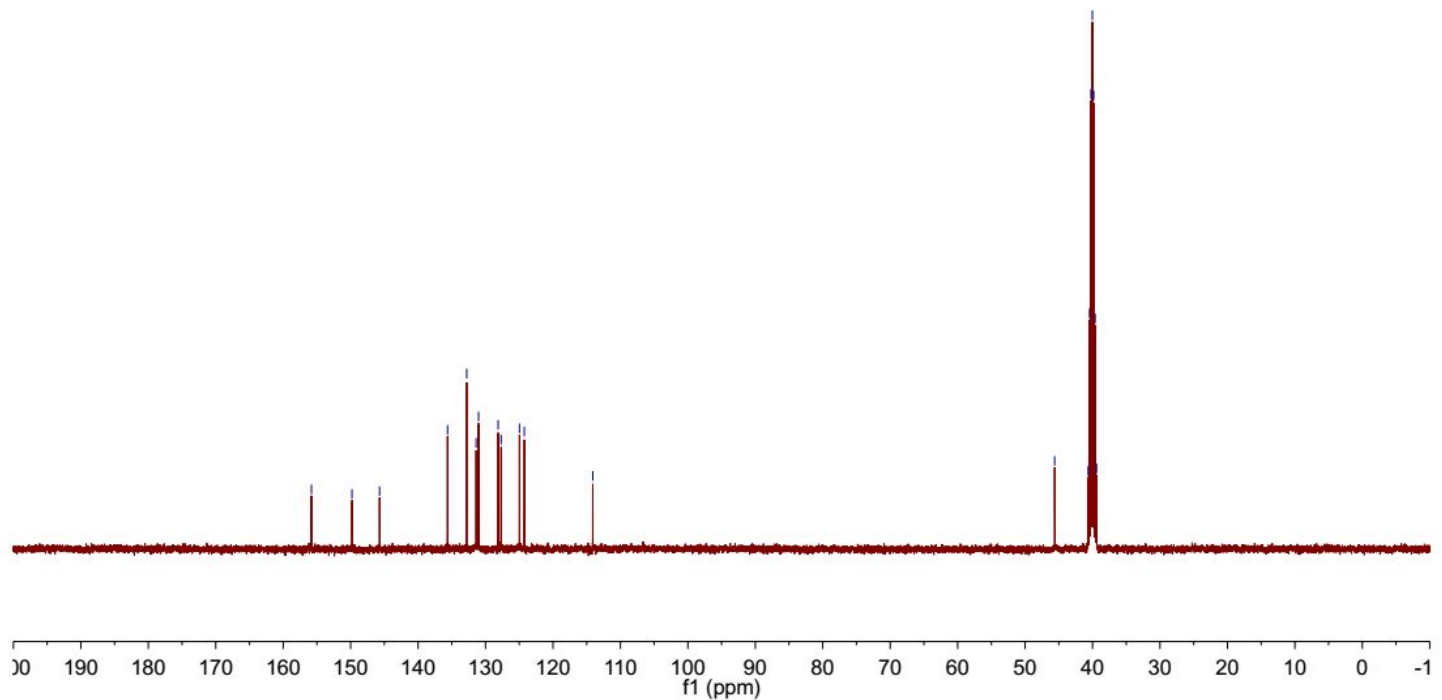


3an

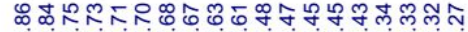

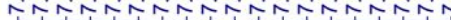

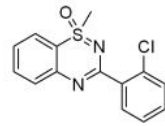
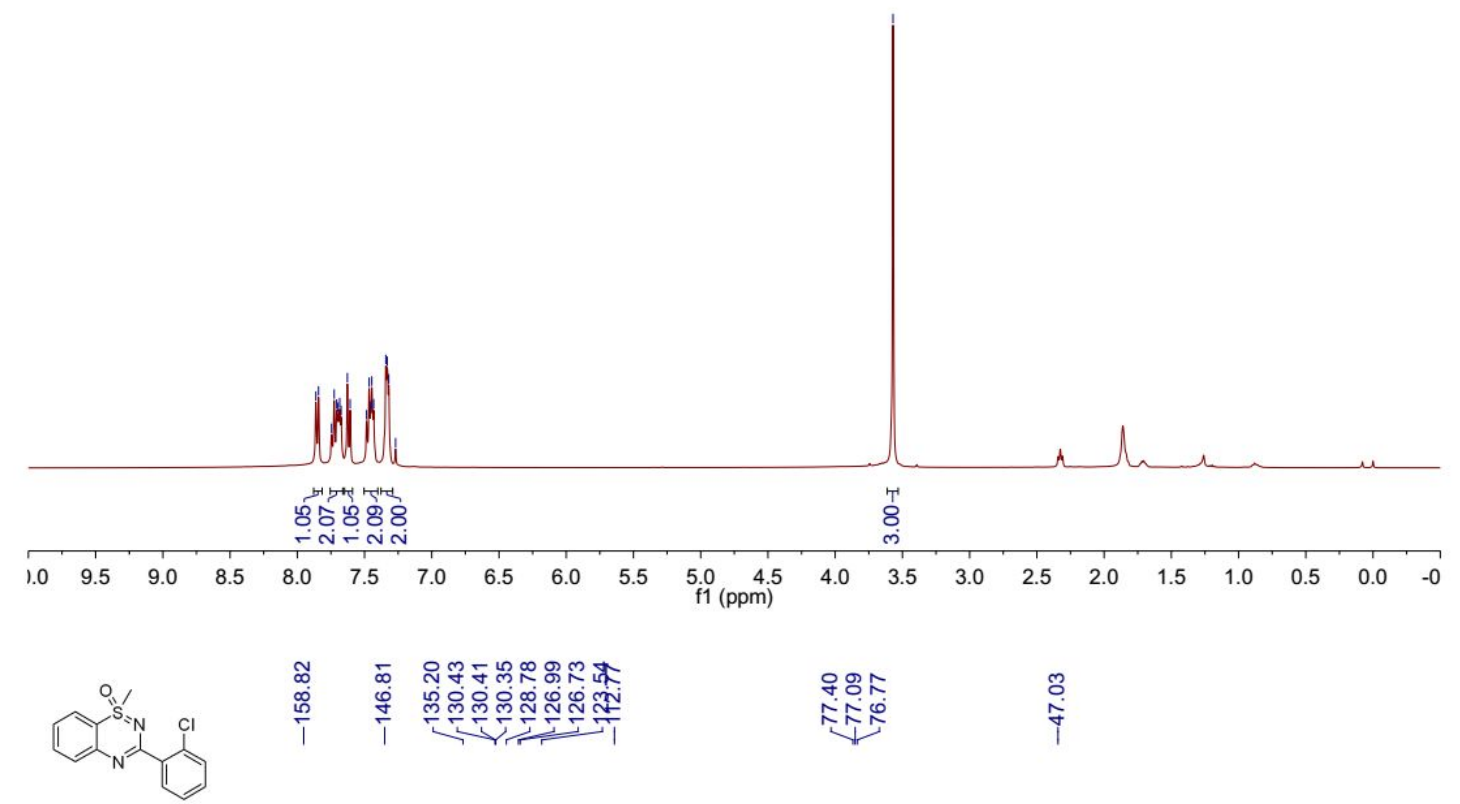

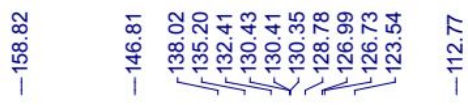
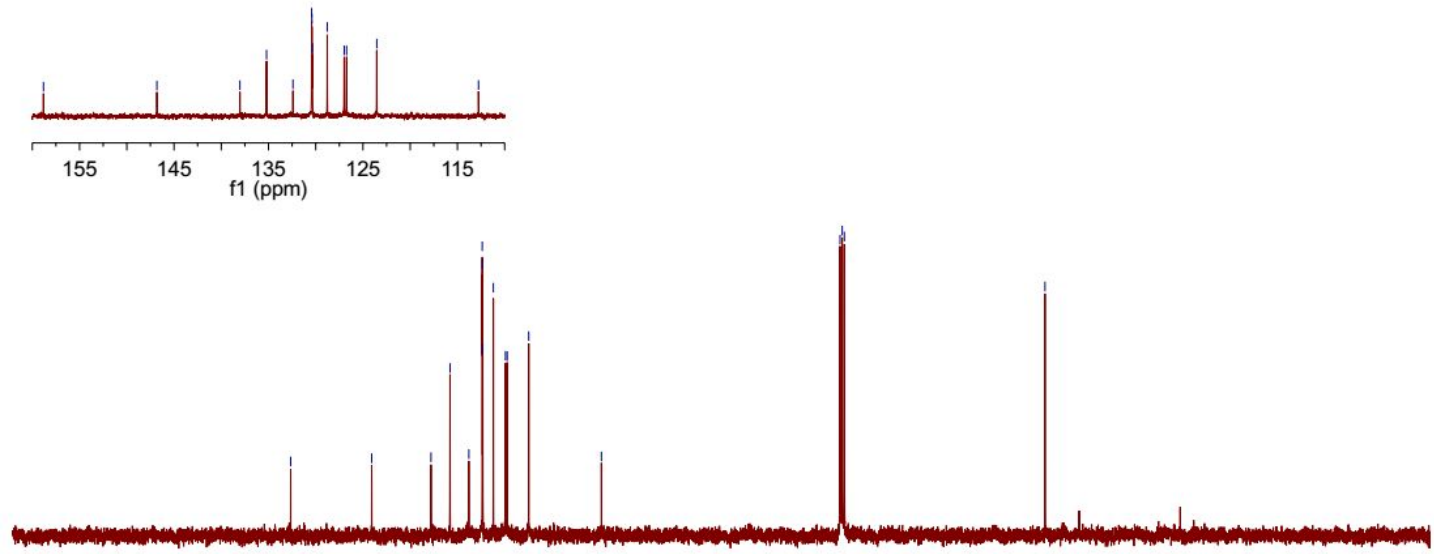

$\begin{array}{llllllllllll}\text { J0 } & 190 & 180 & 170 & 160 & 150 & 140 & 130 & 120 & 110 & 100 & 90\end{array}$ 
$3 a 0$

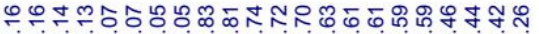

\begin{tabular}{ll}
0 \\
\hline
\end{tabular}

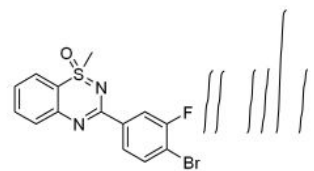
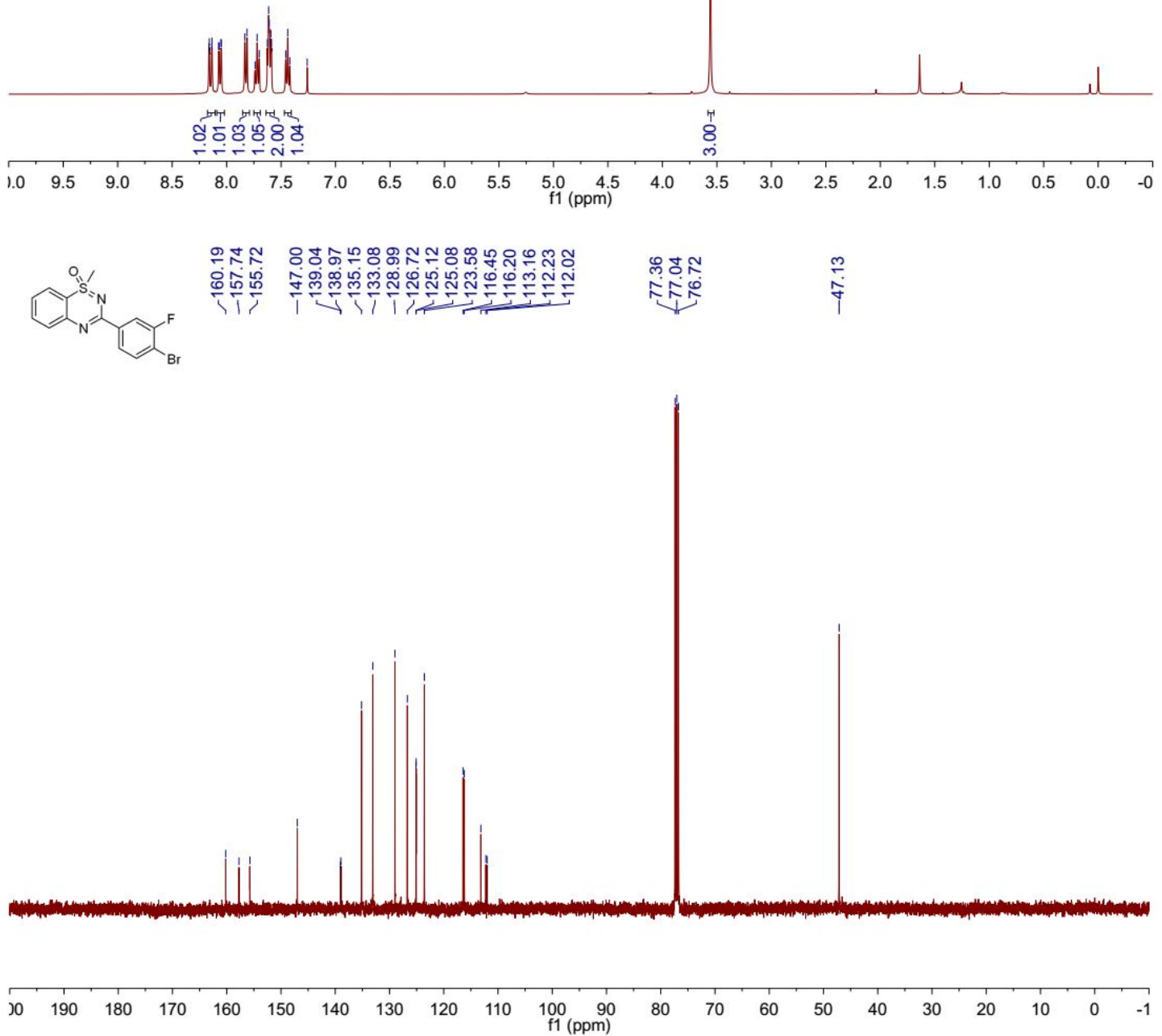

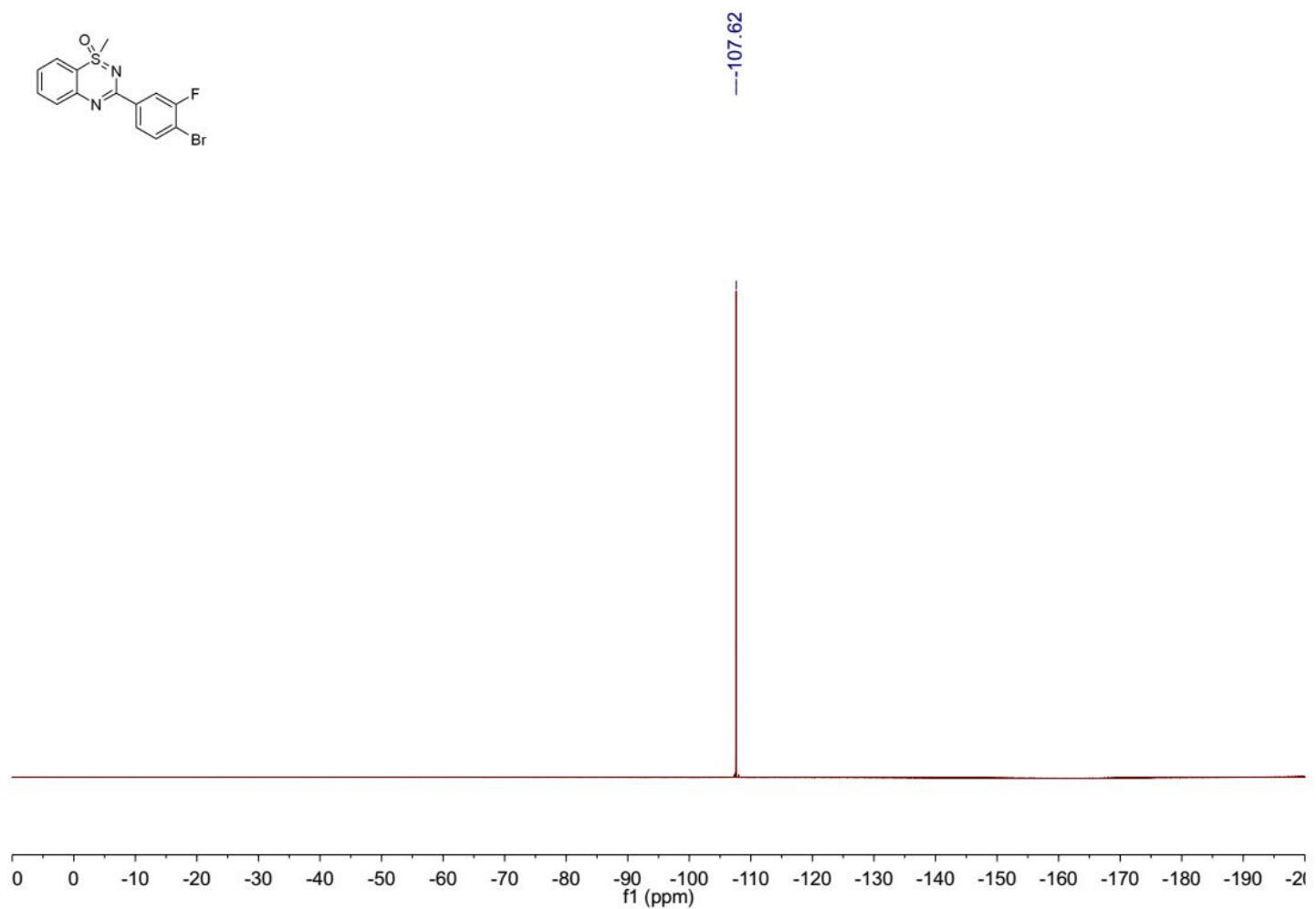
3ap

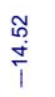

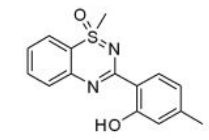

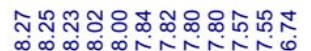

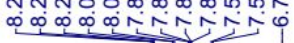

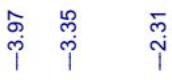

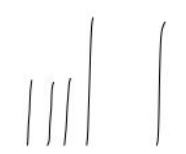

$\mid$

Iit.

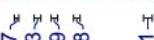

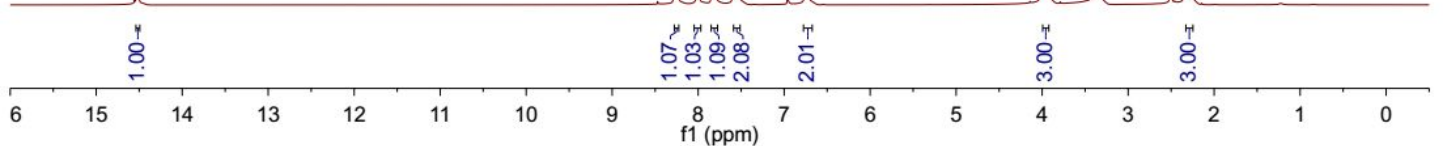

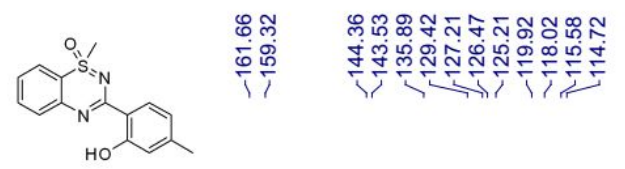

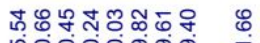

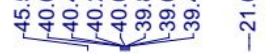

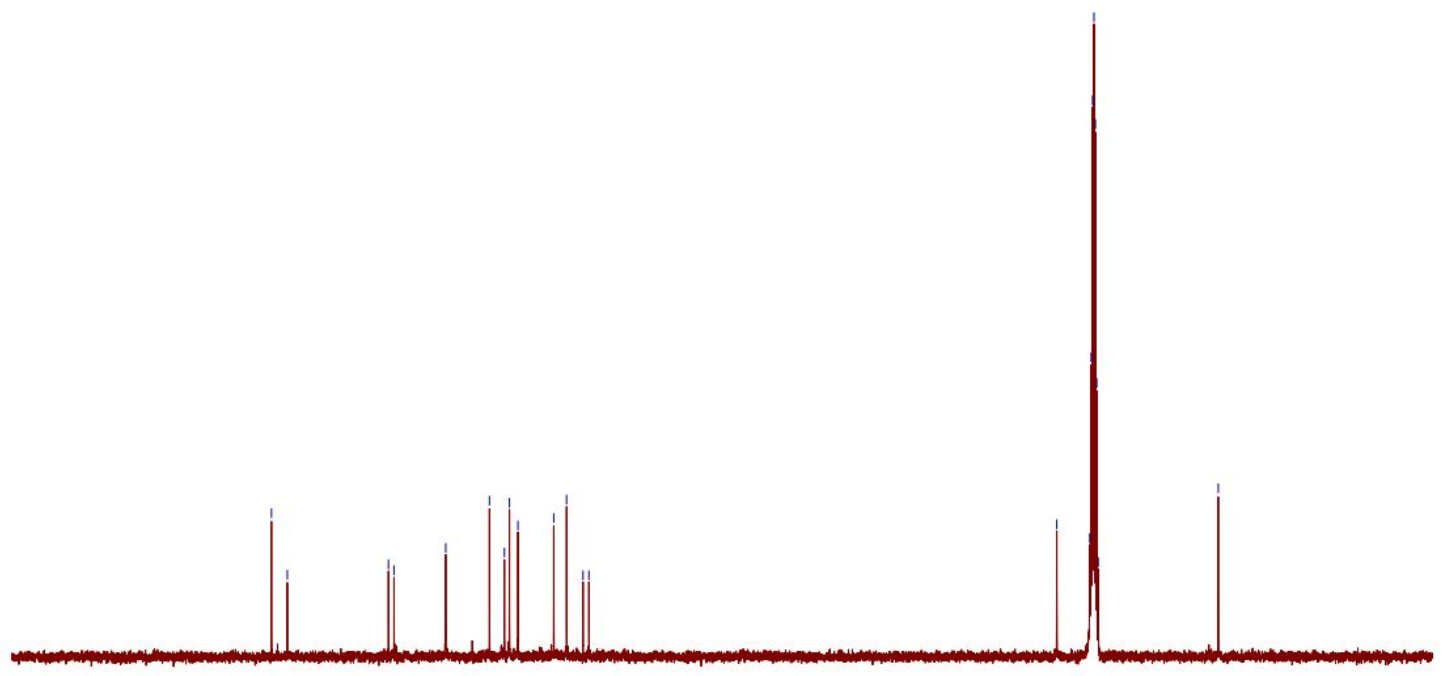

$\begin{array}{lllllllllll}\text { J0 } & 190 & 180 & 170 & 160 & 150 & 140 & 130 & 120 & 110 & \begin{array}{c}100 \\ \mathrm{f} 1(\mathrm{ppm})\end{array}\end{array}$

$\begin{array}{llllllllll}80 & 70 & 60 & 50 & 40 & 30 & 20 & 10 & 0 & -1\end{array}$ 
$3 a q$

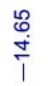

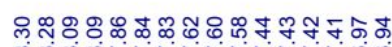

nomitivitiviniog

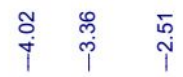
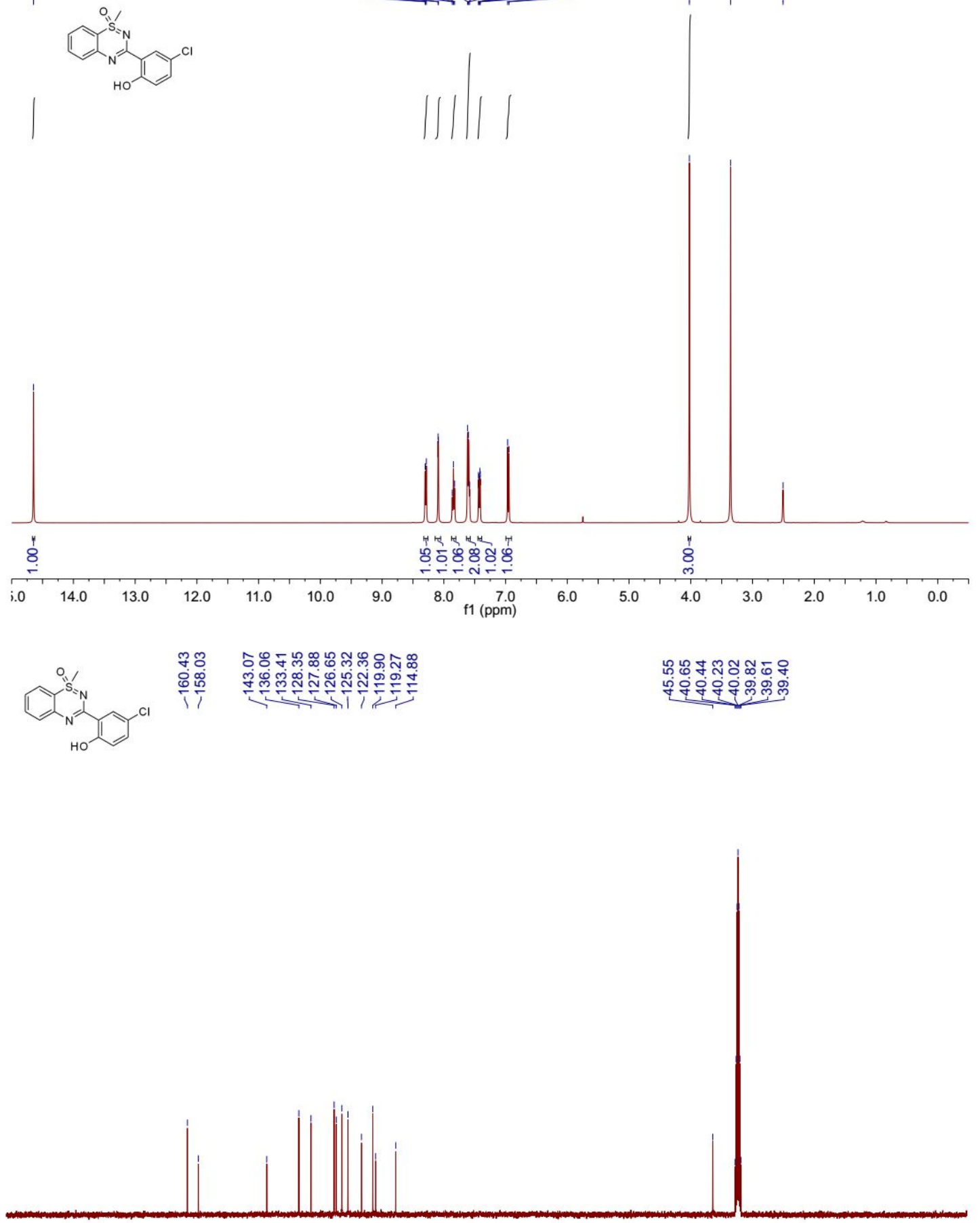

\begin{tabular}{lllllllllll}
\hline 0 & 190 & 180 & 170 & 160 & 150 & 140 & 130 & 120 & 110 & $\underset{\mathrm{f} 1(\mathrm{ppm})}{90}$
\end{tabular} 
3ar

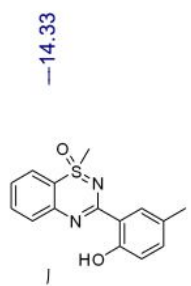

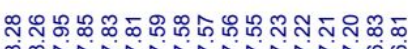

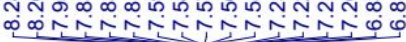

\&
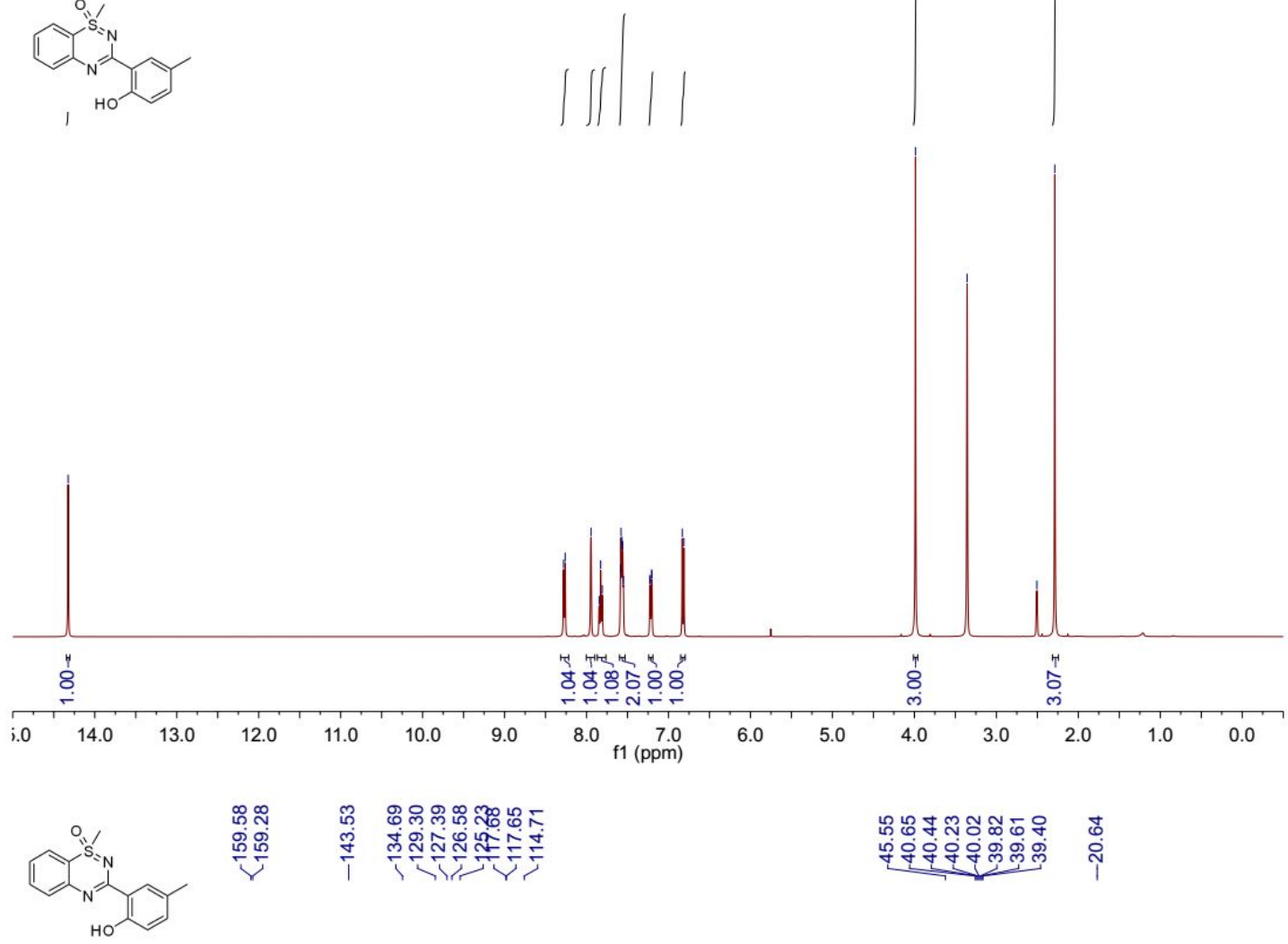

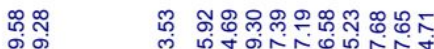

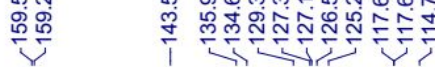

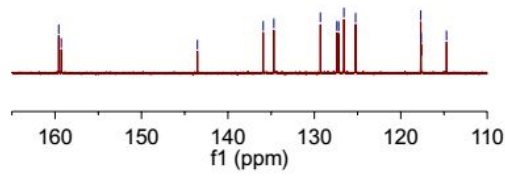

$\begin{array}{lllllllllll}\mathrm{J} 0 & 190 & 180 & 170 & 160 & 150 & 140 & 130 & 120 & 110 & \begin{array}{l}100 \\ \mathrm{f} 1(\mathrm{ppm})\end{array}\end{array}$ 
3as
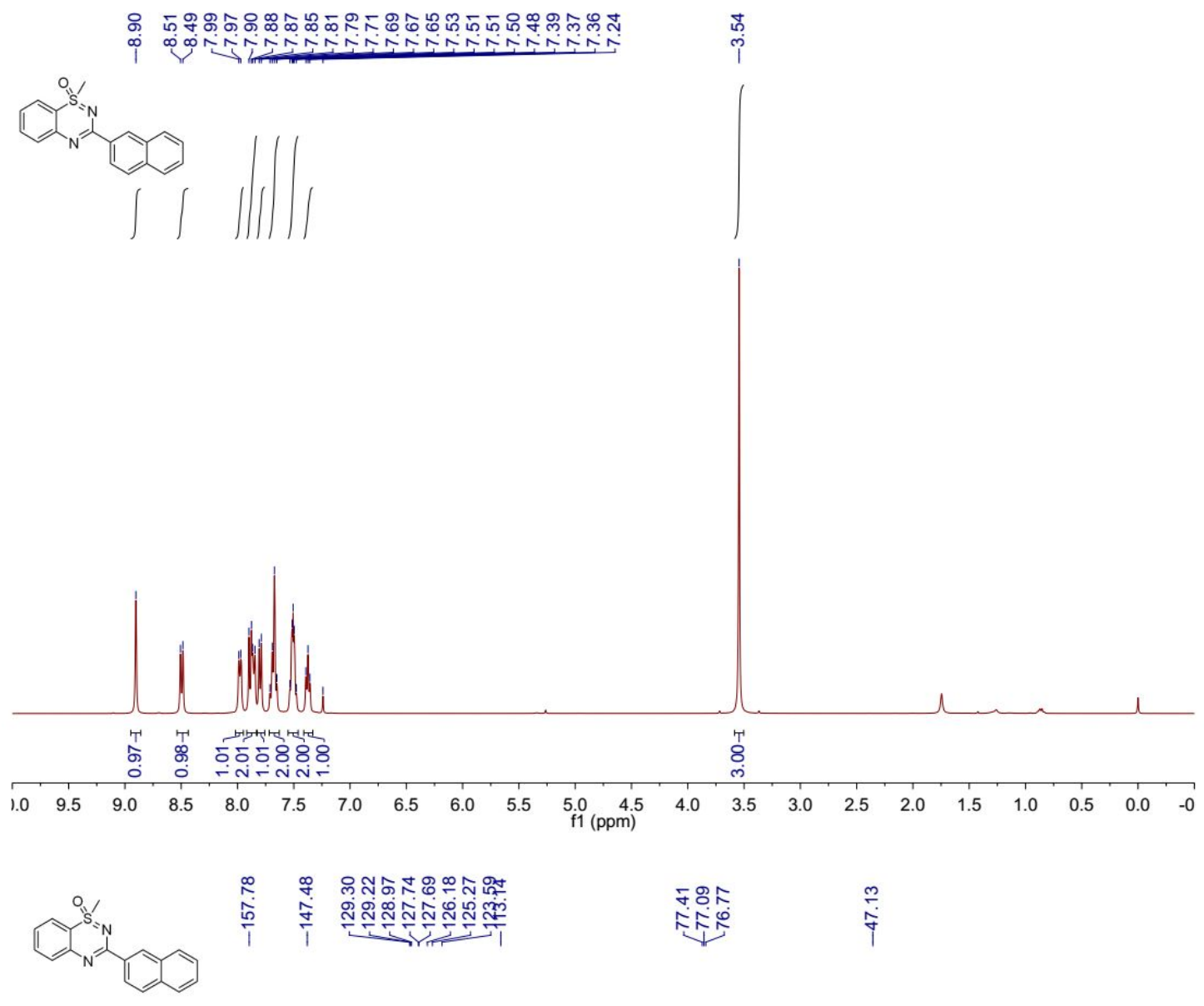

โระกำ

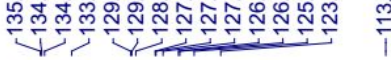
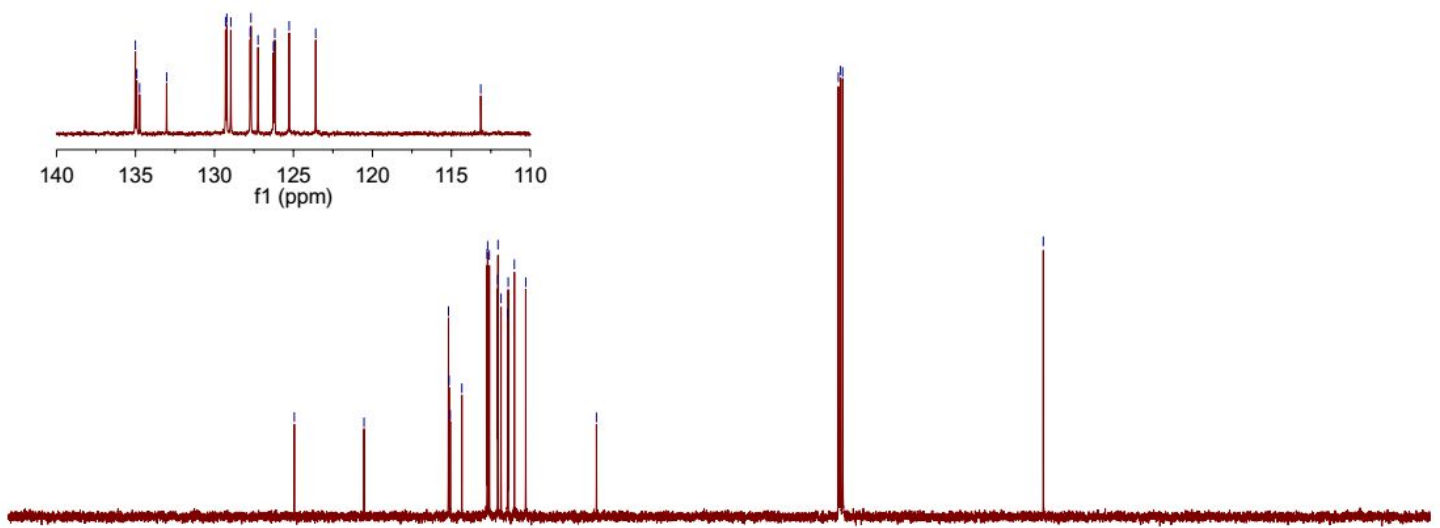

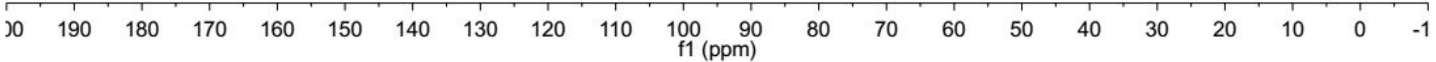


3at
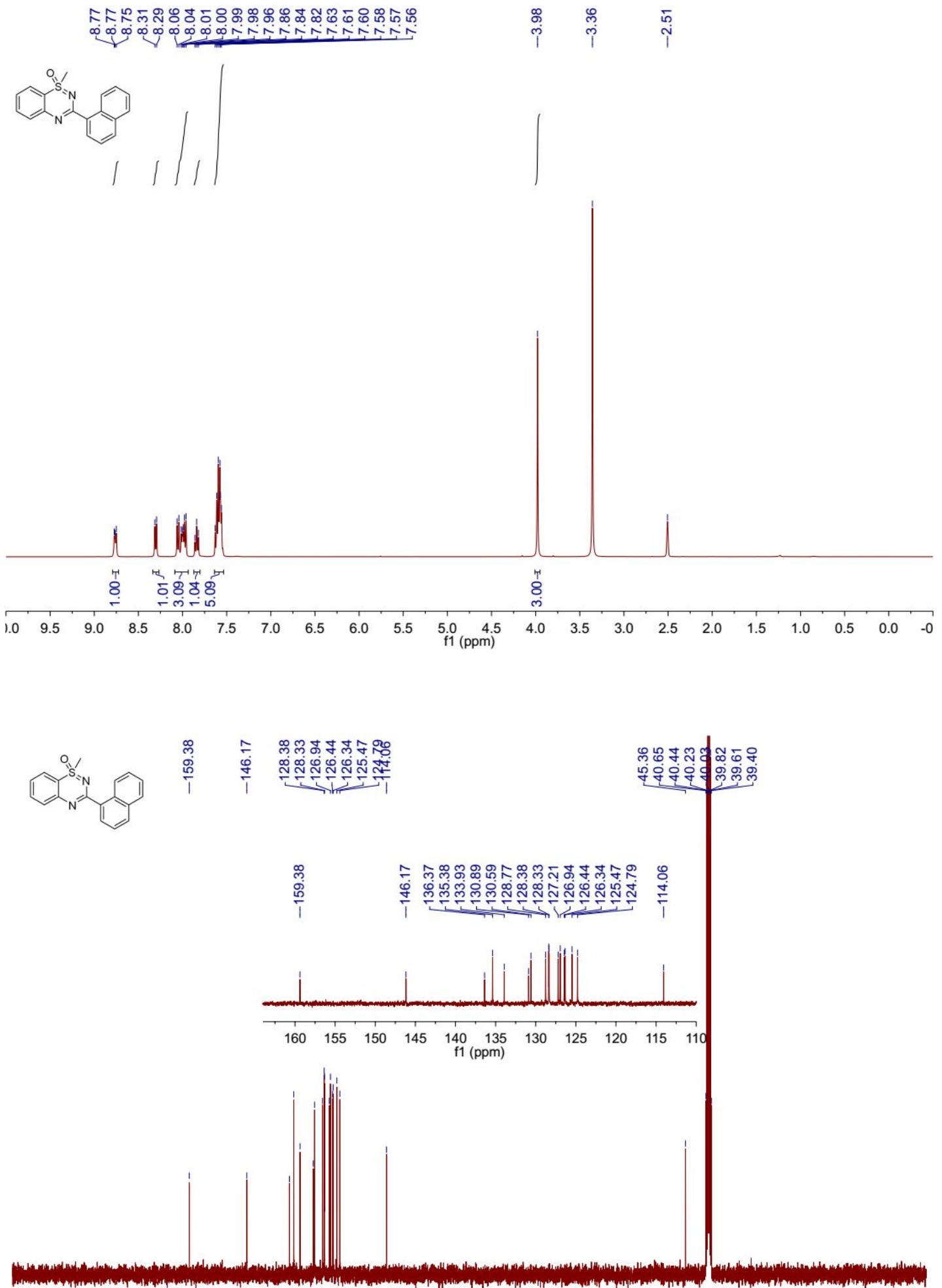

$\begin{array}{lllllllllll}190 & 180 & 170 & 160 & 150 & 140 & 130 & 120 & 110 & 100 & 90\end{array}$ $\begin{array}{llllllllll}80 & 70 & 60 & 50 & 40 & 30 & 20 & 10 & 0 & -1\end{array}$ 
$3 a u$

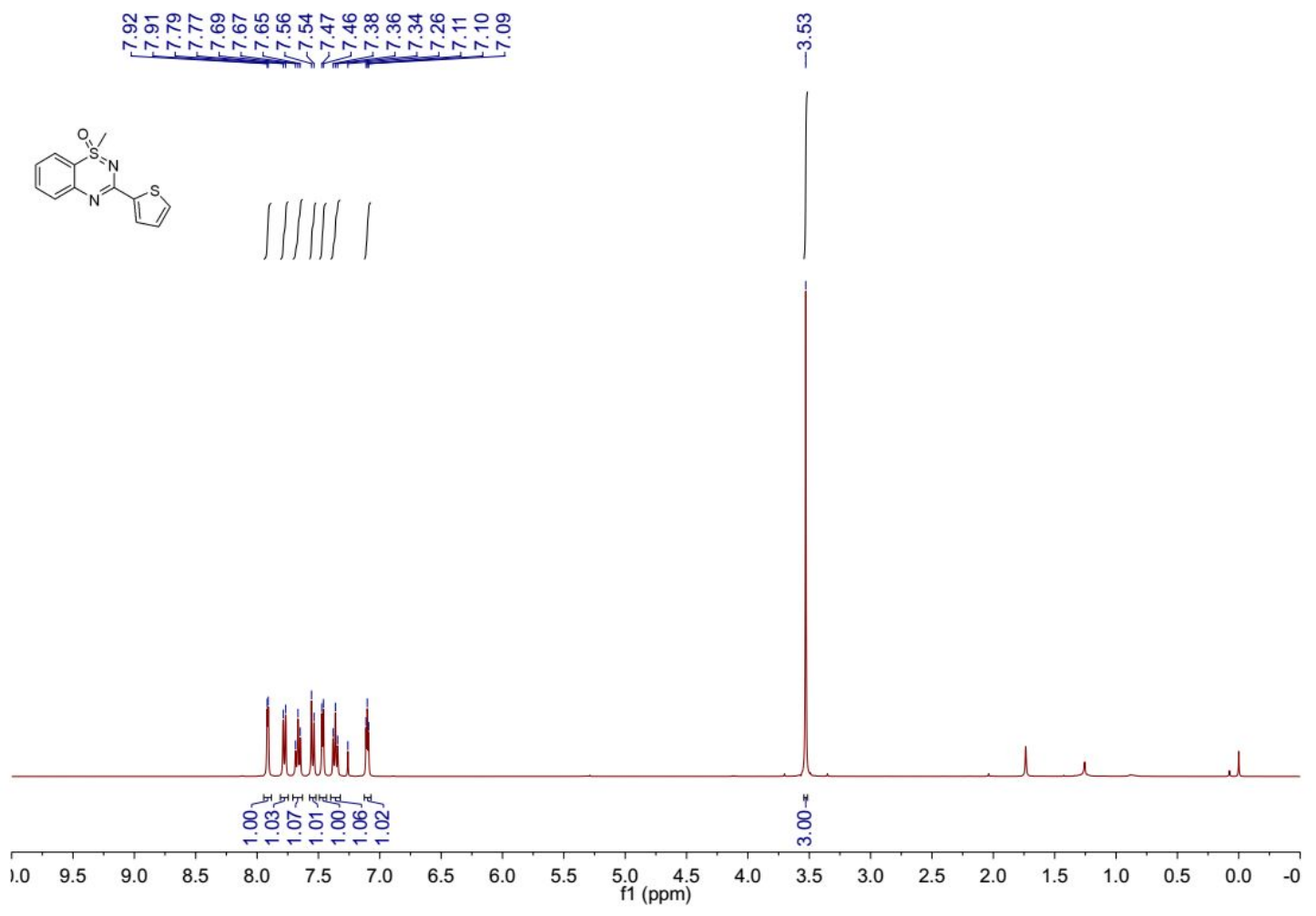

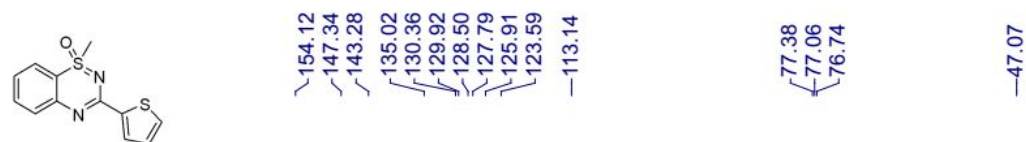

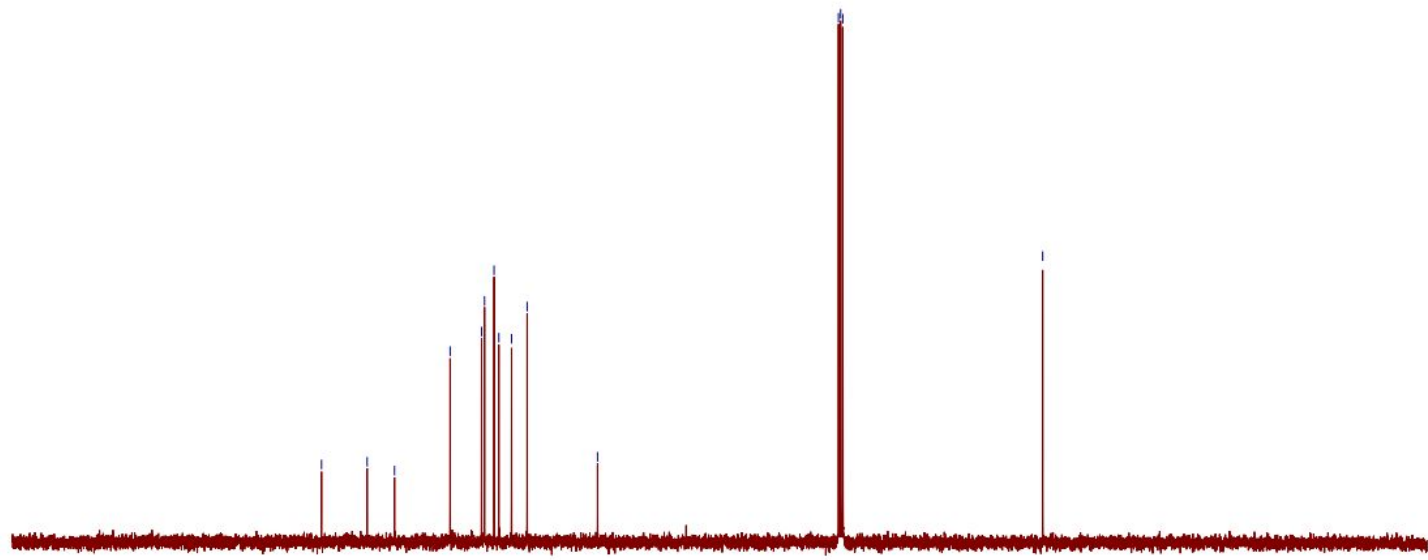

$\begin{array}{lllllllllllllllllllllll}30 & 190 & 180 & 170 & 160 & 150 & 140 & 130 & 120 & 110 & \underset{\mathrm{f} 1}{100}(\mathrm{ppm}) & 90 & 80 & 70 & 60 & 50 & 40 & 30 & 20 & 10 & 0 & -1\end{array}$ 
3av

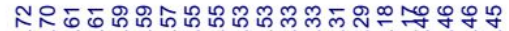

NiNiNiNiNiNiNo

"I.<smiles>Cc1ccccc1</smiles>

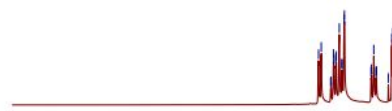

U

8

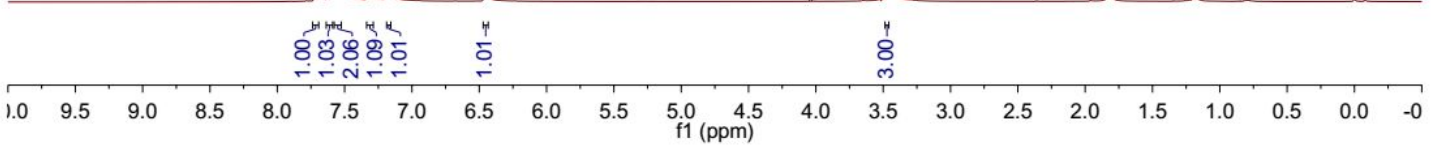

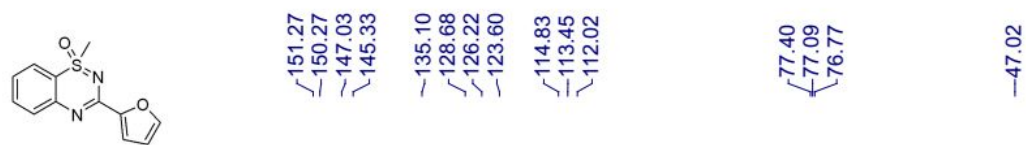

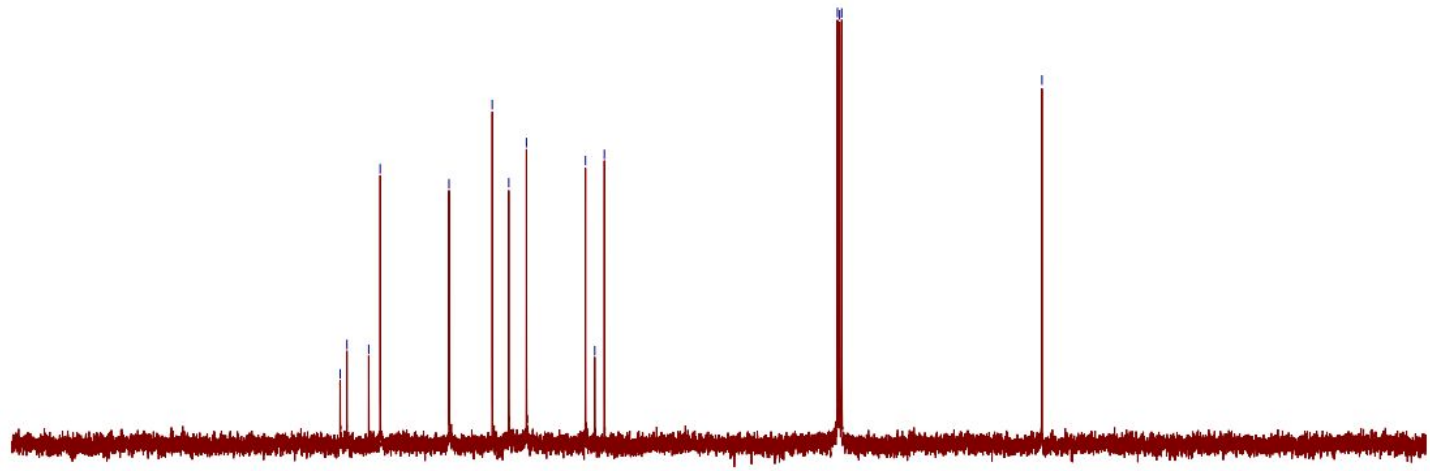

\begin{tabular}{lllllllllll}
\hline 0 & 190 & 180 & 170 & 160 & 150 & 140 & 130 & 120 & 110 & $\begin{array}{l}100 \\
\mathrm{f} 1(\mathrm{ppm})\end{array}$
\end{tabular}

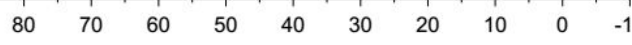


3aw

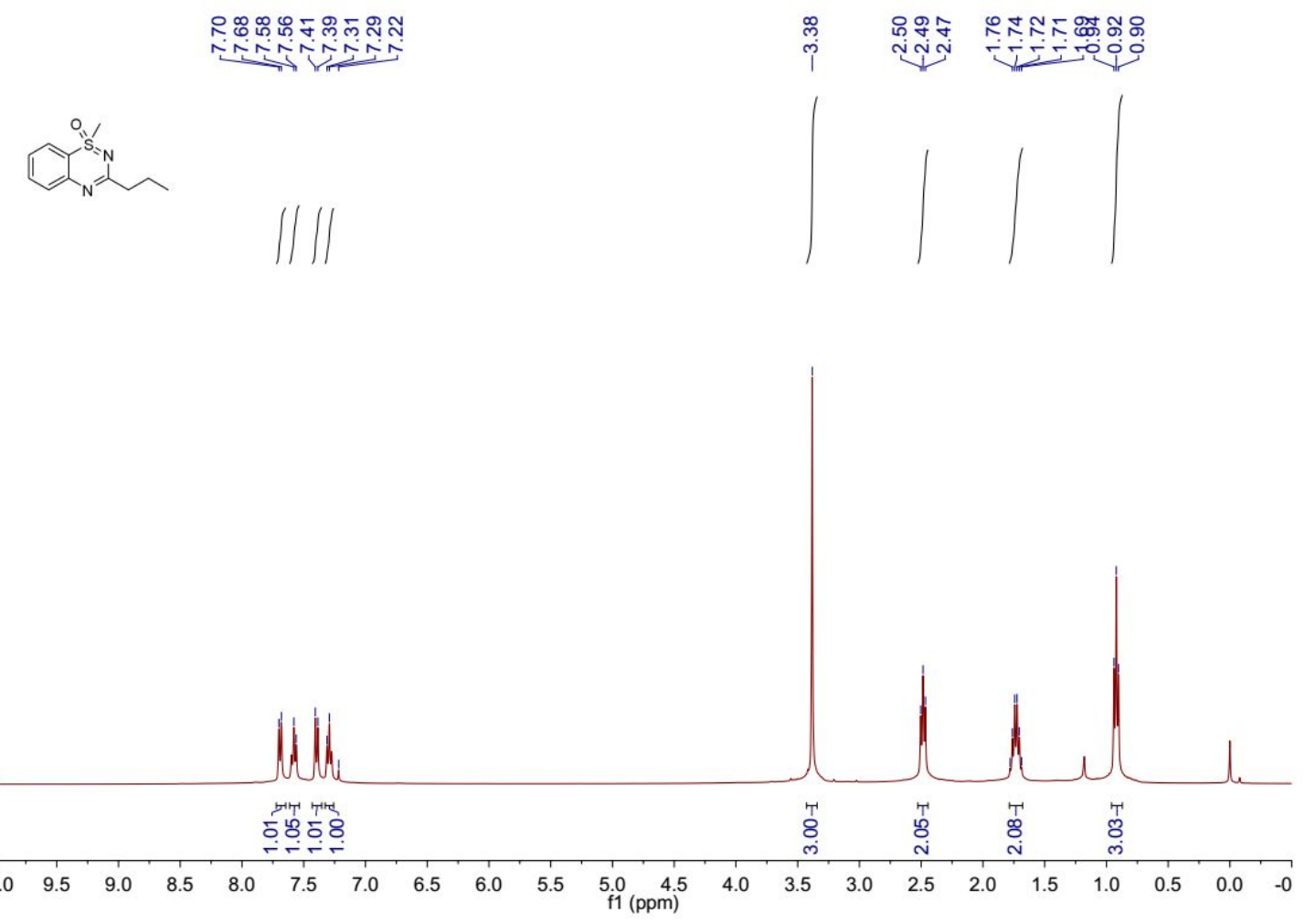

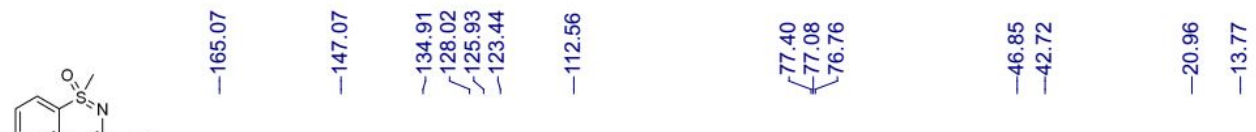

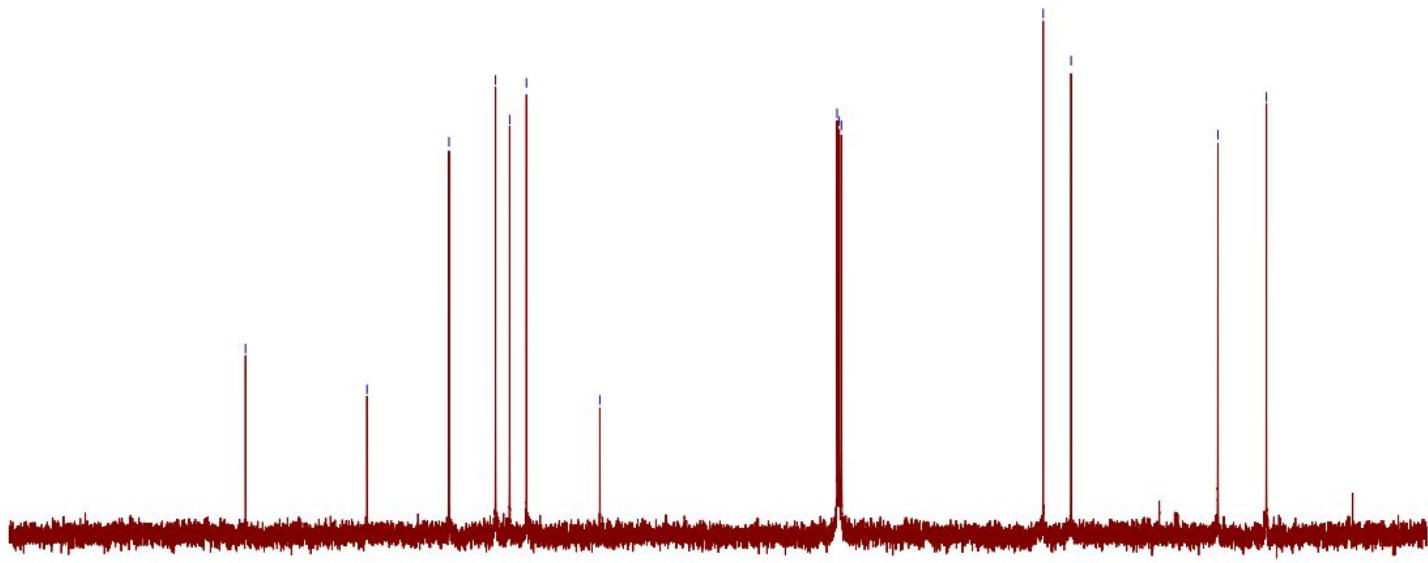

$\begin{array}{lllllllllll}\text { J0 } & 190 & 180 & 170 & 160 & 150 & 140 & 130 & 120 & 110 & 100\end{array}$

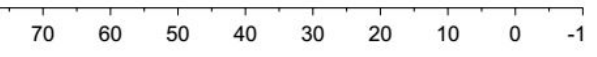


3ax

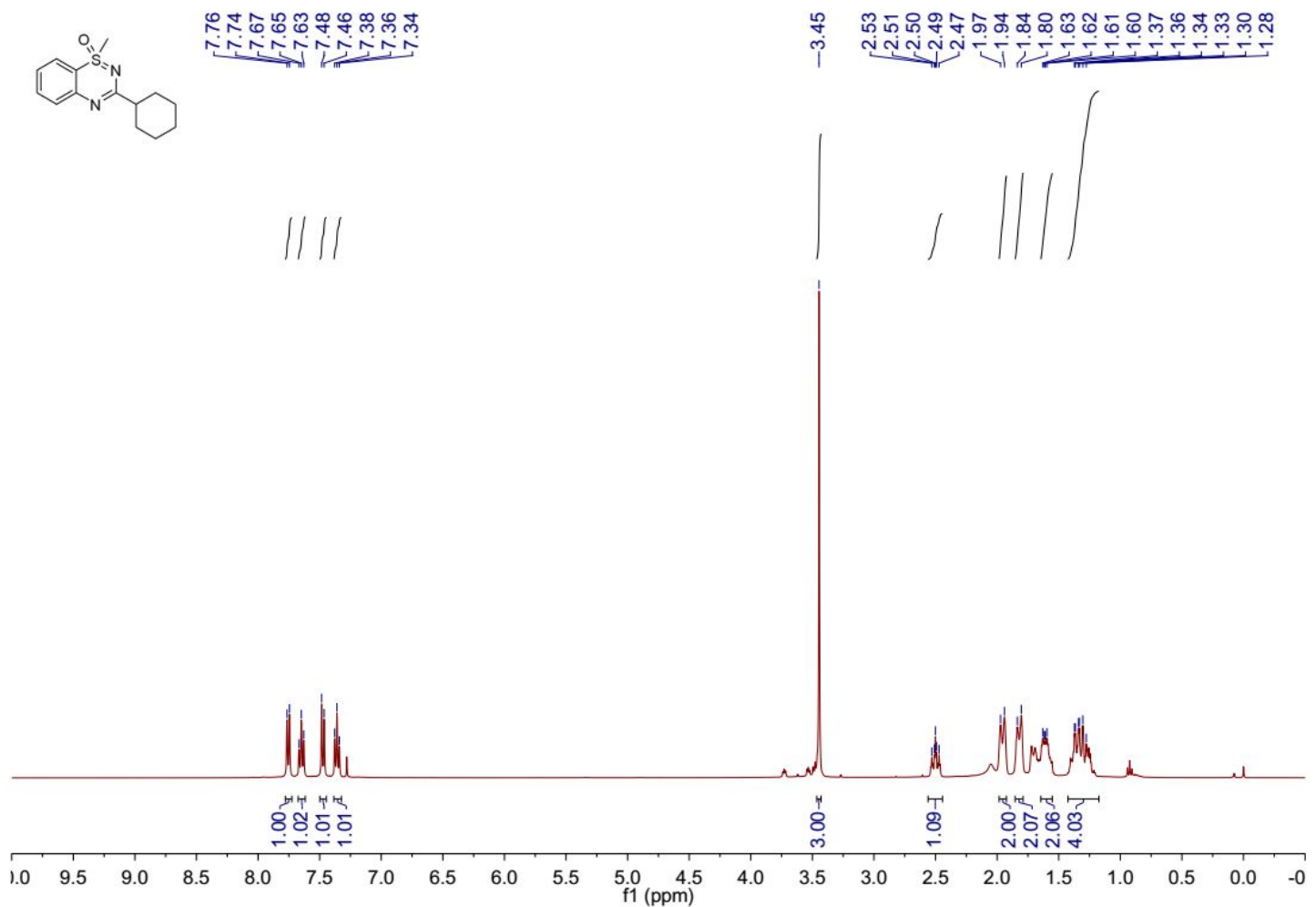

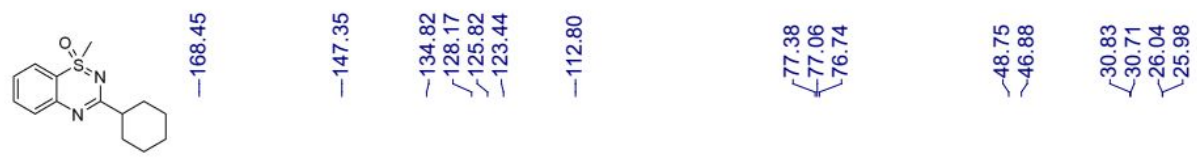

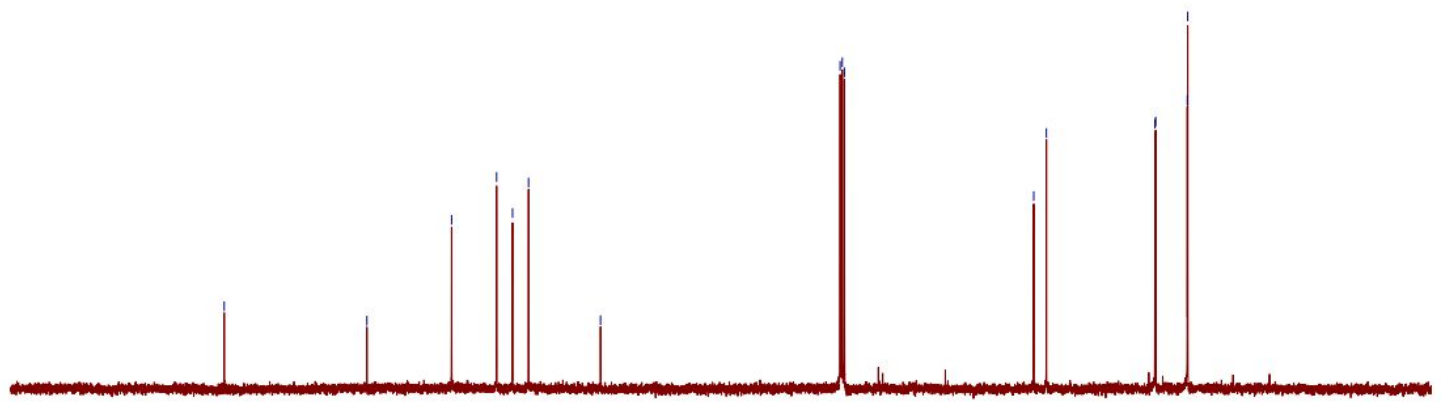

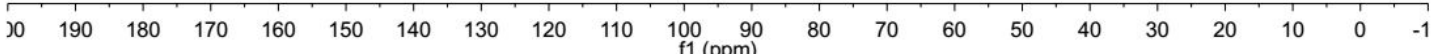


$3 a y$

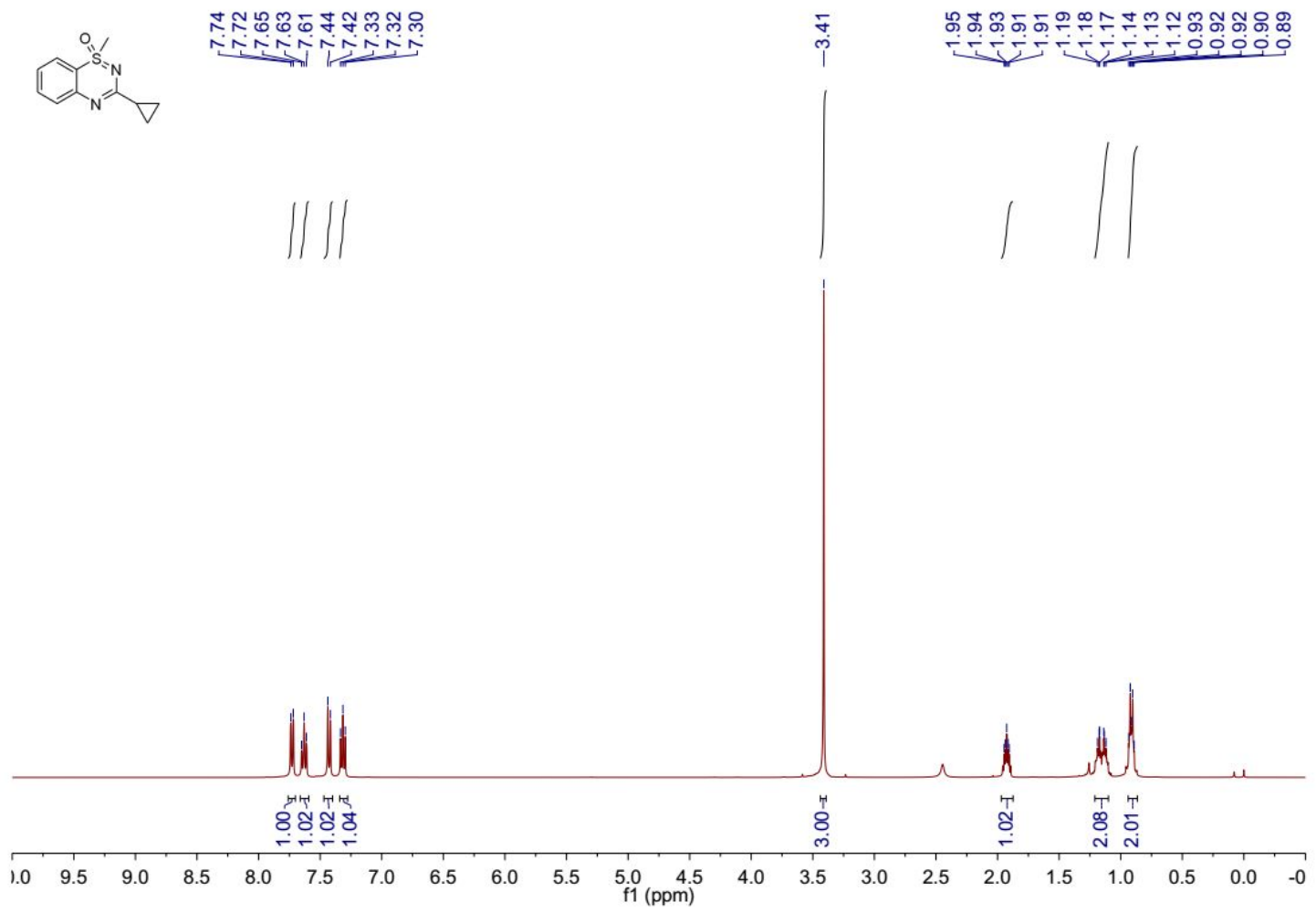

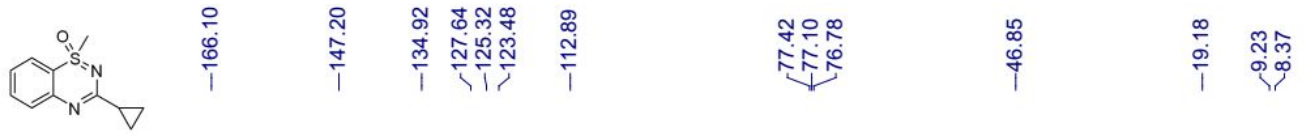

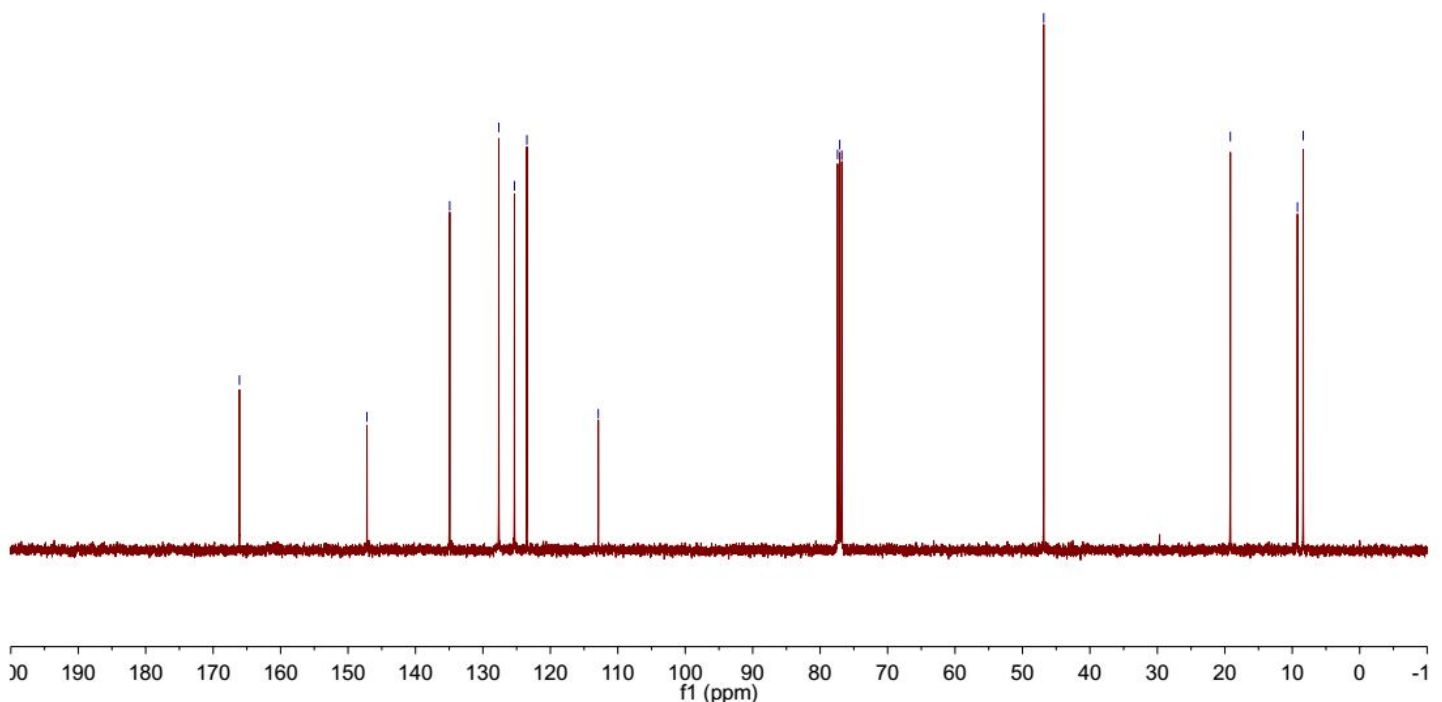


$3 a z$
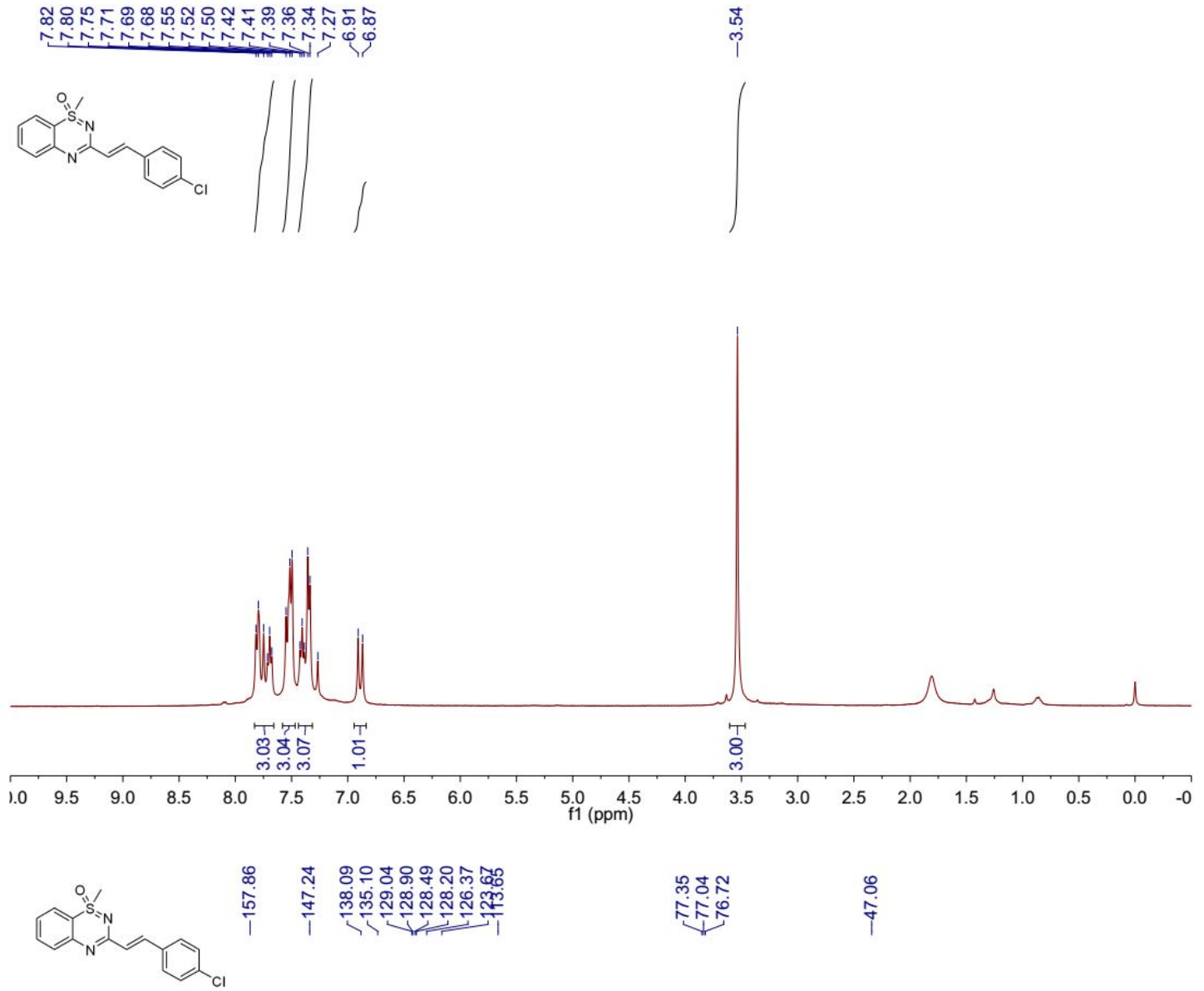

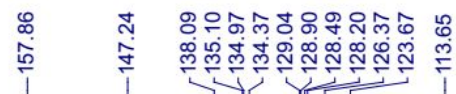
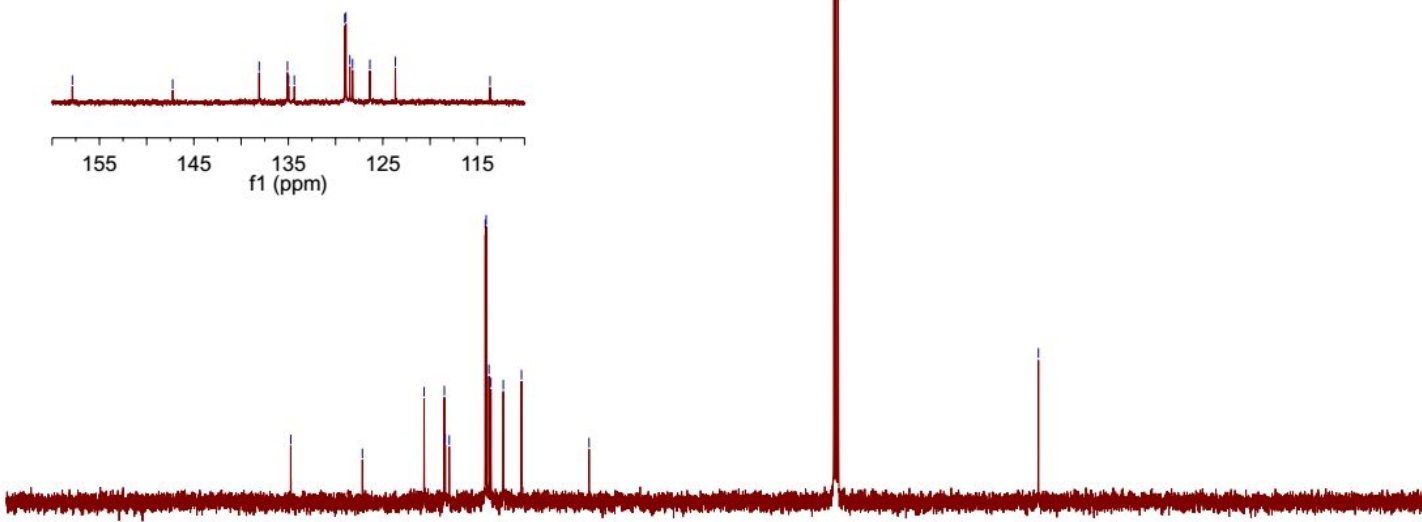

\begin{tabular}{lllllllllllllllllllllll}
\hline 0 & 190 & 180 & 170 & 160 & 150 & 140 & 130 & 120 & 110 & 100 & 90 & 80 & 70 & 60 & 50 & 40 & 30 & 20 & 10 & 0 & -1
\end{tabular} 
3. ${ }^{1} \mathrm{H}$ and ${ }^{13} \mathrm{C}$ NMR spectrum for the preparation of compounds $\mathbf{4 b a}-\mathbf{4 f a}$.

4 ba
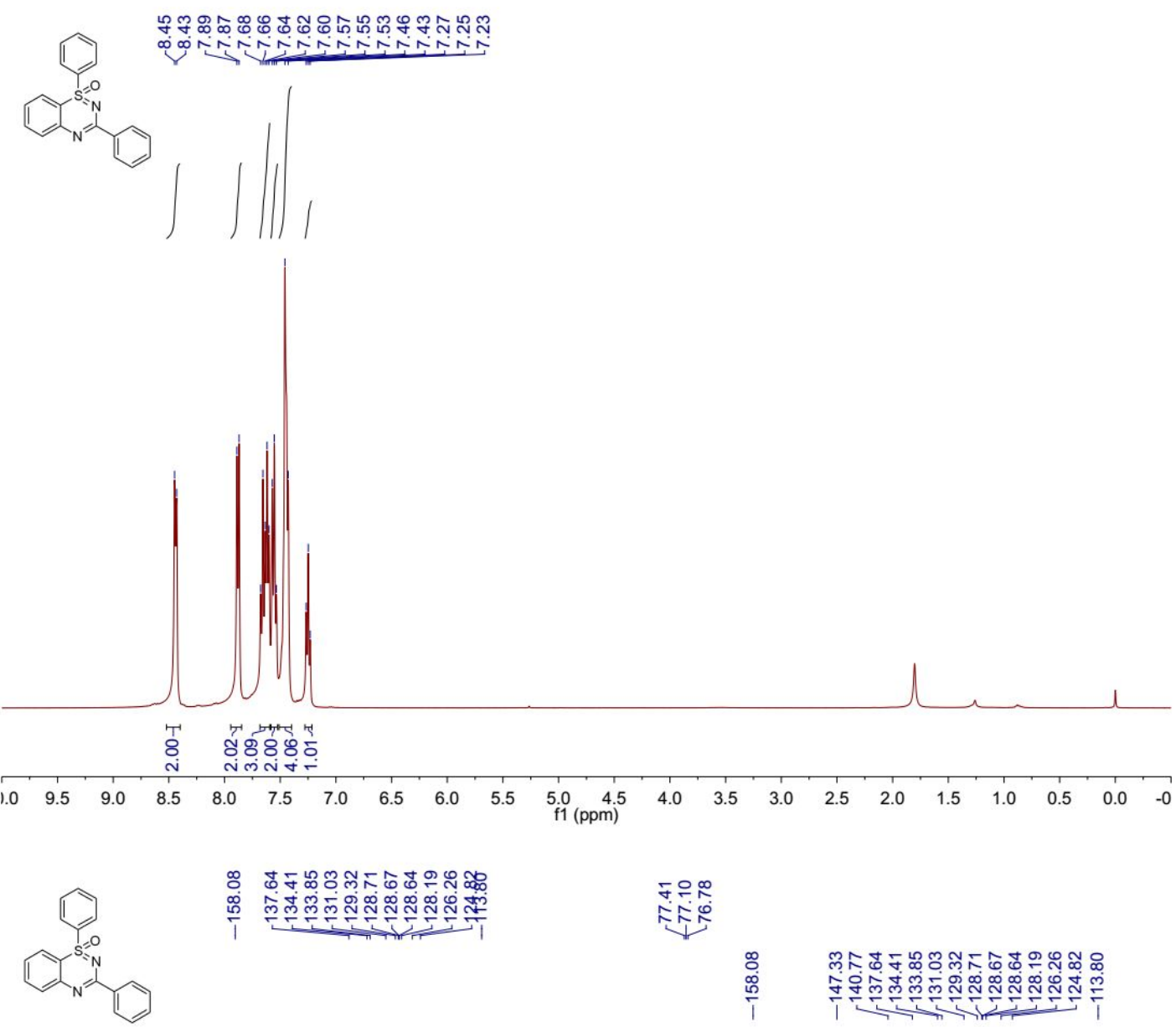

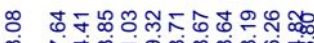

官

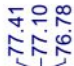

D

i
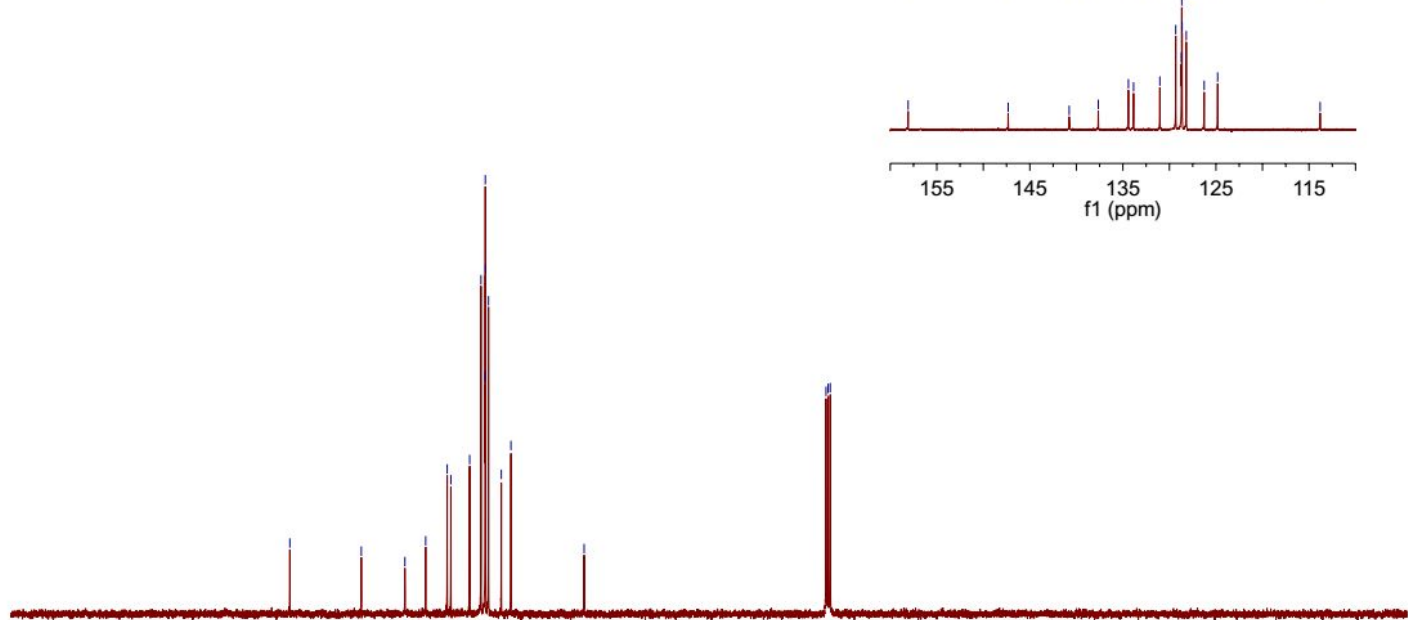

$\begin{array}{lllllllllll}30 & 190 & 180 & 170 & 160 & 150 & 140 & 130 & 120 & 110 & 100\end{array}$

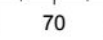

6050

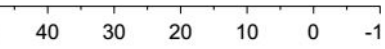


4bb
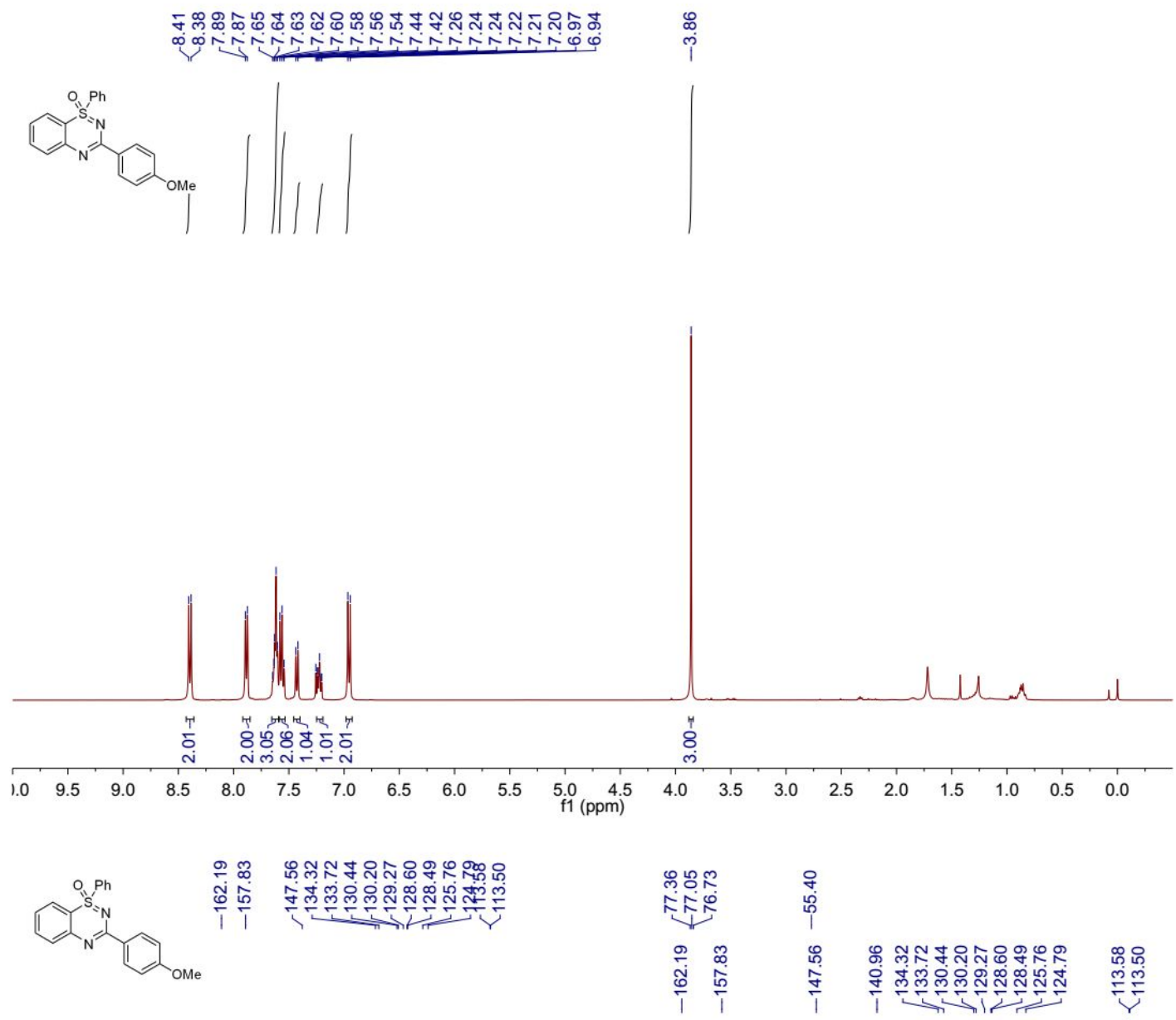

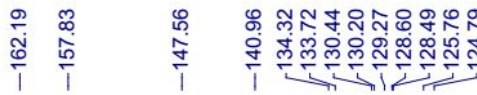

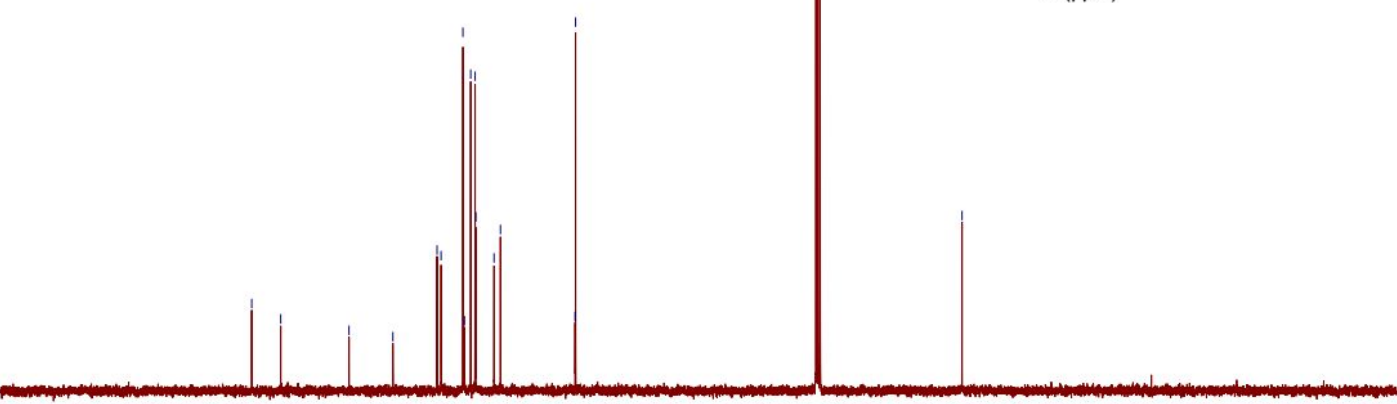

\begin{tabular}{llllllllllllllllllllll}
\hline 0 & 190 & 180 & 170 & 160 & 150 & 140 & 130 & 120 & 110 & $\underset{\mathrm{f} 1}{100}(\mathrm{ppm})$ & 80 & 70 & 60 & 50 & 40 & 30 & 20 & 10 & 0 & -1
\end{tabular} 

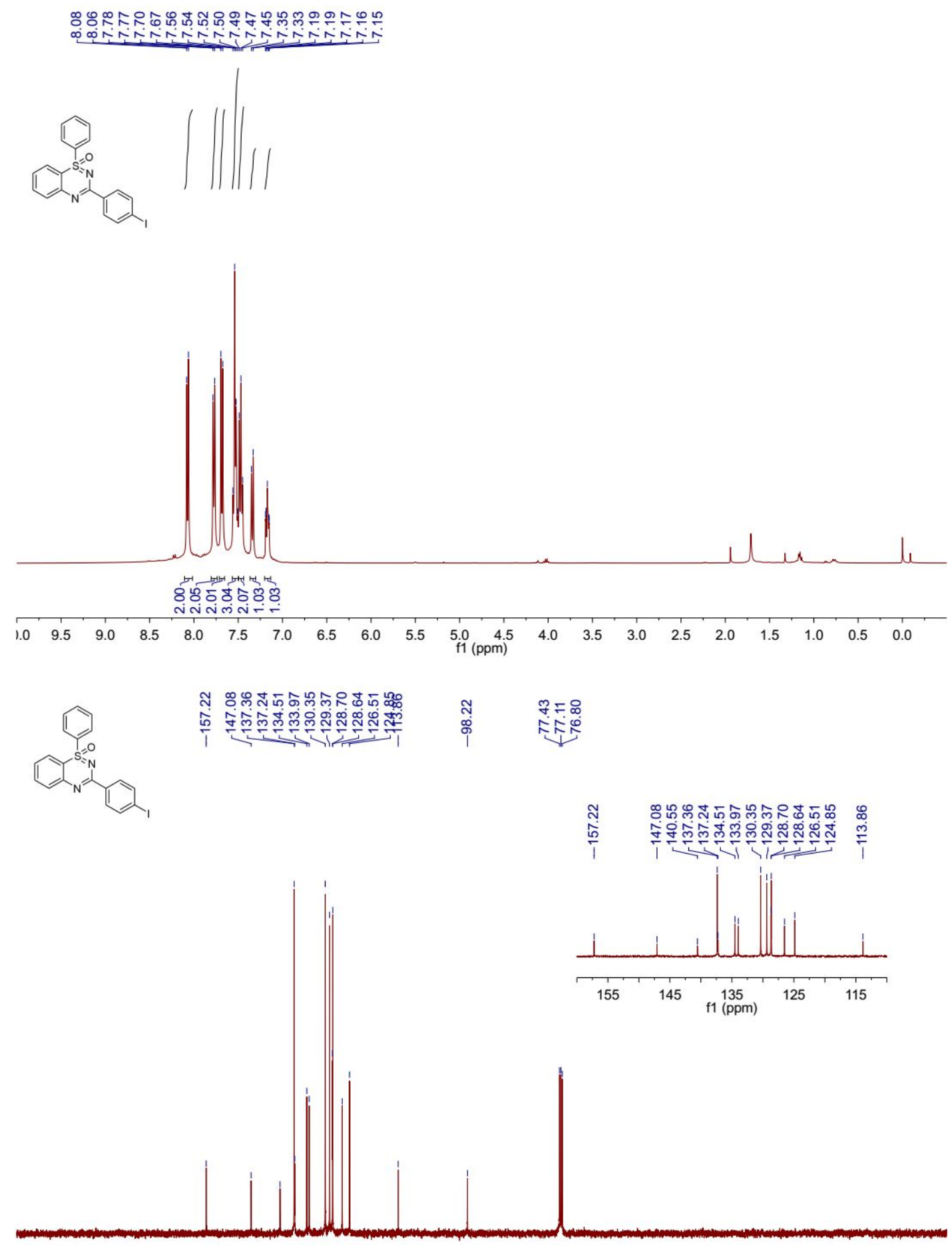

\begin{tabular}{lllllllllllllllllllllllllll}
\hline 0 & 190 & 180 & 170 & 160 & 150 & 140 & 130 & 120 & 110 & $\underset{f}{100}(\mathrm{ppm})$ & 90 & 80 & 70 & 60 & 50 & 40 & 30 & 20 & 10 & 0 & -1
\end{tabular} 
$4 \mathrm{ca}$
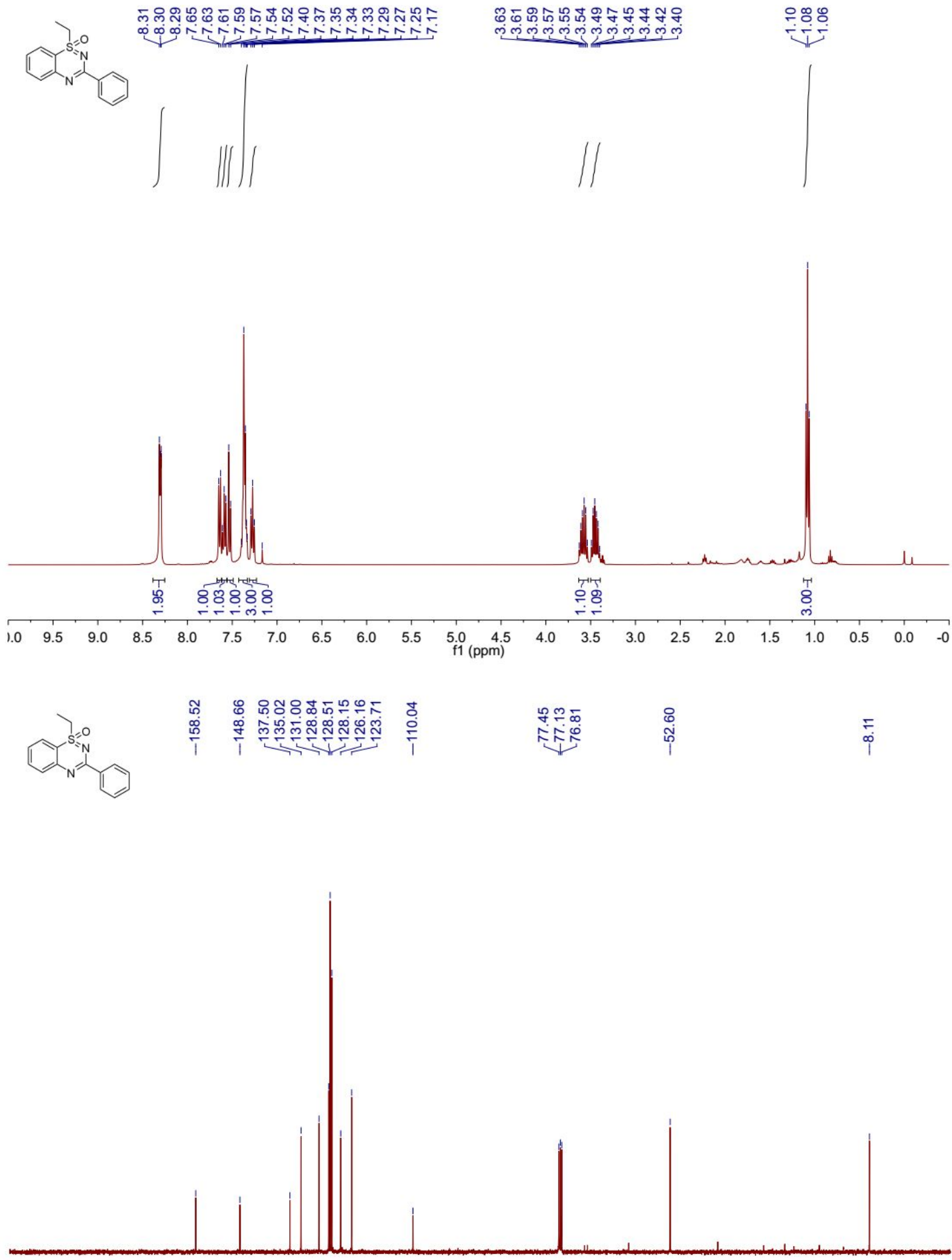

\begin{tabular}{lllllllllllllllllllllllll}
\hline 0 & 190 & 180 & 170 & 160 & 150 & 140 & 130 & 120 & 110 & $\underset{100}{100} 90$ & 80 & 70 & 60 & 50 & 40 & 30 & 20 & 10 & 0 & -1
\end{tabular} 
$4 \mathrm{cb}$
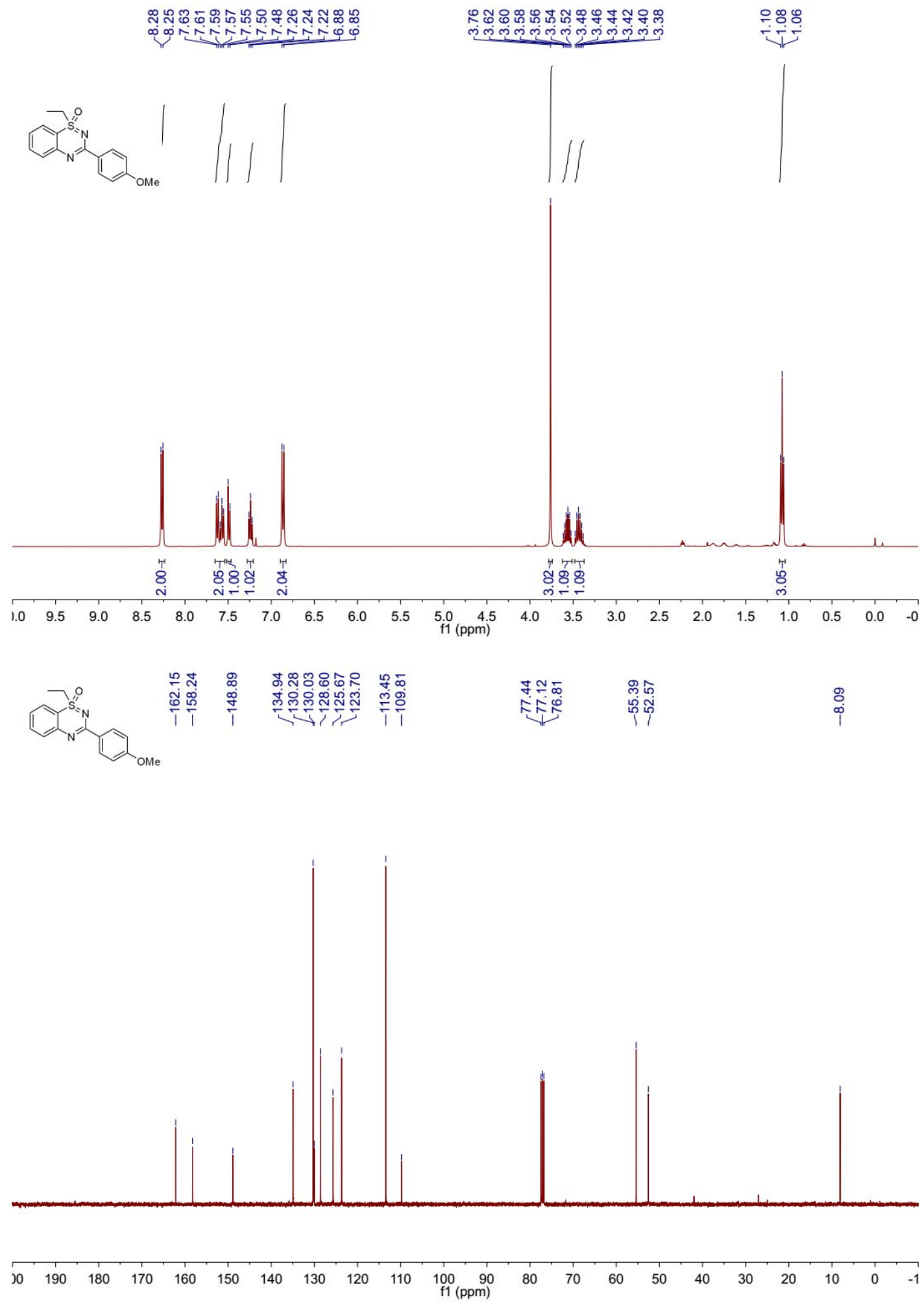


\section{4da}
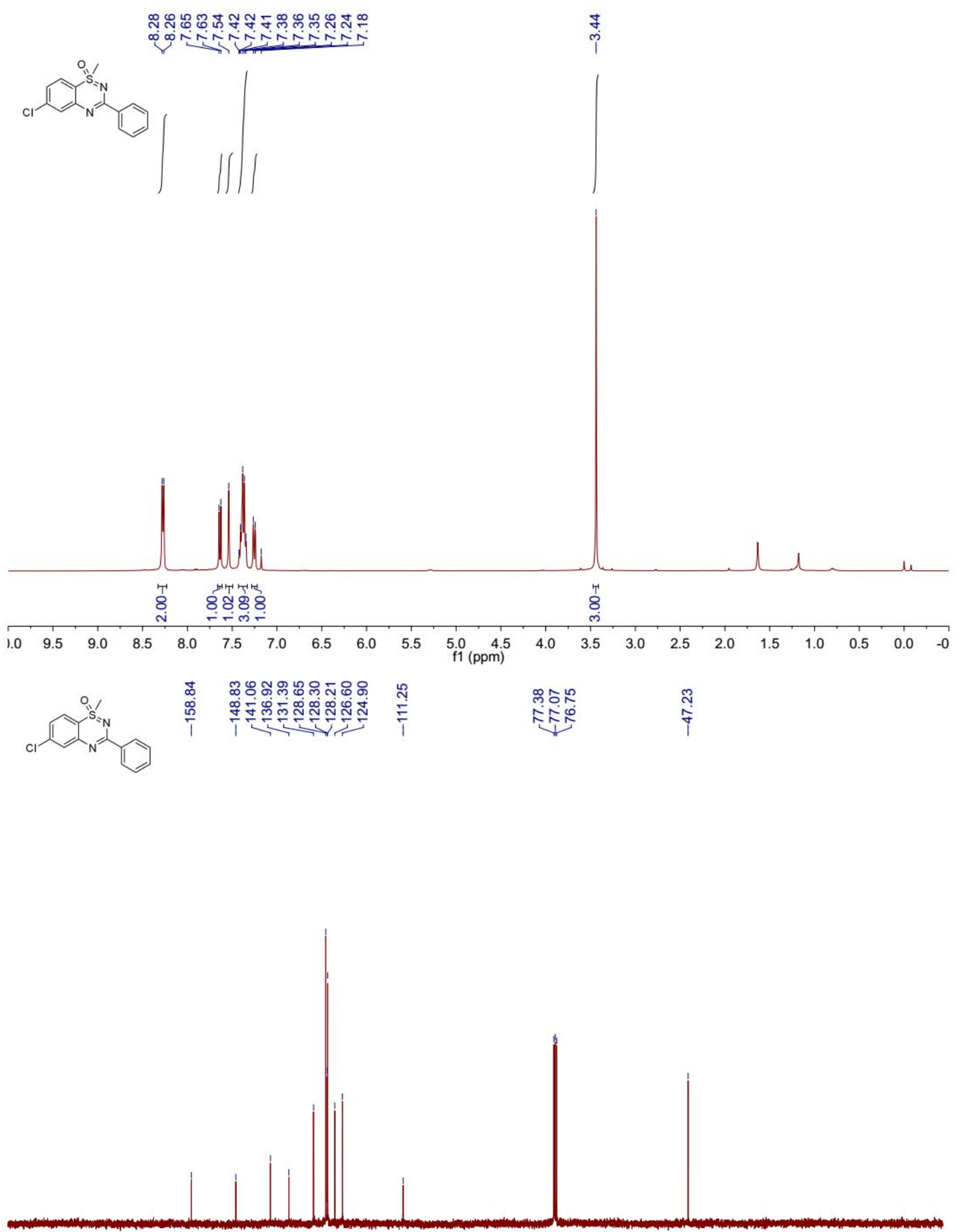

$\begin{array}{llllllllllllllllllllll}\mathrm{J} 0 & 190 & 180 & 170 & 160 & 150 & 140 & 130 & 120 & 110 & \underset{f}{100} \mathrm{f}(\mathrm{ppm}) & 80 & 70 & 60 & 50 & 40 & 30 & 20 & 10 & 0 & -1\end{array}$ 
$4 d b$
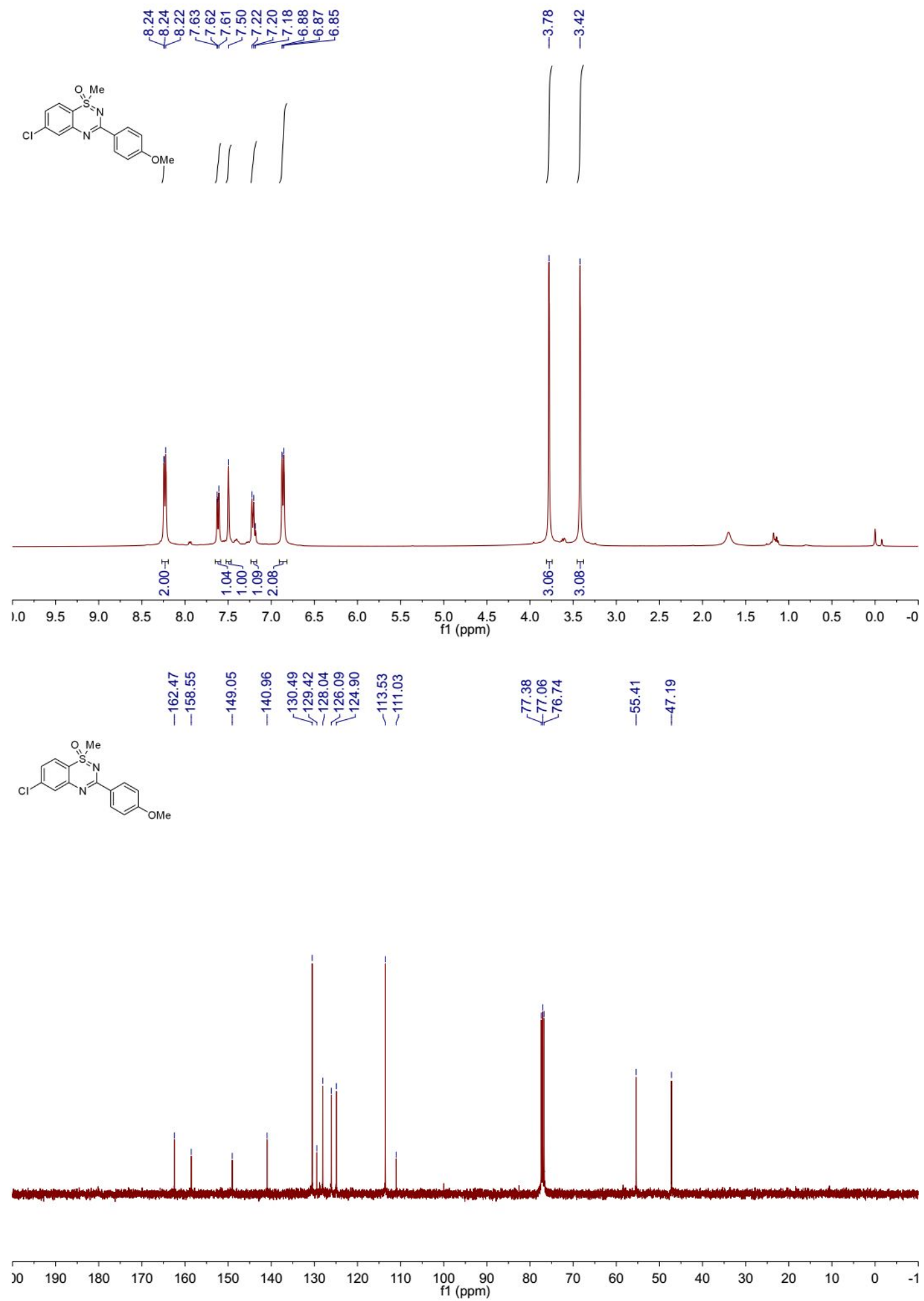
4ea
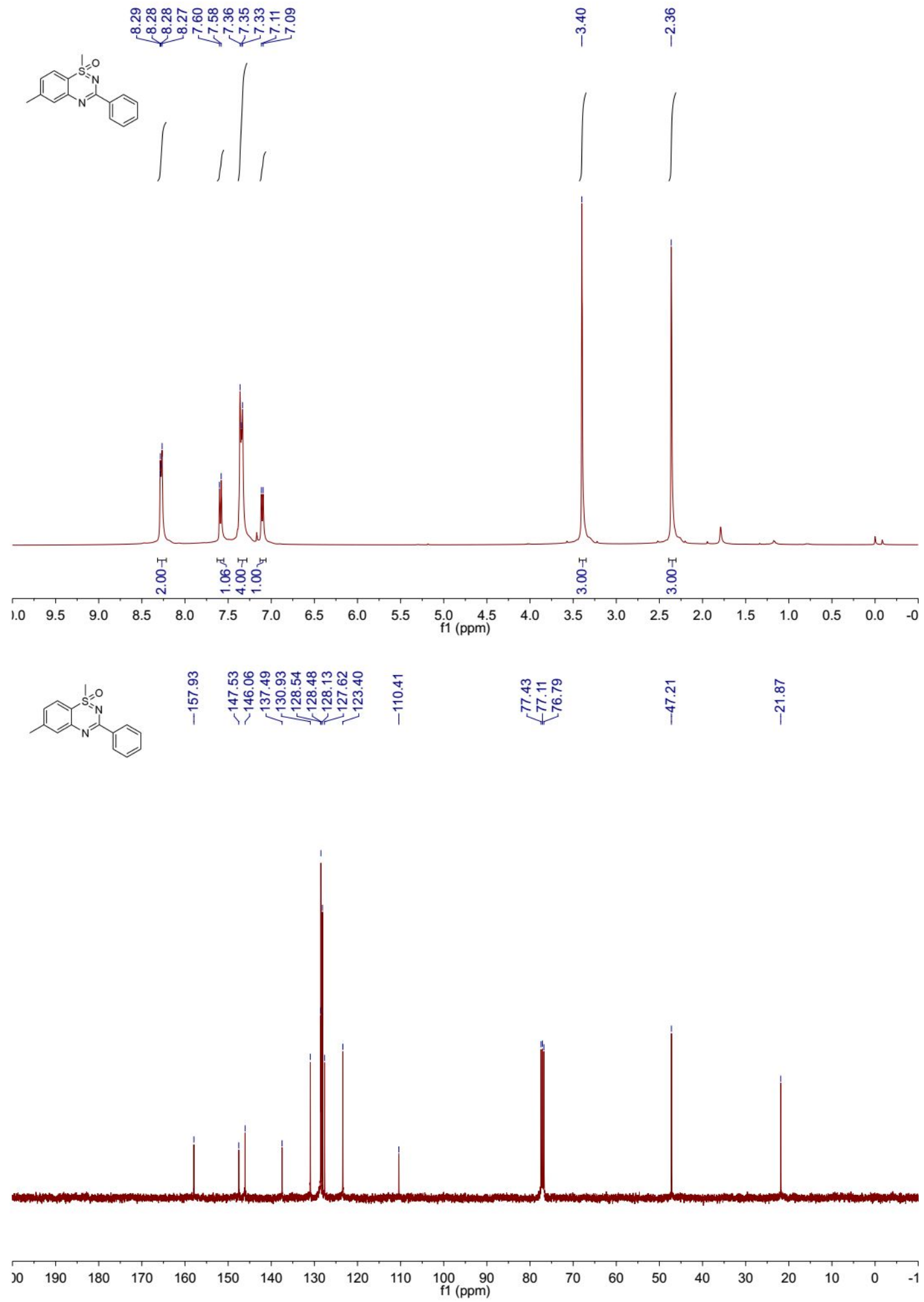
4eb

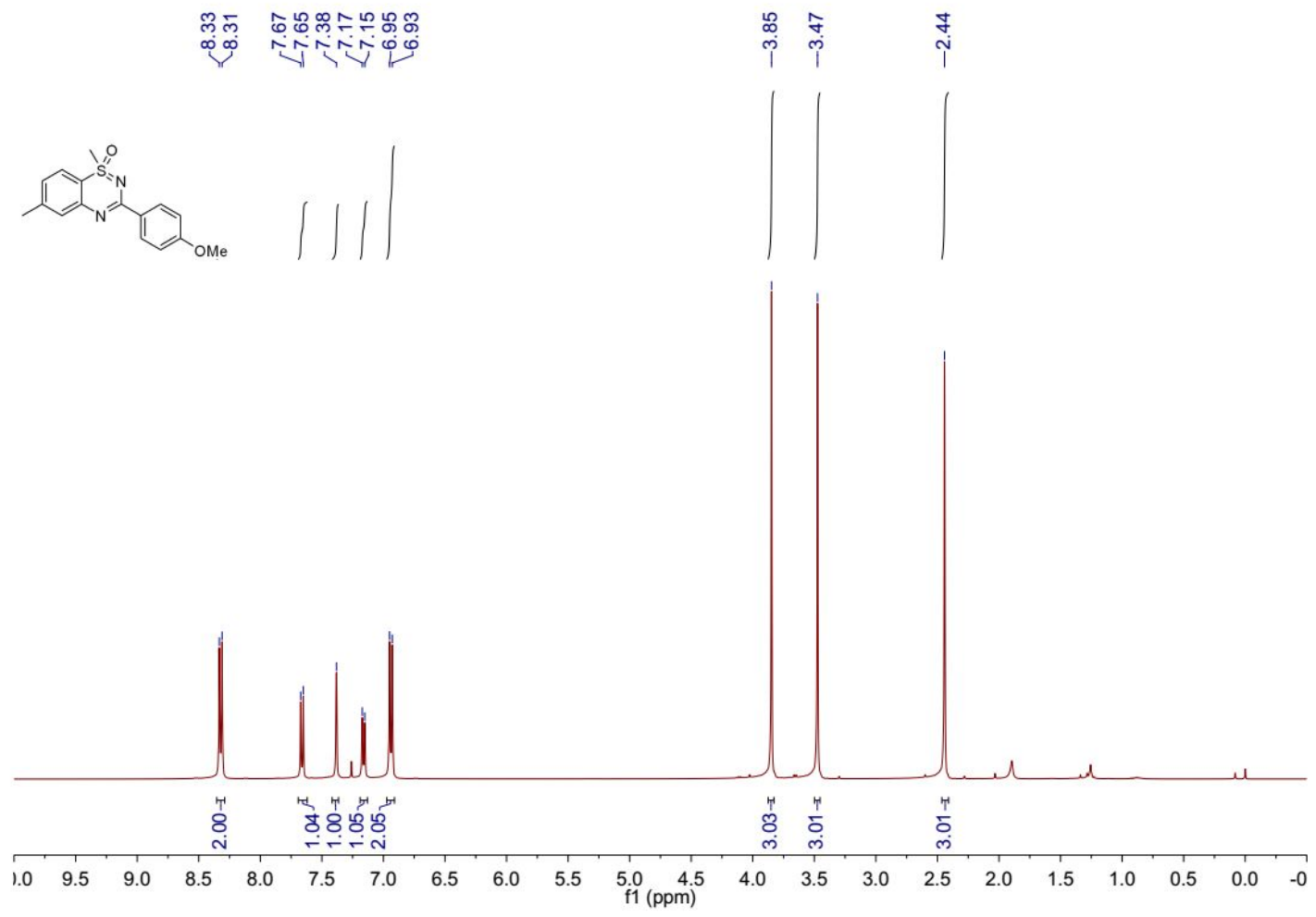

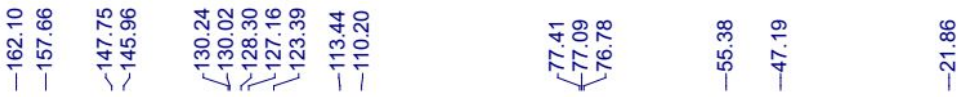
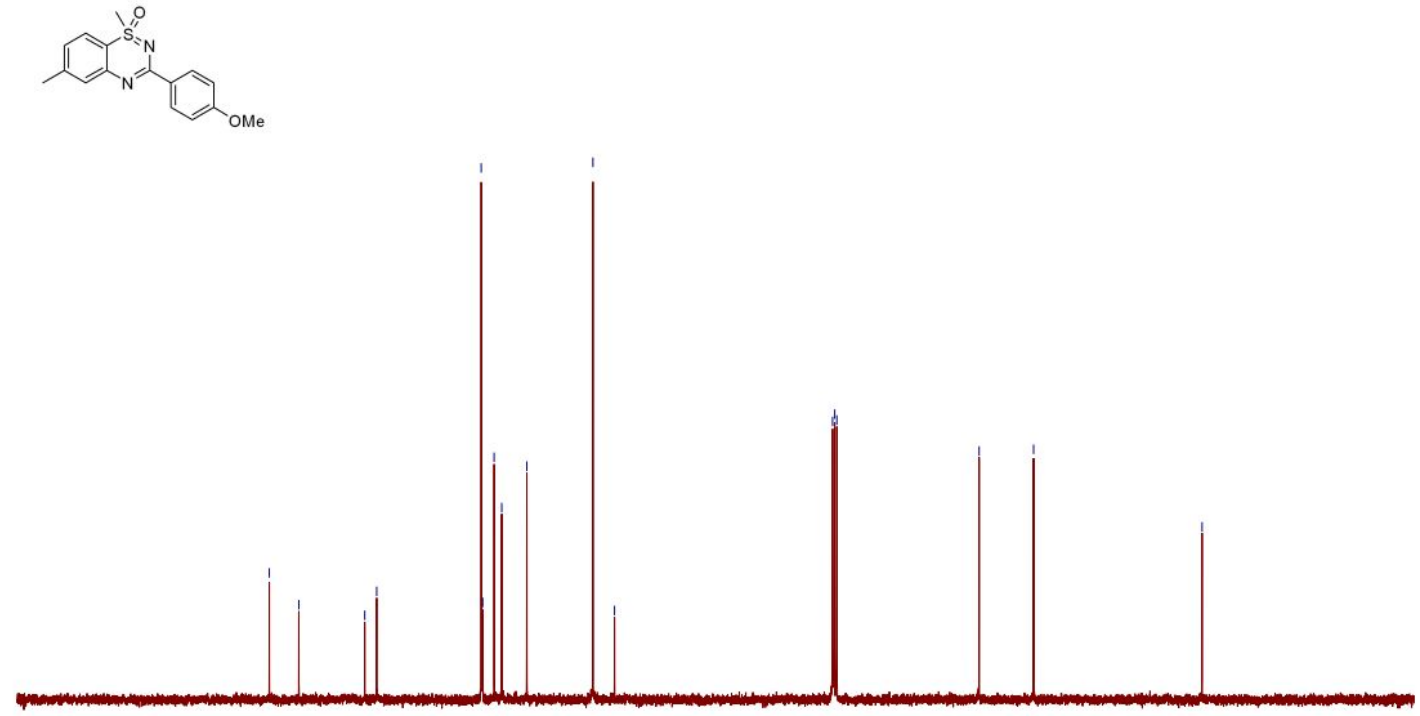

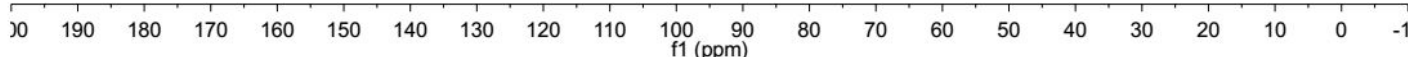


4ef
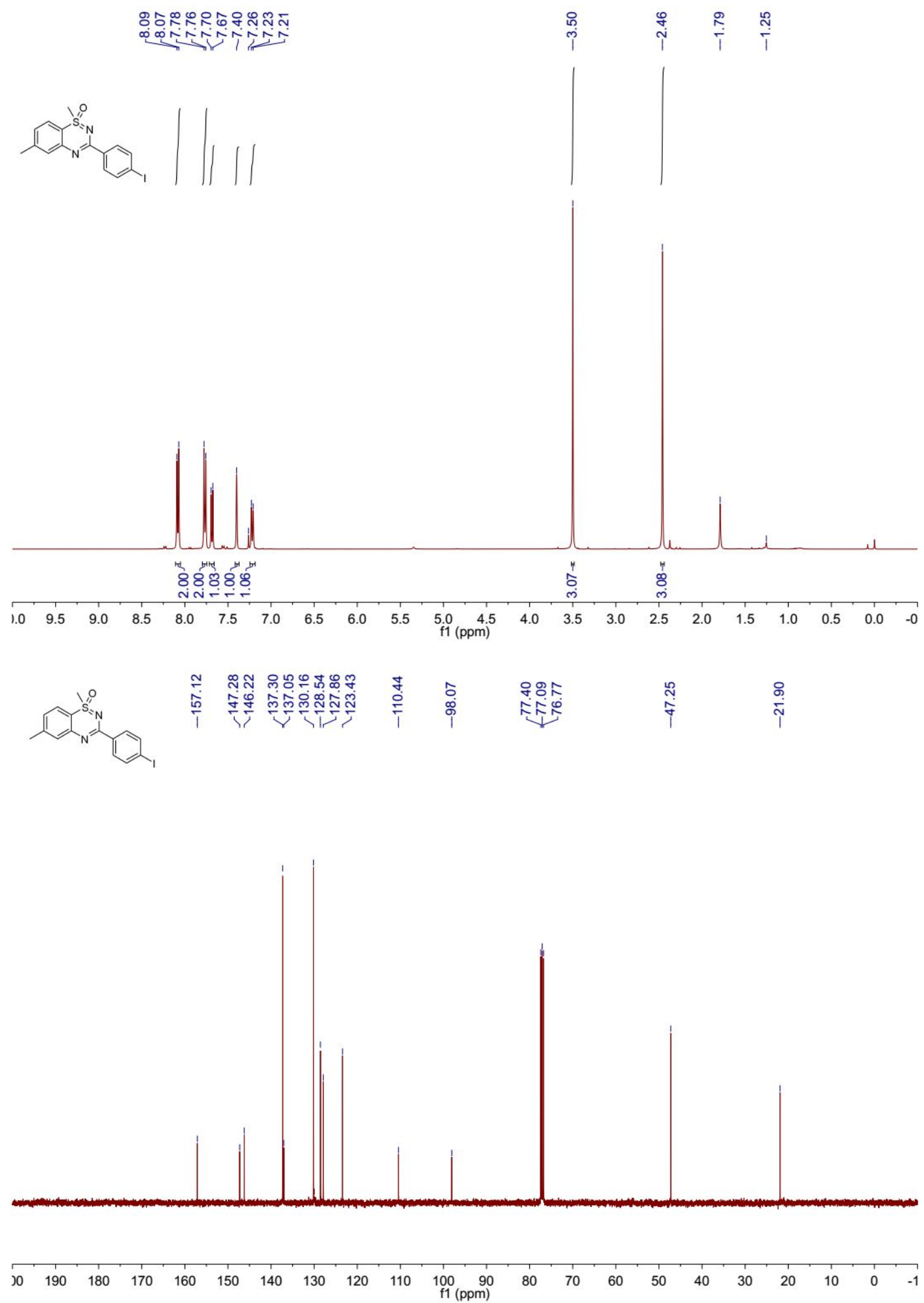

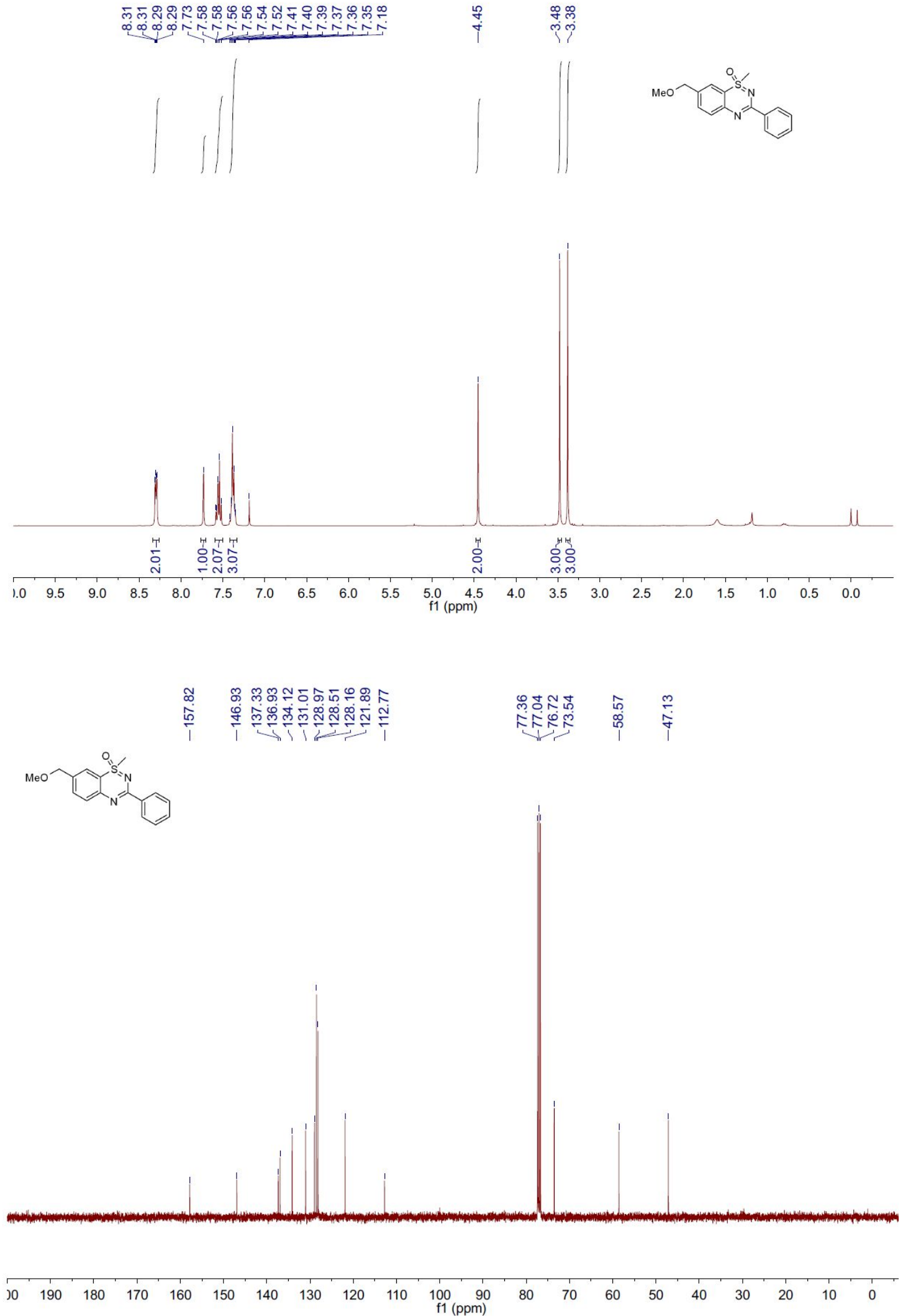
4. ${ }^{1} \mathrm{H}$ and ${ }^{13} \mathrm{C}$ NMR spectrum for the preparation of compounds $\mathbf{5 a}$ and $\mathbf{5} \mathbf{b}$.

$5 \mathbf{a}$
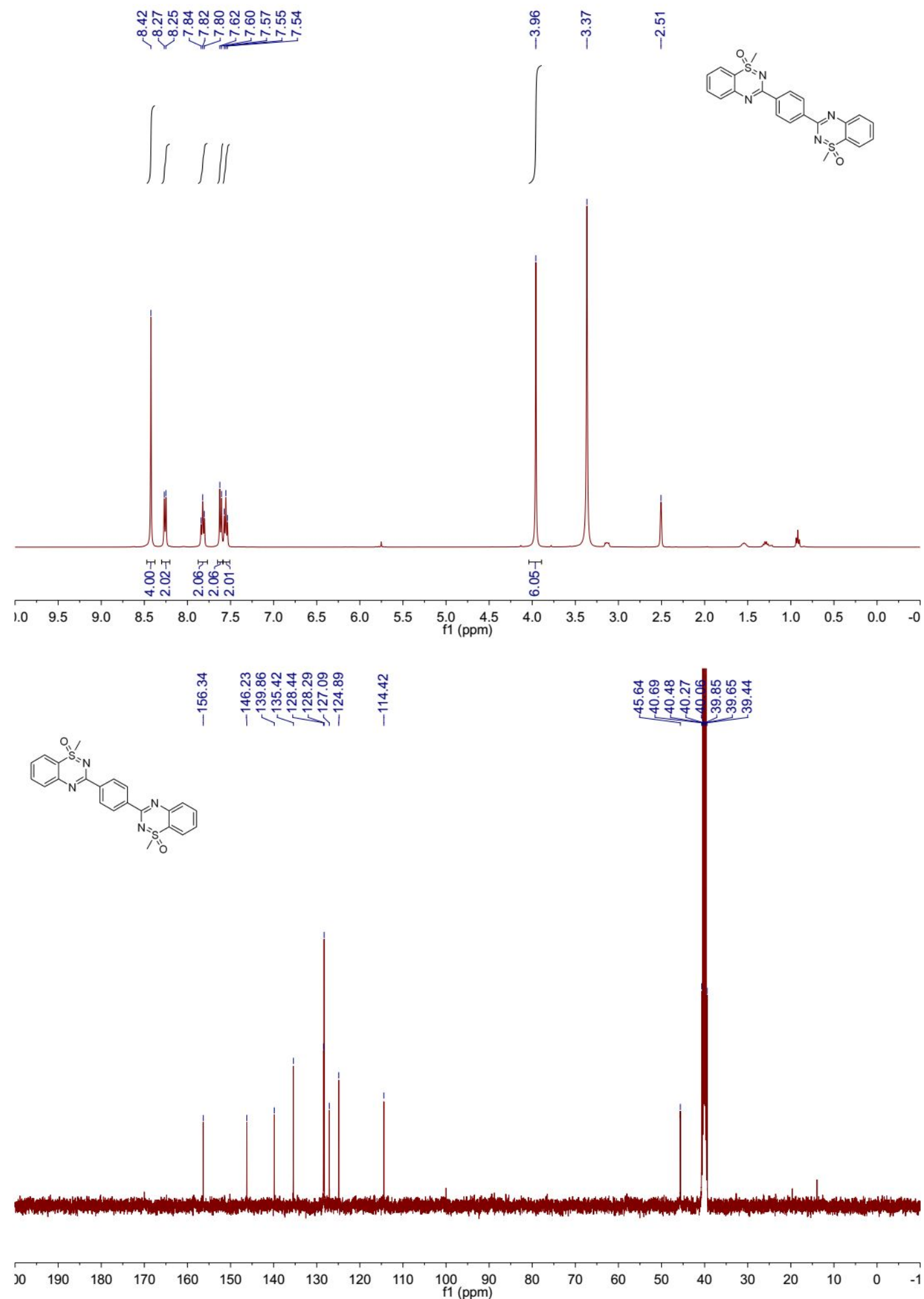
5b
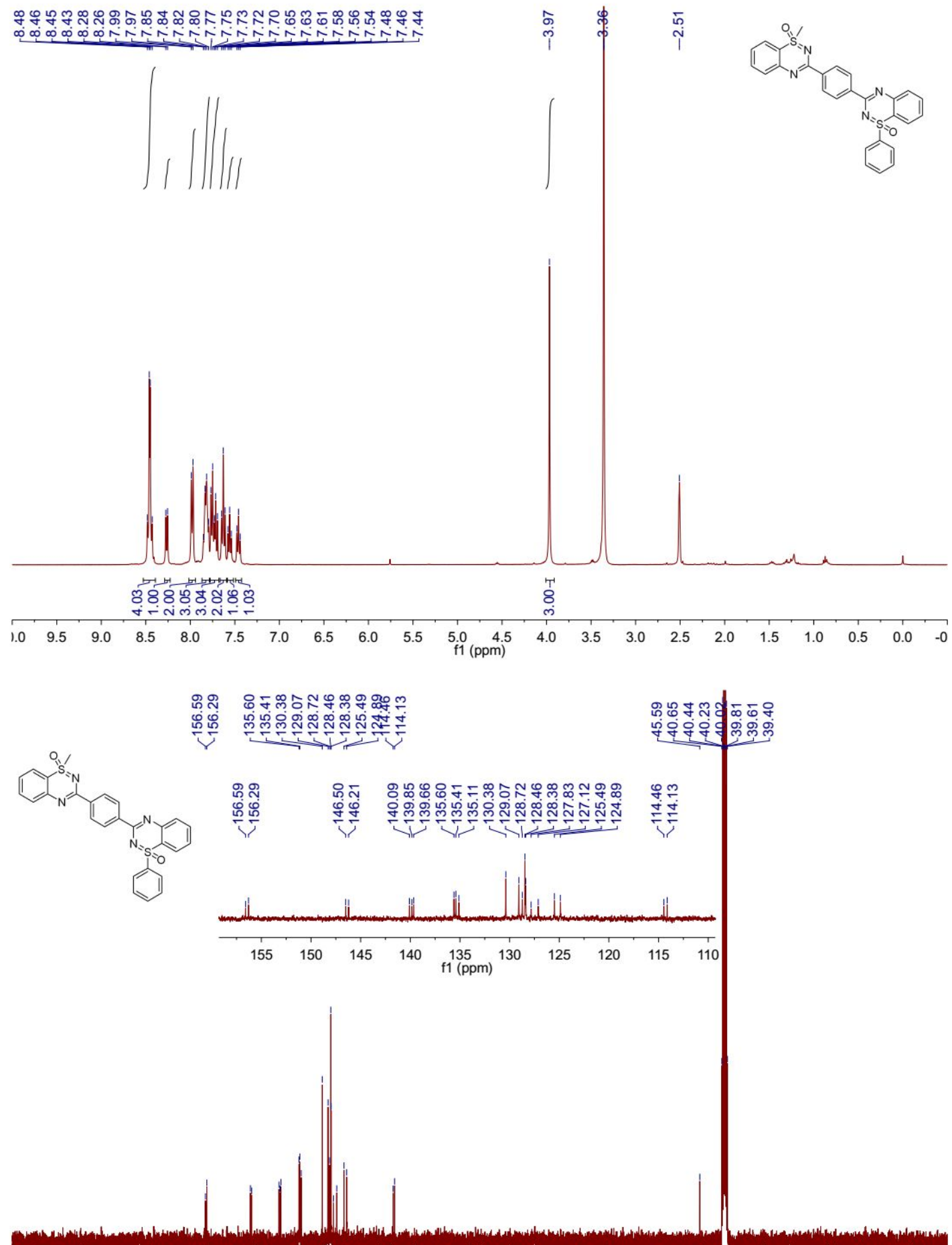

\begin{tabular}{lllllllllllllllllllllll}
\hline$j 0$ & 190 & 180 & 170 & 160 & 150 & 140 & 130 & 120 & 110 & $\underset{\mathrm{f} 1}{100}(\mathrm{ppm})$ & 90 & 80 & 70 & 60 & 50 & 40 & 30 & 20 & 10 & 0 & -1
\end{tabular} 
6. ${ }^{1} \mathrm{H}$ and ${ }^{13} \mathrm{C}$ NMR spectrum for the preparation of compounds 6 (S46).

6
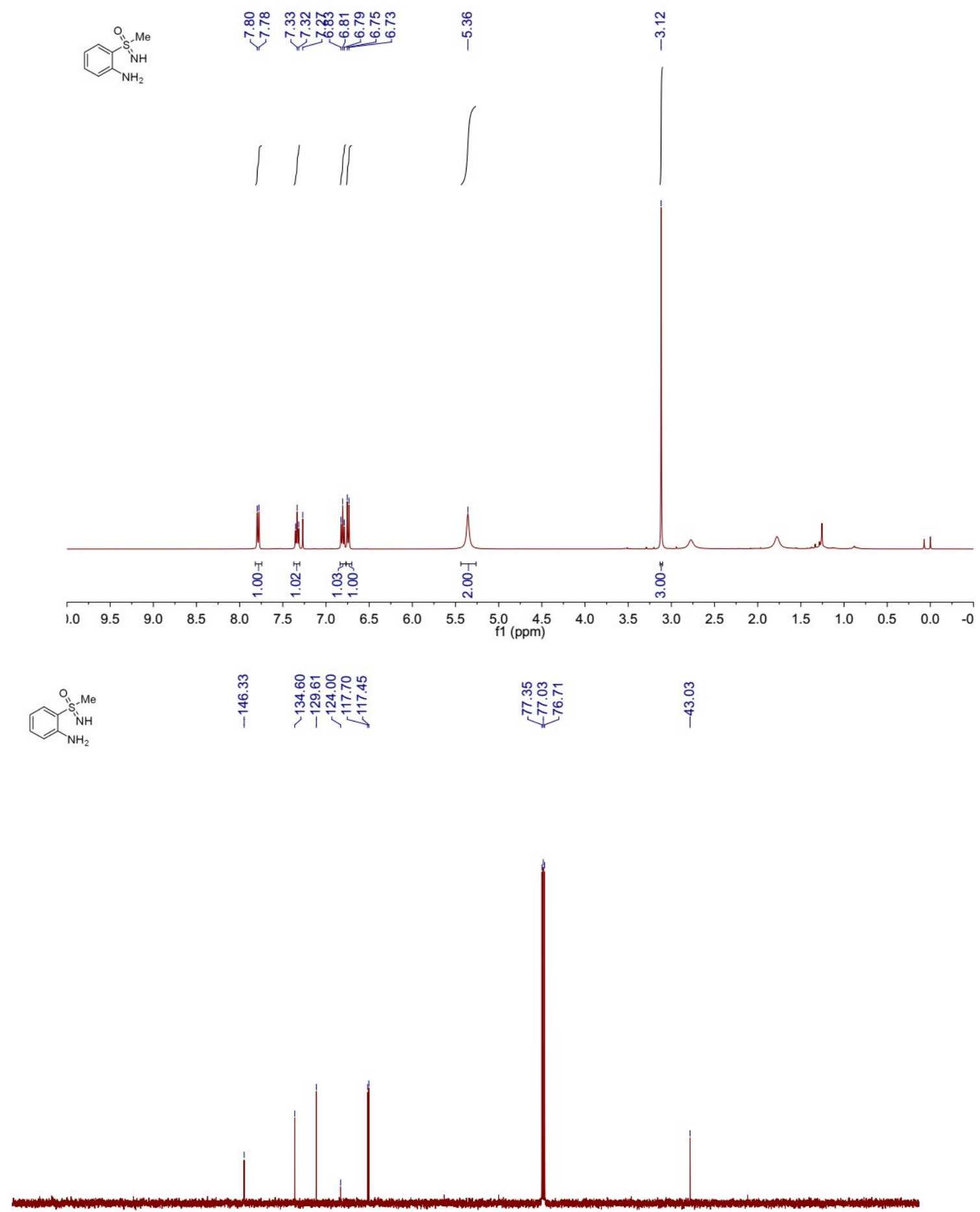

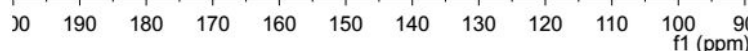


7. ${ }^{1} \mathrm{H}$ and ${ }^{13} \mathrm{C}$ NMR spectrum for the preparation of compound 10 (S47).

10
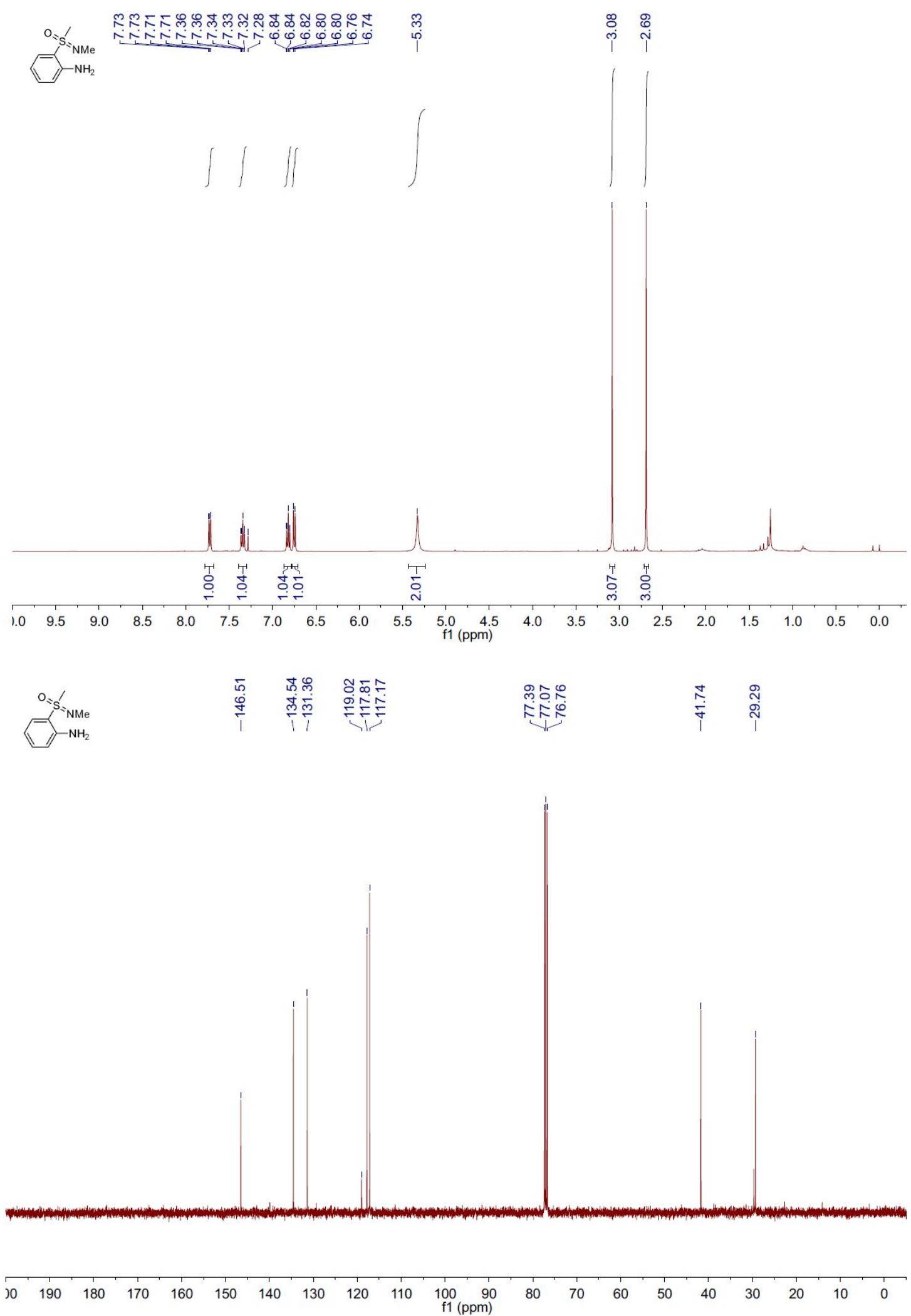